\title{
200 I USPHS/IDSA Guidelines for the Prevention of Opportunistic Infections in Persons Infected with Human Immunodeficiency Virus
}

\author{
US Public Health Service (USPHS), Infectious Diseases Society of America (IDSA), USPHS/IDSA \\ Prevention of Opportunistic Infections Working Group
}

\section{INTRODUCTION}

In 1995, the US Public Health Service (USPHS) and the Infectious Diseases Society of America (IDSA) developed guidelines for preventing opportunistic infections (OIs) in persons infected with human immunodeficiency virus (HIV) ${ }^{1-3}$. These guidelines, written for health-care providers and patients, were revised in $1997^{4}$ and again in $1999^{5}$. They have been published in the MMWR ${ }^{1,4,5}$, Clinical Infectious Diseases $^{2,6,7}$, the Annals of Internal Medicine ${ }^{3,8}$, the American Family Physician ${ }^{9,10}$, and Pediatrics ${ }^{11}$; accompanying editorials have appeared in $J A M A^{12,13}$. Response to these guidelines (e.g., the many requests for reprints, numerous web site contacts and observations from health-care providers) suggests they have served as a valuable reference for HIV care providers. Because the 1995, 1997 and 1999 guidelines included ratings indicating the strength of each recommendation and the quality of supporting evidence, readers have been able to assess the relative importance of each recommendation.

Since AIDS was first recognized 20 years ago, remarkable progress has been made in improving the quality and duration of life of HIV-infected persons in the industrialized world. During the first decade of the epidemic, this improvement occurred because of better recognition of opportunistic disease processes, better therapy for acute and chronic complications and the introduction of chemoprophylaxis against important opportunistic pathogens. The second decade of the epidemic has witnessed extraordinary progress in developing highly active antiretroviral therapies (HAART) as well as continuing progress in preventing and treating individual OIs. HAART has reduced the incidence of OIs and extended life substantially ${ }^{14-16}$. HAART is the most effective approach to preventing OIs and should be considered for all HIV-infected persons who qualify for such therapy ${ }^{14-16}$. However, some patients are not ready or able to take HAART and others have tried HAAR T regimens, but therapy has failed. Such patients will benefit from prophylaxis against $\mathrm{OIs}^{15}$. In addition, prophylaxis against specific OIs continues to provide survival benefits even among persons who are receiving HAART ${ }^{15}$.

Since HAART was introduced in the United States in 1995, it has become increasingly clear that chemoprophylaxis for OIs need not necessarily be life-long. Antiretroviral therapy can restore immune function. The period of susceptibility to opportunistic processes continues to be accurately indicated by the $\mathrm{CD}^{+} \mathrm{T}$ lymphocyte count for patients who are receiving HAART. Thus, a strategy of stopping primary or secondary prophylaxis for certain patients whose immunity has improved as a consequence of HAART seems logical. Stopping prophylactic regimens can simplify treatment, reduce toxicity and drug interactions, lower cost of care and potentially facilitate adherence to antiretroviral regimens. 
In 1999, the USPHS/IDSA guidelines suggested that it may be safe to stop primary or secondary prophylaxis for some (but not all) pathogens if HAART has led to an increase in $\mathrm{CD}^{+} \mathrm{T}$ lymphocyte counts above specified threshold levels. Recommendations were made for only those pathogens for which adequate clinical data were available. Data generated since 1999 continue to support these recommendations and allow additional recommendations to be made concerning the safety of stopping primary or secondary prophylaxis for other pathogens.

For recommendations on discontinuation of chemoprophylaxis, readers will note that criteria vary by such factors as duration of $\mathrm{CD}^{+} \mathrm{T}$ lymphocyte count increase, and, in the case of secondary prophylaxis, duration of treatment of the initial episode of disease. These differences reflect the criteria used in specific studies. Therefore, some inconsistency in the format of these criteria is unavoidable.

Although considerable data are now available concerning discontinuing primary and secondary OI prophylaxis, essentially no data are available regarding restarting prophylaxis when the $\mathrm{CD}^{+} \mathrm{T}$ lymphocyte count decreases again to levels at which the patient is likely to again be at risk for OI. For primary prophylaxis, whether to use the same threshold at which prophylaxis may be stopped (derived from data in studies addressing prophylaxis discontinuation), or to use the threshold below which initial prophylaxis is recommended is unknown. Therefore in this revision of the guidelines, in some cases ranges are provided for restarting primary or secondary prophylaxis. For prophylaxis against Pneumocystis carinii pneumonia (PCP), the suggested threshold for restarting both primary and secondary prophylaxis is $200 \mathrm{cells} / \mu 1$. For all these recommendations, the roman numeral ratings reflect the lack of data available to assist in making these decisions (see description of rating system below).

During the development of these revised guidelines, working group members reviewed published manuscripts as well as abstracts and material presented at professional meetings. A series of teleconferences were held to develop the revisions. In this revision, information and recommendations which are new since the 1999 publication are indicated in bold.

\section{MAJOR CHANGES IN THESE RECOMMENDATIONS}

Major changes in the guidelines since 1999 include:

1. Higher level ratings have been provided for discontinuing primary prophylaxis for PCP and MAC when $\mathrm{CD}^{+} \mathrm{T}$ lymphocytes have increased to $>200 \mathrm{cells} / \mu \mathrm{l}$ and $>100$ cells $/ \mu 1$, respectively, for 3 months in response to HAART (AI), and a new recommendation to discontinue primary toxoplasma prophylaxis has been provided when the $\mathrm{CD}^{+} \mathrm{T}$ lymphocyte count has increased to $>200$ cells $/ \mu 1$ for 3 months (AI).

2. Secondary PCP prophylaxis should be discontinued in patients whose $\mathrm{CD}^{+}$counts have increased to $>200$ cells $/ \mu 1$ for 3 months as a consequence of HAART (BII).

3. Secondary prophylaxis for disseminated MAC may be discontinued in patients with a sustained (e.g., 6 months) increase in $\mathrm{CD}^{+}$count to $>100$ cells $/ \mu 1$ in response to HAART if they have completed 12 months of MAC therapy and have no symptoms or signs attributable to MAC (CIII).

4. Secondary prophylaxis for toxoplasmosis and cryptococcosis may be discontinued in patients with a sustained increase in CD4+ counts (e.g. 6 months) to $>200$ cells $/ \mu 1$ and $>100-200$ cells $/ \mu 1$ respectively, in response to HAART if they have completed their initial therapy and have no symptoms or signs attributable to these pathogens (CIII). 
5. The importance of screening all HIV-infected individuals for hepatitis $\mathrm{C}$ virus $(\mathrm{HCV})$ is emphasized (BIII).

6. Additional information about transmission of human herpes virus 8 infection $(\mathrm{HHV}-8)$ is provided.

7. New information on drug interactions is provided, especially with regard to rifamycins and antiretroviral drugs.

8. Revised recommendations for immunization of HIV exposed/infected adults and children are provided.

\section{HOW TO USE THE INFORMATION IN THIS REPORT}

For each of the 19 diseases covered in this report, specific recommendations are provided that address a) prevention of exposure to the opportunistic pathogen, b) prevention of the first episode of disease and c) prevention of disease recurrence. Recommendations are rated by a revised version of the IDSA rating system $^{17}$. In this system, the letters A-E signify the strength of the recommendation for or against a preventive measure and roman numerals I-III indicate the quality of evidence supporting the recommendation (see Table 1).

This report incldes a number of tables that summarize recommendations. They are as follows: dosages for prophylaxis to prevent first episode of opportunistic disease in HIV infected adults and adolescents (Table 2); dosages for prophylaxis to prevent recurrence of opportunistic disease in HIV-infected adults and adolescents (Table 3); effects of food on drugs used to treat OIs (Table 4); effects of medications on drugs used to treat OIs (Table 5); effects of OI medications on drugs commonly administered to HIV-infected persons (Table 6); adverse effects of drugs used to manage HIV infection (Table 7); dosages of drugs for prevention of OIs for persons with renal insufficiency (Table 8); costs of agents recommended for the prevention of OIs in adults with HIV infection (Table 9); immunologic categories for HIV-infected

Table I System used to rate the strength and quality of evidence supporting recommendations for prevention of opportunistic infections in persons infected with HIV

\begin{tabular}{|c|c|}
\hline Rating & Strength of the recommendation \\
\hline A & $\begin{array}{l}\text { Both strong evidence for efficacy and substantial clinical benefit support recommendation for use. Should always } \\
\text { be offered }\end{array}$ \\
\hline B & $\begin{array}{l}\text { Moderate evidence for efficacy - or strong evidence for efficacy but only limited clinical benefit - supports } \\
\text { recommendation for use. Should generally be offered }\end{array}$ \\
\hline $\mathrm{C}$ & $\begin{array}{l}\text { Evidence for efficacy is insufficient to support a recommendation for or against use. Or evidence for efficacy might } \\
\text { not outweigh adverse consequences (e.g.,drug toxicity, drug, interactions) or cost of the chemoprophylaxis or } \\
\text { alternative approaches. Optional }\end{array}$ \\
\hline D & $\begin{array}{l}\text { Moderate evidence for lack of efficacy or for adverse outcome supports a recommendation against use. Should } \\
\text { generally not be offered }\end{array}$ \\
\hline $\mathrm{E}$ & $\begin{array}{l}\text { Good evidence for lack of efficacy or for adverse outcome supports a recommendation against use. Should never } \\
\text { be offered } \\
\text { Quality of evidence supporting the recommendation }\end{array}$ \\
\hline I & Evidence from at least one properly randomized, controlled trial \\
\hline II & $\begin{array}{l}\text { Evidence from at least one well-designed clinical trial without randomization, from cohort or case-controlled } \\
\text { analytic studies (preferably from more than one center), or from multiple time-series studies. Or dramatic results } \\
\text { from uncontrolled experiments }\end{array}$ \\
\hline III & $\begin{array}{l}\text { Evidence from opinions of respected authorities based on clinical experience, descriptive studies, or reports of } \\
\text { expert committees }\end{array}$ \\
\hline
\end{tabular}


Table 2 Prophylaxis to prevent first episode of opportunistic disease in adults and adolescents infected with human immunodeficiency virus

\begin{tabular}{|c|c|c|c|}
\hline \multirow[b]{2}{*}{ Pathogen } & \multicolumn{3}{|c|}{ Preventive regimens } \\
\hline & Indication & First choice & Alternatives \\
\hline $\begin{array}{l}\text { I. Strongly recommended } \\
\text { as standard of care } \\
\text { Pneumocystis carinii' }\end{array}$ & $\begin{array}{l}\mathrm{CV} 4^{+} \text {count }<200 / \mu \mathrm{l} \text { or } \\
\text { oropharyngeal candidiasis }\end{array}$ & $\begin{array}{l}\text { Trimethoprim-sulfamethoxa } \\
\text { zole (TMP-SMZ), I DS po } \\
\text { q.d. (AI) } \\
\text { TMP-SMZ, I SS po q.d. (AI) }\end{array}$ & $\begin{array}{l}\text { Dapsone, } 50 \mathrm{mg} \text { po b.i.d. or } \\
100 \mathrm{mg} \text { po q.d. (BI); } \\
\text { dapsone, } 50 \mathrm{mg} \text { po q.d. plus } \\
\text { pyrimethamine, } 50 \mathrm{mg} \text { po } \\
\text { q.w. plus leucovorin } 25 \mathrm{mg} \\
\text { po q.w. (BI); dapsone } \\
200 \mathrm{mg} \text { po plus } \\
\text { pyrimethamine, } 75 \mathrm{mg} \text { po } \\
\text { plus leucovorin, } 25 \mathrm{mg} \text { po } \\
\text { q.w. (BI); aerosolized } \\
\text { pentamidine, } 300 \mathrm{mg} \text { q. } \\
\text { month via Respirgard IITM } \\
\text { nebulizer (BI); atovaquone, } \\
\text { I500 mg po q.d. (BI); TMP- } \\
\text { SMZ, I DS po t.i.w. (BI) }\end{array}$ \\
\hline $\begin{array}{l}\text { Mycobacterium tuberculosis } \\
\text { Isoniazid-sensitive }^{2}\end{array}$ & $\begin{array}{l}\text { TST reaction } \geq 5 \mathrm{~mm} \text { or } \\
\text { prior positive TST result } \\
\text { without treatment or } \\
\text { contact with case of active } \\
\text { tuberculosis regardless of } \\
\text { TST result (BIII) }\end{array}$ & $\begin{array}{l}\text { Isoniazid, } 300 \mathrm{mg} \text { po plus } \\
\text { pyridoxine, } 50 \mathrm{mg} \text { po } \\
\text { q.d. } \times 9 \mathrm{mo} \text { (All) or isoniazid, } \\
900 \mathrm{mg} \text { po plus pyridoxine, } \\
100 \mathrm{mg} \text { po b.i.w. } \times 9 \mathrm{mo} \\
(\text { BII); rifampin, } 600 \mathrm{mg} \text { plus } \\
\text { pyrazinimide, } 15-20 \mathrm{mg} / \mathrm{kg} \\
\text { po q.d. } \times 2 \mathrm{mo}(\mathrm{Al})\end{array}$ & $\begin{array}{l}\text { Rifabutin } 300 \mathrm{mg} \text { po q.d. plus } \\
\text { pyrazinamide, I }-20 \mathrm{mg} / \mathrm{kg} \\
\text { po q.d. } \times 2 \mathrm{mo} \text { (BIII); } \\
\text { rifampin } 600 \mathrm{mg} \text { po } \\
\text { q.d. } \times 4 \mathrm{mo}(\text { BIII) }\end{array}$ \\
\hline
\end{tabular}

Isoniazid-resistant

Multidrug-(isoniazid and rifampin) resistant

Toxoplasma gondii ${ }^{3}$
Same as above; high probability of exposure to isoniazid-resistant tuberculosis

Same as above; high probability of exposure to multidrug-resistant tuberculosis

IgG antibody to Toxoplasma and $\mathrm{CD} 4^{+}$count $<100 / \mu 1$
Rifampin $600 \mathrm{mg}$ plus pyrazinamide, $15-20 \mathrm{mg} / \mathrm{kg}$ po q.d. $\times 2 \mathrm{mo}(\mathrm{Al})$

Choice of drugs requires consultation with public health authorities. Depends on susceptibility of isolate from source patient TMP-SMZ, I DS po q.d. (All) MP-SMZ, I SS po q.d. (BIII); dapsone, $50 \mathrm{mg}$ po q.d. plus pyrimethamine, $50 \mathrm{mg}$ po q.w. plus leucovorin, $25 \mathrm{mg}$ po q.w. (BI); atovaquone, $1500 \mathrm{mg}$ po q.d. with or without pyrimethamine, $25 \mathrm{mg}$ po q.d. plus leucovorin, $10 \mathrm{mg}$ po q.d. (CIII) 
Table 2 Continued

\begin{tabular}{ll}
\hline $\begin{array}{l}\text { Mycobacterium avium } \\
\text { complex }\end{array}$ & CD4 ${ }^{+}$count $<50 / \mu \mathrm{l}$ \\
Varicella zoster virus (VZV) & $\begin{array}{l}\text { Significant exposure to } \\
\text { chickenpox or shingles for } \\
\text { patients who have no history } \\
\text { of either condition or, if } \\
\text { available, negative antibody } \\
\text { to VZV }\end{array}$
\end{tabular}

Azithromycin, $1200 \mathrm{mg}$ po

q.w., (Al) or clarithromycin*, 500 mg po b.i.d. (Al)

Varicella zoser immune globulin (VZIG), 5 vials ( $1.25 \mathrm{ml}$ each) im, administered $\leq 96 \mathrm{~h}$ after exposure, ideally within $48 \mathrm{~h}$ (AIII)

\section{Generally}

\section{Recommended}

Streptococcus pneumoniae ${ }^{5}$

Hepatitis B virus ${ }^{6,7}$

Influenza virus ${ }^{6,8}$

Hepatitis A virus ${ }^{6}$

\section{Evidence for Efficacy but Not Routinely Indicated}

Bacteria

\section{CD4 $^{+}$count $\geq 200 / \mu$ I}

All susceptible (anti-HBc-negative) patients

All patients (annually, before influenza season)

All susceptible (anti-HAV-negative) patients at increased risk for HAV infection (e.g., illicit drug users, men who have sex with men, hemophiliacs) or with chronic liver disease, including chronic hepatitis B or hepatitis C

Neutropenia

CD4 ${ }^{+}$count $<50 / \mu \mathrm{I}$
23 valent polysaccharide vaccine, $0.5 \mathrm{ml} \mathrm{im} \mathrm{[BII]}$

Hepatitis B vaccine: 3 doses (BII)

\section{Inactivated trivalent} influenza virus vaccine one annual dose $(0.5 \mathrm{ml}) \mathrm{im}$ (BIII)

Hepatitis A vaccine: two doses (BIII)

Granulocyte-colonystimulating factor (G-CSF), $5-10 \mu g / k g$ sc q.d. $\times 2-4$ w or granulocyte-macrophage colony-stimulating factor (GM-CSF), $250 \mu \mathrm{g} / \mathrm{m}^{2}$ sc iv $\times 2-4 \mathrm{w}(\mathrm{CII})$

Fluconazole, 100-200 mg po q.d. (Cl)
Rifabutin, 300 mg po q.d.

(BI); azithromycin, I,200 mg po q.w. plus rifabutin, 300 mg po q.d. (Cl)

None

None

Oseltamivir, 75 mg po q.d. (influenza A or B) (CIII); rimantadine, $100 \mathrm{mg}$ po b.i.d. (CIII), or amantadine, $100 \mathrm{mg}$ po b.i.d. (CIII) (influenza A only)

None

None

Itraconazole capsule, 200 mg po q.d. (CIII) 
Table 2 Continued

\begin{tabular}{llll}
\hline Histoplasma Capsulatum $^{9}$ & $\mathrm{CD}^{+}$count $<100 / \mu \mathrm{l}$, & Itraconazole capsule, $200 \mathrm{mg}$ & None \\
endemic geographic area & po q.d. $(\mathrm{Cl})$ & \\
Cytomegalovirus $(\mathrm{CMV})^{10}$ & $\begin{array}{l}\mathrm{CD} 4^{+} \text {count }<50 / \mu \mathrm{l} \text { and } \\
\mathrm{CMV} \text { antibody positivity }\end{array}$ & $\begin{array}{l}\text { Oral ganciclovir, Ig po t.i.d. } \\
\text { (Cl) }\end{array}$ & None \\
& &
\end{tabular}

NOTES: Information included in these guidelines might not represent Food and Drug Administration (FDA) approval or approved labeling for the particular products or indications in question. Specifically, the terms 'safe' and 'effective' might not be synonymous with the FDA-defined legal standards for product approval. The Respirgard II ${ }^{\mathrm{TM}}$ nebulizer is manufactured by Marquest, Englewood, Colorado. Letters and Roman numerals in parentheses after regimens indicate the strength of the recommendation and the quality of evidence supporting it (see Table I).

ABBREVIATIONS: Anti-HBc = antibody to hepatitis B core antigen; b.i.w. = twice a week; DS = double-strength tablet; HAART = highly active antiretroviral therapy; HAV = hepatitis A virus; HIV = human immunodeficiency virus; im = intramuscular; iv = intravenous; po = by mouth; q.d. = daily; q.m. = monthly; q.w. = weekly; SS = single-strength tablet; t.i.w. = three times a week;

TMP-SMZ = trimethoprim-sulfamethoxazole; $\mathrm{sc}=$ subcutaneous; and TST = tuberculin skin test.

'Prophylaxis should also be considered for persons with a CV4+ percentage of $<14 \%$, for persons with a history of an AIDS-defining illness, and possibly for those with CD4+ counts $>200$ but $<250$ cells/ $\mu$ l. TMP-SMZ also reduces the frequency of toxoplasmosis and some bacterial infections. Patients receiving dapsone should be tested for glucose- 6 phosphate dehydrogenase deficiency. A dosage of $50 \mathrm{mg}$ q.d. is probably less effective than $100 \mathrm{mg}$ q.d. The efficacy of parenteral pentamidine (e.g. $4 \mathrm{mg} / \mathrm{kg} / \mathrm{month}$ ) is uncertain. Fansidar (sulfadoxine-pyrimethamine) is rarely used because of severe hypersensitivity reactions. Patients who are being administered therapy for toxoplasmosis with sulfadiazine-pyrimethamine are protected against Pneumocystis carinii pneumonia and do not need additional prophylaxis against PCP.

${ }^{2}$ Directly observed therapy is recommended for isoniazid, e.g., $900 \mathrm{mg}$ b.i.w.; isoniazid regimens should include pyridoxine to prevent peripheral neuropathy. If rifampin or rifabutin are administered concurrently with protease inhibitors or non-nucleoside reverse transcriptase inhibitors, careful consideration should be given to potential pharmacokinetic interactions (54). See discussion of rifamycin interactions in paragraph $\mathrm{II}$ in section on Tuberculosis. Exposure to multidrug-resistant tuberculosis might require prophylaxis with two drugs; consult public health authorities. Possible regimens include pyrazinamide plus either ethambutol or a fluoroquinolone.

${ }^{3}$ Protection against toxoplasmosis is provided by TMP-SMZ, dapsone plus pyrimethamine, and possibly by atovaquone. Atovaquone may be used with or without pyrimethamine. Pyrimethamine alone probably provides little, if any, protection.

${ }^{4}$ See paragraph 9, in section on 'Disseminated Infection with Mycobacterium avium complex and references 53-54 for discussion of drug interactions.

${ }^{5}$ Vaccination may be offered to persons who have a CD4 ${ }^{+}$T-lymphocyte count $<200$ cells/ $\mu$, although the efficacy is likely to be diminished. Revaccination 5 years after the first dose or sooner if the initial immunization was given when the CD4 ${ }^{+}$count was $<200$ cells $/ \mu \mathrm{l}$ and the $\mathrm{CD} 4^{+}$count has increased to $>200$ cells/ $\mu \mathrm{l}$ on HAART is considered optional. Some authorities are concerned that immunizations might stimulate the replication of HIV.

${ }^{6}$ Data do not conclusively demonstrate clinical benefit of these vaccines in this population, although it is logical to assume that those patients who develop antibody responses will derive some protection. Some authorities are concerned that immunizations might stimulate HIV replication, although for influenza vaccination, a large observational study of HIV-infected persons in clinical care showed no adverse effect of this vaccine, including multiple doses, on patient survival (J. Ward, CDC, personal communication). Also, this concern may be less relevant in the setting of HAART. However, because of the theoretical concern that increases in HIV plasma RNA following vaccination during pregnancy might increase the risk of perinatal transmission of HIV, providers may wish to defer vaccination for such patients until after HAART is initiated.

${ }^{7}$ Hepatitis B vaccine has been recommended for all children and adolescents and for all adults with risk factors for hepatitis B virus (HBV).

${ }^{8}$ Oseltamivir is appropriate during outbreaks of either influenza A or influenza B. Rimantadine and amantadine are appropriate during outbreaks of influenza A (although neither rimantadine nor amantadine is recommended during pregnancy). Dosage reduction for antiviral chemoprophylaxis against influenza might be indicated for decreased renal or hepatic function, and for persons with seizure disorders. Physicians should consult the frug package inserts and the annual CDC influenza guidelines for more specific information about adverse effects and dosage adjustments. For additional information regarding vaccination against hepatitis $A$ and $B$ and vaccination and antiviral therapy against influenza see $C D C$. Prevention of hepatitis $A$ through active or positive immunization: recommendations of the Advisory Committee on Immunization Practices (ACIP). MMWR 1999;48(No. RR-12); CDC. Hepatitis B virus: a comprehensive strategy for eliminating transmission in the United States through universal childhood vaccination: recommendations of the Advisory Committee on Immunization Practices (ACIP). MMWR 199I;40(No. RR- I3); and CDC. Prevention and control of influenza: recommendations of the Advisory Committee on Immunization Practices (ACIP). For additional information about vaccination and antiviral therapy against influenze see: CDC, Prevention and Control of Influenza: Recommendations of the Advisory Committee on Immunization Practices (ACIP). MMWR 2000;50(No. RR-4). 9 In a few unusual occupational or other circumstances, prophylaxis should be considered; consult a specialist.

10. Acyclovir is not protective against CMV. Valacyclovir is not recommended because of an unexplained trend toward increased mortality observed in persons with AIDS who were being administered this drug for prevention of CMV disease.

*During pregnancy, azithromycin is preferred over clarithromycin because of the teratogenicity in animals of clarithromycin. 
Table 3 Prophylaxis to prevent recurrence of opportunistic disease in adults (after chemotherapy for acute disease) in adults and adolescents infected with human immunodeficiency virus

\begin{tabular}{llll}
\hline & \multicolumn{3}{c}{ Preventive Regimens } \\
\cline { 2 - 4 } Pathogen & Indication & First Choice & Alternatives \\
\hline
\end{tabular}

\section{Recommended as standard of care}

Pneumocystis carinii

Prior P. carinii pneumonia

Toxoplasma gondii

Mycobacterium avium complex ${ }^{2}$

Cytomegalovirus

Cryptococcus neoformans

Histoplasma capsulatum
Prior end-organ disease

Prior toxoplasmic encephalitis

Documented disseminated disease

Clarithromycin*, 500 mg po b.i.d. (Al) plus ethambutol, $15 \mathrm{mg} / \mathrm{kg}$ po q.d. (AII); with or without rifabutin, $300 \mathrm{mg}$ po q.d.

$(\mathrm{Cl})$

Ganciclovir, 5-6 mg/kg/day iv 5-7 days/wk or 1,000 mg po t.i.d. (Al); or foscarnet, $90-120 \mathrm{mg} / \mathrm{kg}$ iv q.d. (Al); or (for retinitis) ganciclovir sustained-release implant $\mathrm{q}$ 6-9 months plus ganciclovir, I.0-I.5 g po t.i.d. (Al);

Fluconazole, $200 \mathrm{mg}$ po q.d. (Al)

Itraconazole capsule, $200 \mathrm{mg}$ po b.i.d. (Al)
Dapsone, $50 \mathrm{mg}$ po b.i.d. or $100 \mathrm{mg}$ po q.d. (BI); dapsone, $50 \mathrm{mg}$ po q.d. plus pyrimethamine, $50 \mathrm{mg}$ po q.w. plus leucovorin, $25 \mathrm{mg}$ po q.w. (BI); dapsone, $200 \mathrm{mg}$ po plus pyrimethamine, $75 \mathrm{mg}$ po plus leucovorin, 25 mg po q.w. (BI); aerosolized pentamidine, 300 mg q.m. via Respirgard II ${ }^{\mathrm{TM}}$ nebulizer (BI); atovaquone, 1500 mg po q.d. (BI); TMP-SMZ, I DS po t.i.w. (Cl)

Clindamycin, 300-450 mg po q $6-8 \mathrm{~h}$ plus pyrimethamine, $25-50 \mathrm{mg}$ po q.d. plus, leucovorin 10-25 mg po q.d. (BI); atovaquone $750 \mathrm{mg}$ po q 6-12 h with or without pyrimethamine, $25 \mathrm{mg}$ po q.d. plus leucovorin, $10 \mathrm{mg}$ po, q.d. (CIII)

Azithromycin, $500 \mathrm{mg}$ po q.d. (AII) plus ethambutol, $15 \mathrm{mg} / \mathrm{kg}$ po q.d. (AlI); with or without rifabutin, $300 \mathrm{mg}$ po q.d. $(\mathrm{Cl})$

Cidofovir, 5 mg/kg iv q.o.w. with probenecid 2 grams po 3 hours before the dose followed by I gram po 2 hours after the dose, and I gram po 8 hours after the dose (total of 4 grams) (Al). Fomivirsen I vial $(330 \mu \mathrm{g})$ injected into the vitreous, then repeated every 2-4 wks (Al); valganciclovir 900 mg po q.d. (BI)

Amphotericin B, 0.6-1.0 mg/kg iv q.w.-t.i.w. (Al); itraconazole, $200 \mathrm{mg}$ po q.d. (BI)

Amphotericin B, $1.0 \mathrm{mg} / \mathrm{kg}$ iv q.w. (Al) 
Table 3 Continued

\begin{tabular}{|c|c|c|c|}
\hline Coccidioides immitis & Documented disease & $\begin{array}{l}\text { Fluconazole, } 400 \text { mg po } \\
\text { q.d. (AII) }\end{array}$ & $\begin{array}{l}\text { Amphotericin B, I.0 mg/kg iv } \\
\text { q.w. (Al); itraconazole, } 200 \mathrm{mg} \\
\text { capsule po b.i.d. (All) }\end{array}$ \\
\hline $\begin{array}{l}\text { Salmonella species, } \\
\text { (non-typhi) }^{3}\end{array}$ & Bacteremia & $\begin{array}{l}\text { Ciprofloxacin, } 500 \text { mg po } \\
\text { b.i.d. for several months } \\
\text { (BII) }\end{array}$ & $\begin{array}{l}\text { Antibiotic chemoprophylaxis } \\
\text { with another active agent (CIII) }\end{array}$ \\
\hline \multicolumn{4}{|c|}{ II. Recommended only if subsequent episodes are frequent or severe } \\
\hline Herpes simplex virus & $\begin{array}{l}\text { Frequent/severe } \\
\text { recurrences }\end{array}$ & $\begin{array}{l}\text { Acyclovir, } 200 \text { mg po t.i.d. } \\
\text { or } 400 \text { mg po b.i.d. (Al) } \\
\text { Famciclovir } 500 \text { mg po } \\
\text { b.i.d. (Al) }\end{array}$ & $\begin{array}{l}\text { Valacyclovir, } 500 \text { mg po b.i.d. } \\
\text { (CIII) }\end{array}$ \\
\hline $\begin{array}{l}\text { Candida (oropharyngeal or } \\
\text { vaginal) }\end{array}$ & $\begin{array}{l}\text { Frequent/severe } \\
\text { recurrences }\end{array}$ & $\begin{array}{l}\text { Fluconazole } 100-200 \mathrm{mg} \\
\text { po q.d. (Cl) }\end{array}$ & $\begin{array}{l}\text { Itraconazole solution, } 200 \mathrm{mg} \text { po } \\
\text { q.d. (Cl); }\end{array}$ \\
\hline Candida (esophageal) & $\begin{array}{l}\text { Frequent/severe } \\
\text { recurrences }\end{array}$ & $\begin{array}{l}\text { Fluconazole } 100-200 \mathrm{mg} \\
\text { po q.d. (BI) }\end{array}$ & $\begin{array}{l}\text { Itraconazole solution, } 200 \text { mg po } \\
\text { q.d. (BI); }\end{array}$ \\
\hline
\end{tabular}

NOTES: Information included in these guidelines might not represent Food and Drug Administration (FDA) approval or approved labeling for the particular products or indications in question. Specifically, the terms 'safe' and 'effective' might not be synonymous with the FDA-defined legal standards for product approval. The Respirgard II ${ }^{\mathrm{TM}}$ nebulizer is manufactured by Marquest, Englewood, Colorado. Letters and Roman numerals in parentheses after regimens indicate the strength of the recommendation and the quality of evidence supporting it (see Table I).

ABBREVIATIONS: b.i.d. = twice a day; DS = double-strrength tablet; po = by mouth; q.d. = daily; q.m. = monthly; q.w. = weekly; q.o.w. = every other week; $S S=$ single-strength tablet; t.i.d. = three times a day; t.i.w. = three times a week; and TMP-SMZ = trimethoprim-sulfamethoxazole.

'Pyrimethamine-sulfadiazine confers protection against PCP as well as toxoplasmosis; clindamycin-pyrimethamine does not offer protection against PCP.

${ }^{2}$ Many multiple-drug regimens are poorly tolerated. Drug interactions (e.g., those seen with clarithromycin and rifabutin) can be problematic; rifabutin has been associated with uveitis, especially when administered at daily doses of $>300 \mathrm{mg}$ or concurrently with fluconazole or clarithromycin. See discussion of rifamycin interactions in paragraph 9 in section on Tuberculosis (54).

${ }^{3}$ Efficacy for eradication of Salmonella has been demonstrated only for ciprofloxacin.

*During pregnancy, azithromycin is recommended instead of clarithromycin because clarithromycin is teratogenic in animals.

Table 4 Effects of Food on Drugs used to prevent opportunistic infections

\begin{tabular}{|c|c|c|}
\hline Drug & Food effect & Recommendation \\
\hline Atovaquone & $\begin{array}{l}\text { Bioavailability increased up to threefold with high-fat } \\
\text { meal. }\end{array}$ & Administer with food. \\
\hline Ganciclovir (capsules) & High-fat meal results in $22 \%$ increase in AUC. & Administer with food. \\
\hline Itraconazole & Grapefruit juice results in $30 \%$ decrease in AUC. & Avoid concurrent grapefruit juice \\
\hline Itraconazole (capsules) & $\begin{array}{l}\text { Significant increase in bioavailability when taken with a } \\
\text { full meal. }\end{array}$ & Administer with food. \\
\hline Itraconazole (solution) & $\begin{array}{l}31 \% \text { increase in } A \cup C \text { when taken under fasting } \\
\text { conditions }\end{array}$ & Take without food if possible. \\
\hline
\end{tabular}

children (Table 10); immunization schedule for HIV-infected children (Table 11); dosages for prophylaxis to prevent first episode of opportunistic disease in HIV-infected infants and children (Table 12); dosages for prophylaxis to prevent recurrence of opportunistic disease in HIV-infected infants and children (Table 13); and criteria for discontinuing and restarting OI prophylaxis for adult patients with HIV infection 
Table 5 Effects of medications on drugs used to prevent opportunistic infections

\begin{tabular}{llll}
\hline Affected drug & Interacting drug(s) & Mechanism/effect & Recommendations \\
\hline Atovaquone & Rifampin & $\begin{array}{l}\text { Induction of metabolism - } \\
\text { decreased drug levels }\end{array}$ & $\begin{array}{l}\text { Concentrations might not } \\
\text { be therapeutic; avoid } \\
\text { combination or increase } \\
\end{array}$ \\
& & atovaquone dose
\end{tabular}

Atovaquone Lopinavir-ritonavir

Clarithromycin

Clarithromycin

Clarithromycin

Clarithromycin

Ketoconazole

Ketoconazole

Quinolone antibiotics (ciprofloxacin, levofloxacin, gatifloxacin, Moxifloxacin)

\section{Efavirenz}

Ritonavir

Lopinavir-Ritonavir

Nevirapine

\section{Lopinavir-ritonavir}

Antacids, didanosine, Buffered products, H2-blockers, proton Pump inhibitors

Didanosine, antacids, iron products, calcium products, sucralfate (cation preparations)
Potential for induction of metabolism - decreased drug levels

Induction of metabolism

- decrease in clarithromycin AUC by $39 \%$, increase in AUC of I4-OH clarithromycin by $34 \%$

Inhibition of metabolism

- increased

clarithromycin drug

levels by $77 \%$

Inhibition of metabolism

- increased

clarithromycin drug

levels

Induction of metabolism decrease in clarithromycin AUC by $35 \%$, increase in AUC of $14-\mathrm{OH}$ clarithromycin by $27 \%$

Inhibition of metabolism, increased ketonconazole AUC

Increase in gastric $\mathrm{pH}$ that impairs absorption of ketoconazole

Chelation results in marked decrease in quinolone drug levels
Concentrations may not be therapeutic - may require increase atovaquone dose

Clarithromycin efficacy uncertain

Dose adjustment of clarithromycin necessary only if renal dysfunction is present. For $\mathrm{CrCl}$ $<60 \mathrm{ml} / \mathrm{min}$, reduce clarithromycin dose by $50 \%$; for $\mathrm{CrCl}$ $<\mathbf{3 0} \mathrm{ml} / \mathrm{min}$, reduce dose by $75 \%$

\section{Efficacy of MAC}

prophylaxis may be decreased; monitor closely

\section{Use with caution at ktoconazole doses $>200 \mathrm{mg} / \mathrm{day}$}

Avoid use of ketoconazole with $\mathrm{pH}$-raising agents or use alternative antifungal drug

Administer cation preparation at least 2 hours after quinolone 
Table 5 Continued

\begin{tabular}{|c|c|c|c|}
\hline Rifabutin & Fluconazole & $\begin{array}{l}\text { Inhibition of metabolism - } \\
\text { marked increase in rifabutin } \\
\text { drug levels }\end{array}$ & $\begin{array}{l}\text { Monitor for rifabutin } \\
\text { toxicities such as uveitis, } \\
\text { nausea, neutropenia. }\end{array}$ \\
\hline Rifabutin & Efavirenz & $\begin{array}{l}\text { Induction of metabolism - } \\
\text { significant decrease in } \\
\text { rifabutin AUC }\end{array}$ & $\begin{array}{l}\text { Increase rifabutin dose to } \\
450-600 \text { mg daily or } \\
600 \text { mg twice weekly* }\end{array}$ \\
\hline Rifabutin & $\begin{array}{l}\text { Ritonavir, } \\
\text { lopinavir-ritonavir }\end{array}$ & $\begin{array}{l}\text { Inhibition of metabolism } \\
\text { - marked increase in } \\
\text { rifabutin drug levels }\end{array}$ & $\begin{array}{l}\text { Decrease rifabutin to } \\
150 \mathrm{mg} \text { every other day } \\
\text { or three times per week. }\end{array}$ \\
\hline Rifabutin & $\begin{array}{l}\text { Indinavir, nelfinavir, } \\
\text { amprenavir }\end{array}$ & $\begin{array}{l}\text { Inhibition of metabolism } \\
\text { - marked increase in } \\
\text { rifabutin drug levels }\end{array}$ & $\begin{array}{l}\text { Decrease rifabutin to } \\
\text { I } 50 \mathrm{mg} \text { qd or } 300 \mathrm{mg} \\
\text { twice weekly }\end{array}$ \\
\hline
\end{tabular}

*Appropriate dose of efavirenz is uncertain if a protease inhibitor is used with efavirenz plus rifabutin

(Table 14). Recommendations advising patients how to prevent exposure to opportunistic pathogens appear in the Appendix at the end of this report.

This report is oriented toward the prevention of specific OIs in HIV-infected persons in the United States and other industrialized countries. Recommendations for use of HAART, which is designed to prevent immunologic deterioration, to restore immune function and delay the need for many of the chemoprophylactic strategies described in this report, were originally published elsewhere ${ }^{14}$ and are updated regularly (www.hivatis.org) ${ }^{16}$.

Pamphlets for patients regarding prevention of OIs can be obtained from the HIV/AIDS Treatment Information Service (ATIS) by calling (800) 448-0440, (301) 519-0459 (international) or (888) 480-3739 (TTY). They also can be accessed on both the CDC and HIVATIS websites (www.cdc.gov/hiv/pubs/brochure.htm and www.hivatis.org).

New data on prevention of OIs in HIV-infected persons are emerging, and randomized controlled trials addressing some unresolved issues in OI prophylaxis are ongoing. The OI Working Group review emerging data routinely and will update these guidelines on a regular basis.

\section{PNEUMOCYSTIS CARINII PNEUMONIA}

\section{Prevention of exposure}

Although some authorities recommend that persons with HIV infection who are at risk for P. carinii pneumonia (PCP) not share a hospital room with a patient who has PCP, data are insufficient to support this recommendation as standard practice (CIII).

\section{Prevention of disease}

\section{Initiation of primary prophylaxis}

Adults and adolescents who have HIV infection (including pregnant women and those on HAART) should receive chemoprophylaxis against PCP if they have a $\mathrm{CD} 4^{+} \mathrm{T}$ lymphocyte count of less than $200 \mu \mathrm{l}$ (AI) or a history of oropharyngeal candidiasis (AII $)^{18-20}$. Persons who have a CD ${ }^{+} \mathrm{T}$ lymphocyte percentage of less than $14 \%$ or history of an acquired immunodeficiency syndrome (AIDS)-defining illness but do not otherwise qualify should be considered for prophylaxis (BII $)^{18-20}$. When monitoring the CD4 ${ }^{+}$ $\mathrm{T}$ lymphocyte count at least every 3 months is not possible, initiation of chemoprophylaxis at a CD $4^{+}$ $\mathrm{T}$ lymphocyte count of greater than 200 but less than 250 cells $/ \mu 1$ also should be considered (BII) ${ }^{19}$. 
Table 6 Effects of opportunistic infection medications on antiinfective drugs commonly administered to persons infected with human immunodeficiency virus*

\begin{tabular}{|c|c|c|c|}
\hline Affected drug & Interacting drug(s) & Mechanism (effect) & Recommendation \\
\hline $\begin{array}{l}\text { Amprenavir, delavirdine, } \\
\text { indinavir, lopinavir-ritonavir, } \\
\text { nelfinavir, saquinavir }\end{array}$ & Rifampin & $\begin{array}{l}\text { Induction of metabolism - } \\
\text { marked decrease in } \\
\text { protease inhibitor or } \\
\text { delavirdine drug levels }\end{array}$ & Avoid concomitant use \\
\hline
\end{tabular}

Efavirenz, ritonavir, ritonavir-saquinavir, nevirapine

Delavirdine

Indinavir, nelfinavir, amprenavir*

Ritonavir

Efavirenz

Saquinavir

Didanosine

Ganciclovir (po)

Rifampin

Rifabutin

Rifabutin

Rifabutin

Rifabutin

Rifabutin
Potential for decreased saquinavir levels

Increased ddl AUC by approximately 100\% - 50-60\% decrease in delavirdine levels

- $50 \%$ decrease in of Ritonavir

Potential for decreased efavirenz levels
Combinations could possibly be used but limited clinical experience. Consider efavirenz 800 mg q.d. when used with rifampin

Induction of metabolism

Induction of metabolism protease inhibitor levels

Induction of metabolism

\section{Avoid concomitant use}

Consider increase in indinavir dose to 1000 mg q8h; If indinavir is the sole protease inhibitor decrease rifabutin dose to $150 \mathrm{mg}$ q.d.

\section{Consider rifabutin} 150 mg q.o.d. or twice weekly

No dosage change necessary for efavirenz; adjust rifabutin dose to 450-600 mg qd or $600 \mathrm{mg}$ twice daily

Limited data

Clinical significance unknown; monitor for ddl-related adverse effects

* Little data are available for use of rifamycin drugs with ritonavir-boosting protease inhibitor regimens except for ritonavir-saquinavir and ritonavir-lopinavir. Therefore, concomitant use of rifamycins with these regimens must be approached cautiously

Trimethoprim-sulfamethoxazole (TMP-SMZ) is the recommended prophylactic agent $(\mathrm{AI})^{20-23}$. One double-strength tablet per day is the preferred regimen (AI) ${ }^{23}$. However, one single-strength tablet per day is also effective and might be better tolerated than one double strength tablet per day (AI). One double-strength tablet three times per week is also effective $(\mathrm{BI})^{24}$. TMP-SMZ at a dose of one double-strength tablet per day confers cross-protection against toxoplasmosis ${ }^{25}$ and some common respiratory bacterial infections ${ }^{21,26}$. Lower doses of TMP-SMZ also might confer such protection. For patients who have an adverse reaction that is not life-threatening, treatment with TMP-SMZ should be continued 
Table 7 Adverse effects of drugs used in the prevention of opportunistic infections

\begin{tabular}{ll}
\hline $\begin{array}{l}\text { Bone Marrow Suppression } \\
\text { Diarrhea }\end{array}$ & $\begin{array}{l}\text { Cidofovir, dapsone, ganciclovir, pyrimethamine, rifabutin, sulfadiazine, TMP-SMX } \\
\text { Atovaquone, clindamycin }\end{array}$ \\
Clarithromycin, fluconazole, isoniazid, itraconazole, ketoconazole, pyrazinamid, rifabutin, \\
rifampin, TMP-SMX \\
Nephrotoxicity & Amphotericin B, cidofovir, foscarnet, pentamidine, high dose acyclovir \\
Ocular Effects & Cidofovir, ethambutol, rifabutin \\
Pancreatitis & Pentamidine, TMP-SMX \\
Peripheral Neuropathy & Isoniazid \\
Neurotoxicity & Acyclovir (high-dose), quinolones \\
Skin Rash & Atovaquone, dapsone, pyrimethamine, sulfadiazine, TMP-SMX, ribaviron
\end{tabular}

if clinically feasible; for those who have discontinued such therapy because of an adverse reaction, reinstitution of TMP-SMZ should be strongly considered after the adverse event has resolved (AII). Patients who have experienced adverse events, especially fever and rash, might better tolerate reintroduction of the drug with a gradual increase in dose (desensitization) as per published regimens (BI) ${ }^{27,28}$ or reintroduction of TMP-SMZ at a reduced dose or frequency (CIII); up to $70 \%$ of patients can tolerate such reinstitution of therapy ${ }^{26}$.

If TMP-SMZ cannot be tolerated, prophylactic regimens that can be recommended as alternatives include dapsone $(\mathrm{BI})^{21}$, dapsone plus pyrimethamine plus leucovorin $(\mathrm{BI})^{29,30}$, aerosolized pentamidine administered by the Respirgard II TM nebulizer (Marquest, Englewood, Colorado) (BI) ${ }^{22}$ and atovaquone $(\mathrm{BI})^{31,32}$. Atovaquone appears to be as effective as aerosolized pentamidine ${ }^{31}$ or dapsone $(\mathrm{BI})^{32}$ but is substantially more expensive than the other regimens. For patients seropositive for Toxoplasma gondii who cannot tolerate TMP-SMZ, recommended alternatives to TMP-SMZ for prophylaxis against both PCP and toxoplasmosis include dapsone plus pyrimethamine $(\mathrm{BI})^{29,30}$ or atovaquone with or without pyrimethamine (CIII). The following regimens generally cannot be recommended as alternatives because data regarding their efficacy for PCP prophylaxis are insufficient for a firm recommendation: aerosolized pentamidine administered by other nebulization devices, intermittently administered parenteral pentamidine, oral pyrimethamine plus sulfadoxine, oral clindamycin plus primaquine and intravenous trimetrexate. However, clinicians may consider using these agents in unusual situations in which the recommended agents cannot be administered (CIII).

\section{Discontinuation of primary prophylaxis}

Primary pneumocystis prophylaxis should be discontinued in adult and adolescent patients who have responded to HAART with an increase in $\mathrm{CD}^{+} \mathrm{T}$ lymphocyte counts to $>200 \mathrm{cells} / \mu \mathrm{l}$ for at least 3 months (AI). In observational and randomized studies supporting this recommendation, most patients were taking antiretroviral regimens that included a protease inhibitor and most had a $\mathrm{CD}^{+} \mathrm{T}$ lymphocyte count greater than $200 \mathrm{cells} / \mu 1$ for at least 3 months before discontinuation of PCP prophylaxis ${ }^{33-41}$. The median CD4 ${ }^{+}$lymphocyte count at the time prophylaxis was discontinued was $>300$ cells $/ \mu 1$, and many patients had a sustained suppression of HIV plasma RNA levels below detection limits of the assay employed. Median follow-up ranged from 6-16 months. 
Table 8 Dosing of drugs for primary prevention or maintenance therapy for opportunistic infections in renal insufficiency

\begin{tabular}{|c|c|c|c|c|}
\hline Drug & Normal dose & & Renal dysfunction & \\
\hline \multirow[t]{4}{*}{ Acyclovir } & $200 \mathrm{mg}-800 \mathrm{mg}$ BID - & Regimen & $\mathrm{CrCl}\left(\mathrm{ml} / \mathrm{min} / 1.73 \mathrm{~m}^{2}-2\right.$ & Adjusted Dose \\
\hline & $5 \times$ day & 200 mg PO TID & $<10$ & $200 \mathrm{mg} \mathrm{q} / 2 \mathrm{~h}$ \\
\hline & & $400 \mathrm{mg} P O \mathrm{q} / 2 \mathrm{~h}$ & $<10$ & $200 \mathrm{mg} \mathrm{q} \mid 2 \mathrm{~h}$ \\
\hline & & hemodialysis: & & $\begin{array}{l}\text { additional dose after each } \\
\text { dialysis }\end{array}$ \\
\hline
\end{tabular}

Cidofovir

$5 \mathrm{mg} / \mathrm{kg}$ IV every other week (with probenecid and hydration)

Ciprofloxacin $\quad 500 \mathrm{mg}$ PO q $12 \mathrm{hr}$

Clarithromycin $\quad 500 \mathrm{mg}$ BID

Famciclovir

250-500 mg q $12 \mathrm{~h}$

$50 \mathrm{mg}-400 \mathrm{mg}$ qd

Fluconazole

Valganciclovir

$900 \mathrm{mg}$ qd

$90-120 \mathrm{mg} / \mathrm{kg} /$ day

Foscarnet
Reduce from $5 \mathrm{mg} / \mathrm{kg}$ to $3 \mathrm{mg} / \mathrm{kg}$ for an increase in serum creatinine of $0.3-0.4$ above baseline. Discontinue for an increase in creatinine $\geq 0.5$ above baseline or development of $3+$ proteinuria.

Not recommended for patients with baseline serum creatinine $>1.5$,

$\mathrm{CrCl} \leq 55 \mathrm{ml} / \mathrm{min}$, or $\geq 2+$ proteinuria

$\begin{array}{ll}\frac{\mathrm{CrCl}\left(\mathrm{ml} / \mathrm{min} / 1.73 \mathrm{~m}^{2}-2\right.}{30-50} & \text { Dose } \\ <30 & 250 \mathrm{mg}-500 \mathrm{mg} \mathrm{q} \mathrm{I} 2 \mathrm{hrs} \\ \text { hemodialysis: } & 250 \mathrm{mg}-500 \mathrm{mg} \mathrm{q} \mathrm{I} 8 \mathrm{hrs} \\ 250-500 \mathrm{mg} \text { after dialysis }\end{array}$

Reduce dose by one-half or double interval if creatinine clearance $<30 \mathrm{ml} / \mathrm{min}$

$\begin{array}{ll}\frac{\mathrm{CrCl}}{20-39} & \frac{\text { Dose }}{125-250 \mathrm{mg} \mathrm{q} 12 \mathrm{~h}} \\ <20 & 125-250 \mathrm{mg} \mathrm{q} 24 \mathrm{~h} \\ \text { hemodialysis: } & 125 \mathrm{mg} \text { after each dialysis }\end{array}$

$\begin{array}{ll}\frac{\mathrm{CrCl}}{<50 \text { (not on dialysis) }} & \frac{\text { Dose }}{\mathrm{I} / 2 \text { dose }} \\ \text { dialysis } & \text { Full dose after dialysis } \\ \frac{\mathrm{CrCl}}{40-59} & \underline{\text { Dose }} \\ 25-39 & 450 \mathrm{mg} \text { qd } \\ 10-24 & 450 \mathrm{mg} \text { qd } \\ <10 & 450 \mathrm{mg} \text { twice weekly } \\ \text { Dialysis } & \text { not recommended } \\ \end{array}$

Maintenance

\begin{tabular}{ll} 
Low Dose & High Dose \\
\cline { 2 - 2 } $70 \mathrm{mg} \mathrm{q} \mathrm{24} \mathrm{h}$ & $120 \mathrm{mg} \mathrm{q} \mathrm{24} \mathrm{h}$ \\
$70 \mathrm{mg} \mathrm{q} \mathrm{24} \mathrm{h}$ & $90 \mathrm{mg} \mathrm{q} \mathrm{24} \mathrm{h}$ \\
$50 \mathrm{mg} \mathrm{q} \mathrm{24} \mathrm{h}$ & $65 \mathrm{mg} \mathrm{q} \mathrm{24} \mathrm{h}$ \\
$80 \mathrm{mg} \mathrm{q} \mathrm{48} \mathrm{h}$ & $104 \mathrm{mg} \mathrm{q} \mathrm{48} \mathrm{h}$ \\
$60 \mathrm{mg} \mathrm{q} \mathrm{48} \mathrm{h}$ & $80 \mathrm{mg} \mathrm{q} \mathrm{48} \mathrm{h}$ \\
$50 \mathrm{mg} \mathrm{q} \mathrm{48} \mathrm{h}$ & $65 \mathrm{mg} \mathrm{q} \mathrm{48} \mathrm{h}$ \\
not recommended & not recommended
\end{tabular}


Table 8 Continued

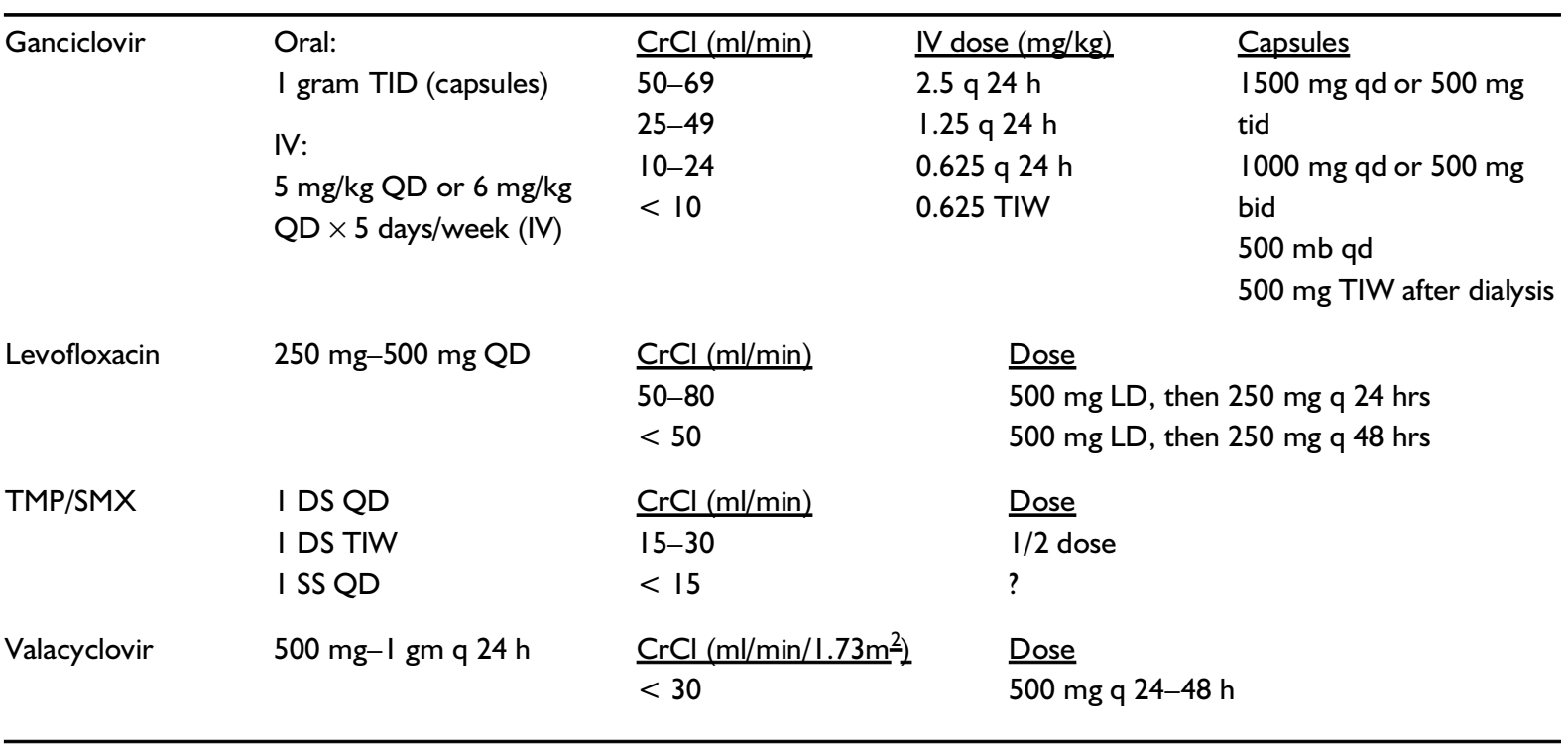

ABBREVIATIONS: b.i.d. = twice daily; $\mathrm{CrCl}=$ creatinine clearance; $\mathrm{DS}=$ double-strength tablet; iv = intravenous; I.d. = loading dose; q.d. = daily; q.o.w. = every other week; SS = single-strength tablet; t.i.d. = three times daily; t.i.w. = three times a week.

*Creatinine clearance for foscarnet is expressed as $\mathrm{ml} / \mathrm{min} / \mathrm{kg}$

*Discontinuation of primary prophylaxis in these patients is recommended not only because prophylaxis appears to add very little to disease prevention (for PCP, toxoplasmosis, or bacterial infections), but also because discontinuation of drug reduces pill burden, the potential for drug toxicity, drug interactions, selection of drug-resistant pathogens and cost.

\section{Restarting primary prophylaxis}

Prophylaxis should be reintroduced if the $\mathrm{CD}^{+} \mathrm{T}$ lymphocyte count decreases to $<200$ cells $/ \mu$ l (AIII).

\section{Prevention of recurrence}

Patients who have a history of PCP should be administered chemoprophylaxis (i.e., secondary prophylaxis or chronic maintenance therapy) with the regimens listed in Table 3 for life (AI) unless immune reconstitution occurs as a consequence of HAART.

\section{Discontinuation of secondary prophylaxis (Chronic maintenance therapy (CMT))}

Secondary prophylaxis should be discontinued for adult and adolescent patients whose CD4 ${ }^{+} \mathrm{T}$ cell count has increased from $<200$ cells $\mu 1$ to $>200$ cells $/ \mu 1$ for at least 3 months due to HAART (BII). Reports from observational studies ${ }^{37,41,42}$ and from a randomized trial ${ }^{39}$, as well as a combined analysis of eight European cohorts being followed prospectively ${ }^{43}$, support this recommendation. In these studies, patients had responded to HAART with an increase in CD4 ${ }^{+}$ T lymphocyte count to $>200$ cells $/ \mu$ f for at least 3 months. Most patients were taking protease inhibitor-containing regimens. The median $\mathrm{CD}^{+} \mathrm{T}$ lymphocyte count at the time prophylaxis was discontinued was $>300$ cells $/ \mu 1$. Most patients had sustained suppression of HIV plasma HIV RNA levels below the detection limits of the assay employed; the longest follow-up was 13 months. If the episode of PCP occurred at a CD4 ${ }^{+} \mathrm{T}$ lymphocyte count $>200 \mathrm{cells} / \mu 1$, it 
Table 9 Wholesale acquisition costs of agents recommended for the prevention of opportunistic infections in adults infected with human immunodeficiency virus

\begin{tabular}{|c|c|c|c|}
\hline Opportunistic pathogen & Drug/Vaccine & Dose & $\begin{array}{c}\text { Annual Cost } \\
\text { Per Patient }\end{array}$ \\
\hline \multirow[t]{4}{*}{ Pneumocystis carinii } & Trimethoprim-sulfamethoxazole & 160/800 mg q.d. & $\$ 135$ \\
\hline & Dapsone & 100 mg q.d. & $\$ 72$ \\
\hline & Aerosolized pentamidine & 300 mg q.m. & $\$ 1185$ \\
\hline & Atovaquone & 1500 mg q.d. & $\$ 11627$ \\
\hline Mycobacterium avium & Clarithromycin & 500 mg b.i.d. & $\$ 2843$ \\
\hline \multirow[t]{2}{*}{ complex } & Azithromycin & I,200 mg q.w. & $\$ 3862$ \\
\hline & Rifabutin & 300 mg q.d. & $\$ 3352$ \\
\hline \multirow[t]{7}{*}{ Cytomegalovirus } & Ganciclovir (po) & I,000 mg t.i.d. & $\$ 17794$ \\
\hline & Ganciclovir implant* & & $\$ 5000$ \\
\hline & Ganciclovir (iv) & 5 mg/kg q.d. & $\$ 13093$ \\
\hline & Foscarnet (iv) & $90-120 \mathrm{mg} / \mathrm{kg}$ q.d. & $\$ 27770-37027$ \\
\hline & Cidofovir (iv) & 375 mg q.o.w. & $\$ 20904$ \\
\hline & Fomivirsen (intravitreal) & I vial every 4 wks & $\$ 12000$ \\
\hline & Valganciclovir & 900 mg q.d. & $\$ 21582$ \\
\hline Mycobacterium & Isoniazid ${ }^{\dagger}$ & 300 mg q.d. & $\$ 23$ (9 months) \\
\hline \multirow[t]{2}{*}{ tuberculosis } & Rifampin & 600 mg q.d. & $\$ 294$ (2 months) \\
\hline & Pyrazinamide & I,500 mg q.d. & $\$ 194$ (2 months) \\
\hline \multirow[t]{4}{*}{ Fungi } & Fluconazole & 200 mg q.d. & $\$ 4603$ \\
\hline & Itraconazole capsules & 200 mg q.d. & $\$ 5340$ \\
\hline & Itraconazole solution & 200 mg q.d. & $\$ 5673$ \\
\hline & Ketoconazole & 200 mg q.d. & $\$ 1230$ \\
\hline \multirow[t]{3}{*}{ Herpes simplex virus } & Acyclovir & 400 mg b.i.d. & $\$ 1384$ \\
\hline & Famciclovir & 500 mg b.i.d. & $\$ 5311$ \\
\hline & Valacyclovir & 500 mg b.i.d. & $\$ 2538$ \\
\hline \multirow[t]{3}{*}{ Toxoplasma gondii } & Pyrimethamine & 50 mg q.w. & $\$ 49$ \\
\hline & Leucovorin & 25 mg q.w. & $\$ 988$ \\
\hline & Sulfadiazine & 500 mg q.i.d. & $\$ 1490$ \\
\hline Streptococcus pneumoniae & 23 -valent pneumococcal vaccine & $0.5 \mathrm{ml} \mathrm{im} \times \mathrm{I}$ & $\$ 13$ \\
\hline Influenza virus & Inactivted trivalent influenza vaccine & $0.5 \mathrm{ml} \mathrm{im} \times \mathrm{I}$ & $\$ 3$ \\
\hline Hepatitis A virus & Hepatitis A vaccine & $1.0 \mathrm{ml} \mathrm{im} \times 2$ & $\$ 124$ \\
\hline Hepatitis $B$ virus & Recombinant hepatitis B & $10-20 \mu \mathrm{g} \mathrm{im} \times 3$ & $\$ 70$ \\
\hline Bacterial infections & G-CSF & $300 \mu g$ t.i.w. & $\$ 29406$ \\
\hline Varicella zoster virus & VZIG & 5 vials $(6.25 \mathrm{ml})$ & $\$ 562$ \\
\hline
\end{tabular}

ABBREVIATIONS: b.i.d. = twice daily; G-CSF = granulocyte-colony-stimulating factor; iv = intravenous; im = intramuscular; po = by mouth; q.d. = daily; q.o.w. = every other week; q.w. = once a week; t.i.d. = three times daily; t.i.w. = three times a week; VZIG = varicella zoster immune globulin.

*Implant generally lasts 6-9 months.

${ }^{\dagger}$ Cost for 9 months of therapy.

Source: Medical Economics. Drug topics red book. Montvale, New Jersey: Medical Economics Inc., 2000 
Table 10 Immunologic categories for human immunodeficiency virus-infected children based on age-specific CD4 ${ }^{+}$ T lymphocyte counts and percentage of total lymphocytes*

\begin{tabular}{|c|c|c|c|}
\hline \multirow[b]{2}{*}{ Immunologic category } & \multicolumn{3}{|c|}{ Age } \\
\hline & $\begin{array}{l}\leq 12 \text { months } \\
\text { cells/ } \mu \mathrm{l}(\%)\end{array}$ & $\begin{array}{c}I-5 \text { years } \\
\text { cells/ } / \mu l(\%)\end{array}$ & $\begin{array}{l}6-12 \text { years } \\
\text { cells/ } / \text { I (\%) }\end{array}$ \\
\hline I. No evidence of suppression & $\geq 1500(25)$ & $\geq 1000(\geq 25)$ & $\geq 500(\geq 25)$ \\
\hline 2. Evidence of moderate suppression & $750-1499(15-24)$ & $500-999(15-24)$ & $200-499(15-24)$ \\
\hline 3. Severe suppression & $<750(<15)$ & $<500(<15)$ & $<200(<15)$ \\
\hline
\end{tabular}

*Adapted from CDC. 1994 revised classification system for human immunodeficiency virus infection in children less than I 3 years of age. MMWR 1994;43(No. RR-12) ${ }^{123}$

is probably prudent to continue PCP prophylaxis for life regardless of how high the CD4+ T lymphocyte count rises as a consequence of HAART (CIII). Discontinuation of secondary prophylaxis for patients is recommended (see above ${ }^{\star}$ ).

\section{Restarting secondary prophylaxis}

Prophylaxis should be reintroduced if the $\mathrm{CD}^{+} \mathrm{T}$ lymphocyte count decreases to $<200$ cells $/ \mu 1$ (AIII), or if PCP recurred at a CD4 ${ }^{+}$T lymphocyte count $>200$ cells $/ \mu 1$ (CIII).

\section{Special Considerations}

\section{Children}

Children born to HIV-infected mothers should be administered prophylaxis with TMP-SMZ beginning at 4-6 weeks of age ${ }^{44}$ (AII). Prophylaxis should be discontinued for children who are subsequently found not to be infected with HIV. HIV-infected children and children whose infection status remains unknown should continue to receive prophylaxis for the first year of life. The need for subsequent prophylaxis should be determined on the basis of age-specific $\mathrm{CD}^{+}{ }^{+} \mathrm{T}$ lymphocyte count thresholds (Table 12) (AII). The safety of discontinuing prophylaxis in HIV-infected children receiving HAART has not been studied extensively. Children who have a history of PCP should be administered lifelong chemoprophylaxis to prevent recurrence ${ }^{44}(\mathrm{AI})$.

\section{Pregnant women}

Chemoprophylaxis for PCP should be administered to pregnant women as is done for other adults and adolescents (AIII). TMP-SMZ is the recommended prophylactic agent; dapsone is an alternative. Because of theoretical concerns regarding possible teratogenicity associated with drug exposures during the first trimester, providers may choose to withhold prophylaxis during the first trimester. In such cases, aerosolized pentamidine may be considered because of its lack of systemic absorption and the resultant lack of exposure of the developing embryo to the drug (CIII).

\section{TOXOPLASMIC ENCEPHALITIS}

\section{Prevention of exposure}

HIV-infected persons should be tested for immunoglobulin G (IgG) antibody to Toxoplasma soon after the diagnosis of HIV infection to detect latent infection with T. gondii (BIII). 
Table I I Recommended immunization schedule for human immunodeficiency virus-infected children

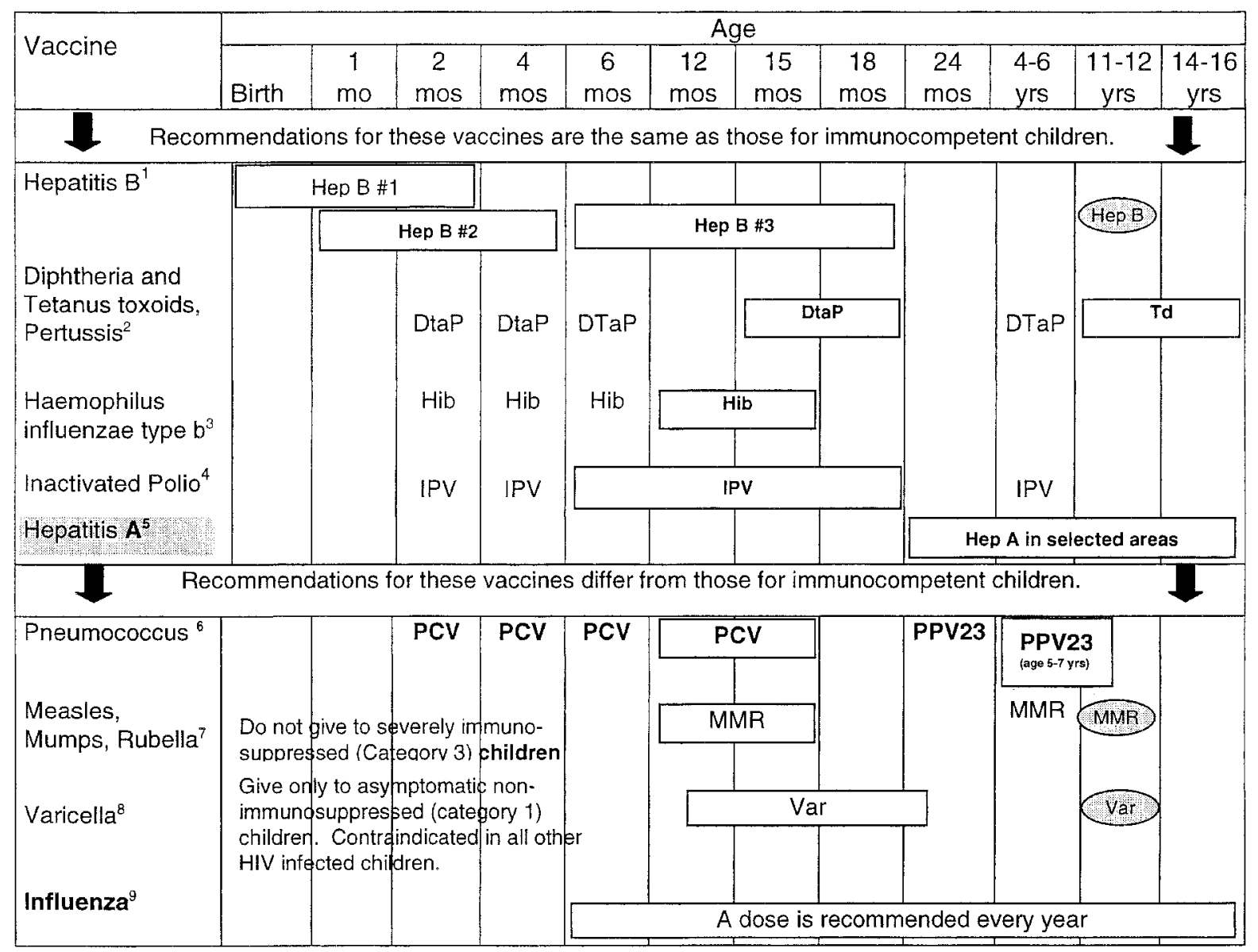

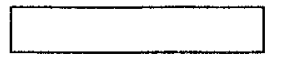

Range of recommended ages for vaccination.

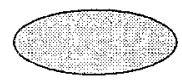

Vaccines to be given if previously recommended doses were missed or were given earlier than the recommended minimum age.

Recommended in selected states and/or regions.

This schedule indicates the recommended ages for routine administration of currently licensed childhood vaccines as of November I, 2000, for children through age 18 years. Additional vaccines may be licensed and recommended during the year. Licensed combination vaccines may be used whenever any components of the combination are indicated and the vaccine's other components are not contraindicated. Providers should consult the manufacturer's package inserts for detailed recommendations.

I. Infants born to hepatitis B surface antigen (HBsAg)-negative mothers should receive the first dose of hepatitis B vaccine (Hep B) at birth and no later than age 2 months. The second dose should be administered at least I month after the first dose. The third dose should be administered at least 4 months after the first dose and at least 2 months after the second dose, but not before age 6 months. Infants born to HBsAg-positive mothers should receive Hep B and $0.5 \mathrm{ml}$ hepatitis B immune globulin (HBIG) within I2 hours of birth at separate sites. The second dose is recommended at age I-2 months and the third dose at age 6 months. Infants born to mothers whose HBsAg status is unknown should receive Hep B within 12 hours of birth. Maternal blood should be drawn at delivery to determine the mother's $\mathrm{HBsAg}$ status; if the $\mathrm{HBsAg}$ test is positive, the infant should receive HIBG as soon as possible (no later than age one week). All children and adolescents (through age 18 years) who have not been immunized against hepatitis B should begin the series during any visit. Providers should make special efforts to immunize children who were born in or whose parents were born in areas of the world where hepatitis B virus infection is moderately or highly endemic.

2. The fourth dose of diphtheria and tetanus toxoids and acellular pertussis vaccine (DTaP) may be administered as early as age 12 months, provided 6 months have elapsed since the third dose and the child is unlikely to return at age 15-18 months. Tetanus and diphtheria toxoids (Td) is recommended at age $1 \mathrm{I}-12$ years if at least 5 years have elapsed since the last dose of diphtheria and tetanus toxoids and pertussis 


\section{Table I I Continued}

vaccine (DTP), DTaP, or diphtheria and tetanus toxoids (DT). Subsequent routine Td boosters are recommended every 10 years. 3. Three Haemophilus influenzae type $b$ (Hib) conjugate vaccines are licensed for infant use. If Hib conjugate vaccine (PRP-OMP) (PedvaxHIB or ComVax [Merck]) is administered at ages 2 and 4 months, a dose at age 6 months is not required. Because clinical studies in infants have demonstrated that using some combination products may induce a lower immune response to the Hib vaccine component, $\mathrm{DTaP} / \mathrm{Hib}$ combination products should not be used for primary immunization in infants at ages 2,4 or 6 months unless approved by the Food and Drug Administration for these ages.

4. An all-inactivated poliovirus vaccine (IPV) schedule is recommended for routine childhood polio vaccination in the United States. All children should receive four doses of IPV at age 2 months, age 4 months, between ages 6 and 18 months, and between ages 4 and 6 years. Oral poliovirus vaccine should not be administered to HIV infected persons or their household contacts.

5. Hepatitis $A$ vaccine (Hep $A)$ is recommended for use in selected states and/or regions, and for certain high-risk groups such as those with Hepatitis B or Hepatitis $C$ infection. Information is available from local public health authorities.

6. The heptavalent pneumococcal conjugate vaccine (PCV) is recommended for all children age 2-59 months with HIV. Children 2 years and older should also receive the 23 valent pneumococcal polysaccharide vaccine; a single revaccination with the 23 valent vaccine should be offered to children after 3-5 years. Refer to the Advisory Committee on Immunization Practices recommendations (80) on dosing intervals for children starting the vaccination schedule after 2 months of age. 7. MMR should not be administered to severely immunocompromisd (category 3) children. HIV infected children without severe immunosuppression would routinely receive their first dose of MMR as soon as possible after reaching their first birthday. Consideration should be given to administering the second dose of MMR as soon as I month (i.e., a minimum of 28 days) after the first dose rather than waiting until school entry.

8. Varicella zoster virus vaccine, $0.5 \mathrm{ml}$, is given as a subcutaneous dose between $\mathbf{I} 2$ months and $\mathrm{I} 2$ years of age; a second dose should be given 3 months later. The vaccine should be given only to asymptomatic, nonimmunosuppressed children. 9. For children aged 6 months to $<9$ years who are receiving influenze vaccine for the first time, two injections given one month apart are recommended. For specific recommendations, see: CDC, Prevention and Control of Influenza: Recommendations of the Advisory Committee on Immunization Practices (ACIP). MMWR 200 I;50:RR-4. Inactivated split influenza virus vaccine should be administered to all HIV infected children $\geq 6$ months of age each year

Table 12 Prophylaxis to prevent first episode of opportunistic disease in infants and children infected with human immunodeficiency virus

Preventive regimens

Pathogen Indication First choice Alternatives

\section{Strongly recommended as standard of care}

Pneumocystis carinii ${ }^{1}$
HIV-infected or

HIV-indeterminate, infants

aged I-I2 mo;

HIV-infected children aged

I-5 yr with CD4 ${ }^{+}$count

$<500 / \mu$ or $\mathrm{CD}^{+}$

percentage < I5\%;

HIV-infected children aged

6-12 yr with CD4 ${ }^{+}$count

$<200 / \mu$ or $\mathrm{CD}^{+}$

percentage $<15 \%$
Trimethoprim-sulfamethoxa zole (TMP-SMZ), $150 / 750 \mathrm{mg} / \mathrm{m}^{2} / \mathrm{d}$ in 2 divided doses po t.i.w. on consecutive days (All)

Acceptable alternative dosage schedules: (AII) -Single dose po t.i.w. on consecutive days;

-2 divided doses po q.d.; 2 divided doses po t.i.w. on alternate days

Isoniazid 10-15 mg/kg (max $300 \mathrm{mg}$ ) po q.d. $\times 9$ mo (AII) or $20-30 \mathrm{mg} / \mathrm{kg}$ (max $900 \mathrm{mg}$ po biw) $\times 9$ months
Dapsone (children aged $\geq 1$ $\mathrm{mo}), 2 \mathrm{mg} / \mathrm{kg}$ ( $\max 100 \mathrm{mg}$ ) po q.d. or $4 \mathrm{mg} / \mathrm{kg}$ ( $\max$ $200 \mathrm{mg}$ ) po q.w. (CII); aerosolized pentamidine (children aged $\geq 5 \mathrm{yr}$ ), 300 mg q.m. via Respirgard II $^{\mathrm{TM}}$ nebulizer (CIII); atovaquone (children aged I-3 mo. and > 24 mo., $30 \mathrm{mg} / \mathrm{kg}$ po q.d., children aged 4-24 mo., $45 \mathrm{mg} / \mathrm{kg}$ po q.d.) (CII)

Rifampin, $10-20$ mg/kg (max $600 \mathrm{mg}$ ) po q.d. plus pyrazinamide I5-20 $\mathrm{mg} / \mathrm{kg}$ po q.d. $(\max 2.0 \mathrm{~g}) \times 2 \mathrm{mo}(\mathrm{Al})$ 
Table 12 Continued

\begin{tabular}{|c|c|c|c|}
\hline Isoniazid-resistant & $\begin{array}{l}\text { Same as above; high } \\
\text { probability of exposure to } \\
\text { isoniazid-resistant } \\
\text { tuberculosis }\end{array}$ & $\begin{array}{l}\text { Rifampin, I0-20 mg/kg } \\
\text { (max } 600 \mathrm{mg} \text { ) po q.d. } \\
\text { plus pyrazinamide } \\
15-20 \mathrm{mg} / \mathrm{kg} \text { po q.d. } \times 2 \\
\text { mo }(\max 2 \mathrm{~g}) \text { (Al) }\end{array}$ & $\begin{array}{l}\text { Rifampin, } 10-20 \mathrm{mg} / \mathrm{kg} \text { (max } \\
600 \mathrm{mg} \text { ) po q.d. } \times 4-6 \mathrm{mo} \\
\text { (BIII) }\end{array}$ \\
\hline $\begin{array}{l}\text { Multidrug-(isoniazid and } \\
\text { rifampin) resistant }\end{array}$ & $\begin{array}{l}\text { Same as above; high } \\
\text { probability of exposure to } \\
\text { multi-drug resistant } \\
\text { tuberculosis }\end{array}$ & $\begin{array}{l}\text { Choice of drugs requires } \\
\text { consultation with public } \\
\text { health authorities and } \\
\text { depends on susceptibility } \\
\text { of isolate from source } \\
\text { patient }\end{array}$ & \\
\hline
\end{tabular}

Mycobacterium avium complex $^{2}$

Varicella zoster virus ${ }^{3}$

Vaccine-preventable pathogens $^{4}$

\section{Generally recommended}

Toxoplasma gondii ${ }^{5}$

Varicella zoster virus ${ }^{3}$
For children aged $\geq 6$ yrs, $\mathrm{CD} 4^{+}$count $<50 / \mu \mathrm{l}$; aged 2-6 yrs CD4 ${ }^{+}$count $<75 / \mu$; aged I-2 yrs, $\mathrm{CD}^{+}$count $<500 / \mu \mathrm{l}$; aged

$<\mathrm{I} \mathrm{yr}, \mathrm{CD}^{+}$count

$<750 / \mu \mathrm{l}$

Significant exposure to varicella or shingles with no history of chickenpox or shingles

HIV exposure/infection IgG antibody to Toxoplasma and severe immunosuppression

HIV-infected children who are asymptomatic and not immunosuppressed
Clarithromycin $7.5 \mathrm{mg} / \mathrm{kg}$ (max $500 \mathrm{mg}$ ) po b.i.d. (All), or azithromycin, $20 \mathrm{mg} / \mathrm{kg}$ (max I200 mg) po q.w. (AII)

Varicella zoster immune globulin (VZIG), I vial ( $1.25 \mathrm{ml}) / 10 \mathrm{~kg}$ (max 5 vials) $\mathrm{im}$, administered $\leq 96 \mathrm{hrs}$ after exposure, ideally within 48 hrs (All)

Routine immunizations (see Table 10)

TMP-SMZ, $150 / 750 \mathrm{mg} / \mathrm{m}^{2} / \mathrm{d}$ in two divided doses po q.d. (BIII)

Varicella zoster vaccine (see vaccine-preventable pathogens section of this table) (BII)
Azithromycin, $5 \mathrm{mg} / \mathrm{kg}$ (max $250 \mathrm{mg}$ ) po q.d. (AII); children aged $\geq 6$ yrs, rifabutin, 300 mg po q.d.

None

None

Dapsone (children aged $\geq 1$ $\mathrm{mo}), 2 \mathrm{mg} / \mathrm{kg}$ or $15 \mathrm{mg} / \mathrm{m}^{2}$ (max $25 \mathrm{mg}$ ) po q.d. plus pyrimethamine, I mg/kg po q.d. plus leucovorin, $5 \mathrm{mg}$ po every 3 days (BIII)

Atovaquone, (aged I-3 mo. and > $24 \mathrm{mo}$., $30 \mathrm{mg} / \mathrm{kg}$ po q.d.; aged l4-24 mo. $45 \mathrm{mg} / \mathrm{kg}$ po q.d.) (CIII) None 
Table 12 Continued

\begin{tabular}{lll}
\hline Influenza virus & All patients (annually, before & Inactivated split trivalent \\
influenza season) & influenza vaccine (see
\end{tabular}

\author{
Oseltamivir (during \\ outbreaks of influenza $A$ \\ or B) for children $\geq 13$ \\ years, 75 mg po q.d. \\ (CIII); Rimantadine or \\ amantadine (during \\ outbreaks of influenza A); \\ aged $\mathrm{I}-9 \mathrm{yr}, 5 \mathrm{mg} / \mathrm{kg}$ in 2 \\ divided doses ( $\mathrm{max}$ \\ 150 mg/day) po q.d.; aged \\ $\geq 10 \mathrm{yr}$, use adult doses \\ (CIII)
}

III. Not recommended for most children; indicated for use only in unusual circumstances

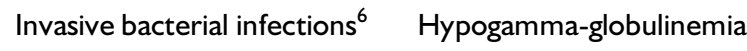
(i.e., lgG $<400 \mathrm{mg} / \mathrm{dl}$ )

Cryptococcus neoformans

Severe immunosuppression

Histoplasma capsulatum

Cytomegalovirus (CMV) ${ }^{7}$
Severe immunosuppression, endemic geographic area

CMV antibody positivity and severe immunosuppression
IVIG (400 mg/kg every 2-4 None

wks) (Al)

Fluconazole, $3-6 \mathrm{mg} / \mathrm{kg}$ po q.d. (CII)

Itraconazole, $2-5 \mathrm{mg} / \mathrm{kg}$ po every I2-24 h (CII)

Itraconazole, $2-5 \mathrm{mg} / \mathrm{kg}$ po None every $12-24 \mathrm{~h}$ (CIII)

Oral ganciclovir $30 \mathrm{mg} / \mathrm{kg}$ po t.i.d. (CII)

NOTES: Information included in these guidelines might not represent Food and Drug Administration (FDA) approval or approved labeling for the particular products or indications in question. Specifically, the terms 'safe' and 'effective' might not be synonymous with the FDA-defined legal standards for product approval. The Respirgard II ${ }^{\mathrm{TM}}$ nebulizer is manufactured by Marquest, Englewood, Colorado. Letters and Roman numerals in parentheses after regimens indicate the strength of the recommendation and the quality of the evidence supporting it (see Box, page 3).

ABBREVIATIONS: b.i.w. = twice a week; IVIG = intravenous immune globulin; q.d. = daily; q.m. = monthly; t.i.d. = three times a day; t.i.w. = three times a week.

'Daily TMP-SMZ reduces the frequency of some bacterial infections. TMP-SMZ, dapsone-pyrimethamine, and possibly atovaquone (with or without pyrimethamine) appear to protect against toxoplasmosis, although data have not been prospectively collected. When compared with weekly dapsone, daily dapsone is associated with lower incidence of Pneumocystis carinii pneumonia (PCP) but higher hematologic toxicity and mortality (Mclntosh K, Cooper E, Xu J, et al. Toxicity and Efficacy of daily vs. weekly dapsone for prevention of Pneumocystis carinii pneumonia in children infected with HIV. Ped Infect Dis J 1999; 18:432-9).

The efficacy of parenteral pentamidine (e.g. $4 \mathrm{mg} / \mathrm{kg} \mathrm{q} \mathrm{2-4} \mathrm{wks)} \mathrm{is} \mathrm{controversial.} \mathrm{Patients} \mathrm{receiving} \mathrm{therapy} \mathrm{for} \mathrm{toxoplasmosis} \mathrm{with}$ sulfadiazine-pyrimethamine are protected against PCP and do not need TMP-SMZ.

${ }^{2}$ Significant drug interactions might occur between rifamycins (rifampin and rifabutin) and protease inhibitors and nonnucleoside reverse transcriptase inhibitors. Consult a specialist.

${ }^{3}$ Children routinely being administered intravenous immune globulin (IVIG) should receive VZIG if the last dose of IVIG was administered $>21$ days before exposure.

${ }^{4} \mathrm{HIV}$-infected and HIV-exposed children should be immunized according to the childhood immunization schedule in this report (Table I0), which has been adapted from the January-December $\mathbf{2 0 0}$ I schedule recommended for immunocompetent children by the Advisory Committee on Immunization Practices, the American Academy of Pediatrics, and the American Academy of Family Physicians. This schedule differs from that for immunocompetent children in that both the conjugate pneumococcal vaccine (PCV-7) and the pneumococcal polysaccharide vaccine (PPV-23) are recommended (BII) and vaccination against influenza (BIII) should be offered. MMR should not be administered to severely immunocompromised children (DIII). Vaccination against varicella is indicated only for asymptomatic nonimmunosuppressed children (BII). Once an HIV-exposed child is determined not to be HIV infected, the schedule for immunocompetent children applies.

${ }^{5}$ Protection against toxoplasmosis is provided by the preferred antipneumocystis regimens and possibly by atovaquone. Atovaquone may be used with or without pyrimethamine. Pyrimethamine alone probably provides little, if any, protection (for definition of severe immunosuppression, see Table 9).

${ }^{6}$ Respiratory syncytial virus (RSV) IVIG $(750 \mathrm{mg} / \mathrm{kg}$ ), not monoclonal RSV antibody, may be substituted for IVIG during the RSV season to provide broad antiinfective protection, if this product is available.

${ }^{7}$ Oral ganciclovir and perhaps valganciclovir results in reduced CMV shedding in CMV-infected children. Acyclovir is not protective against CMV 
Table 13 Prophylaxis to prevent recurrence of opportunistic disease (ater chemotherapy for acute disease) in HIV-infected infants and children

\begin{tabular}{llll} 
& \multicolumn{3}{c}{ Preventive Regimens } \\
\cline { 2 - 4 } Pathogen & Indication & First Choice & Alternatives \\
\hline
\end{tabular}

\section{Recommended for life as standard of care}

Pneumocystis carinii

Prior P. carinii pneumonia

Toxoplasma gondii'

Mycobacterium avium

Complex ${ }^{2}$

Cryptococcus neoformans

Documented disease

Prior toxoplasmic encephalitis

Prior disease

Histoplasma capsulatum

Documented disease

Itraconazole, $2-5 \mathrm{mg} / \mathrm{kg}$ po every 12-48h (AllI)

Coccidioides immitis

Documented disease

Fluconazole, $6 \mathrm{mg} / \mathrm{kg}$ po q.d. (AllI)

Prior end-organ disease

Ganciclovir, $5 \mathrm{mg} / \mathrm{kg}$ iv q.d.; or foscarnet, $90-120 \mathrm{mg} / \mathrm{kg}$ iv q.d. (Al)

TMP-SMZ, $150 / 750 \mathrm{mg} / \mathrm{m}^{2}$ in 2 divided doses po q.d. for

(non-typhi) ${ }^{3}$ several months (CIII)

Bacteremia
Dapsone (children aged $\geq \mathrm{I} \mathrm{mo}$ ), $2 \mathrm{mg} / \mathrm{kg}$ ( $\max 100 \mathrm{mg}$ ) po q.d. or $4 \mathrm{mg} / \mathrm{kg}$ (max $200 \mathrm{mg}$ ) po q.w. (CII); aerosolized pentamidine (children aged $\geq 5$ yrs), $300 \mathrm{mg}$ q.m. via. Respirgard II ${ }^{\mathrm{TM}}$ nebulizer (CIII); atovaquone (aged I-3 months and > 24 mo., $30 \mathrm{mg} / \mathrm{kg}$ po q.d.; aged 4-24 mo., $45 \mathrm{mg} / \mathrm{kg}$ po q.d.) (CII)

Clindamycin, $20-30 \mathrm{mg} / \mathrm{kg} / \mathrm{d}$ in 4 divided doses po q.d. plus pyrimethamine, I mg/kg po q.d. plus leucovorin, $5 \mathrm{mg}$ po every 3 days $(\mathrm{BI})$

Azithromycin, $5 \mathrm{mg} / \mathrm{kg}$ ( $\max$ $250 \mathrm{mg}$ ) po q.d. (All) plus ethambutol, $15 \mathrm{mg} / \mathrm{kg}$ ( $\max$ $900 \mathrm{mg}$ ) po q.d. (All); with or without rifabutin, $5 \mathrm{mg} / \mathrm{kg}$ (max $300 \mathrm{mg}$ ) po q.d. (Cll)

Amphotericin B, $0.5-1.0 \mathrm{mg} / \mathrm{kg}$ iv $\mathrm{I}-3 \times /$ week (Al); itraconazole, 2-5 mg/kg po every I2-24h (BII)

Amphotericin B, $1.0 \mathrm{mg} / \mathrm{kg}$ iv q.w. (AllI)

Amphotericin B, $1.0 \mathrm{mg} / \mathrm{kg}$ iv q.w. (All); itraconazole, 2-5 mg/kg po every 12-48h (AlI)

(For retinitis) Ganciclovir sustained-release implant every 6-9 mo. Plus ganciclovir, $30 \mathrm{mg} / \mathrm{kg}$ po t.i.d. (BIII)

Antibiotic chemoprophylaxis with another active agent (CIII) 
Table 13 Continued

\section{Recommended only if subsequent episodes are frequent or severe}

Invasive bacterial

Infections ${ }^{4}$

\author{
$>2$ infections in \\ I-year period
}

Herpes simplex virus

Frequent/severe recurrences

Candida (oropharyngeal)

Frequent/severe recurrences

Candida (esophageal)
Frequent/severe recurrences
TMP-SMZ, I $50 / 750 \mathrm{mg} / \mathrm{m}^{2}$, in 2 divided doses po q.d. (BI); or IVIG, 400 mg/kg every 2-4 wks. (BI)

Acyclovir, 80 mg/kg/d in 3-4

divided doses po q.d. (All)

Fluconazole, 3-6 mg/kg po q.d. (CIII)

Fluconazole, 3-6 mg/kg po q.d. (BIII)
Antibiotic chemoprophylaxis with another active agent (BIII)

NOTES: Information included in these guidelines might not represent Food and Drug Administration (FDA) approval or approved labeling for the particular products or indications in question. Specifically, the terms 'safe' and 'effective' might not be synonymous with the FDA-defined legal standards for product approval. The Respirgard II ${ }^{\mathrm{TM}}$ nebulizer is manufactured by Marquest, Englewood, Colorado. Letters and Roman numerals in parentheses after regimens indicate the strength of the recommendations and the quality of evidence supporting it (see Box, page 3).

ABBREVIATIONS: IVIG = intravenous immune globulin; po = by mouth; q.d. = daily; q.m. = monthly; q.w. = weekly; t.i.d. = three times a day; t.i.w. = three times a week; and TMP-SMZ = trimethoprim-sulfamethoxazole.

'Only pyrimethamine plus sulfadiazine confers protection against PCP as well as toxoplasmosis. Although the clindamycin plus pyrimethamine regimen is recommended in adults, it has not been tested in children. However, these drugs are safe and are used for other infections.

${ }^{2}$ Significant drug interactions might occur between rifabutin and protease inhibitors and nonnucleoside reverse transcriptase inhibitors. Consult an expert.

${ }^{3}$ Drug should be determined by susceptibilities of the organism isolated. Alternatives to TMP-SMZ include ampicillin, chloramphenicol, or ciprofloxacin. However, ciprofloxacin is not approved for use in persons aged $<18$ years; therefore, it should be used in children with caution and only if no alternatives exist.

${ }^{4}$ Antimicrobial prophylaxis should be chosen based on the microorganism and antibiotic sensitivities. TMP-SMZ, if used, should be administered daily. Providers should be cautious about using antibiotics solely for this purpose because of the potential for development of drug-resistant microorganisms. IVIG might not provide additional benefit to children receiving daily TMP-SMZ but may be considered for children who have recurrent bacterial infections despite TMP-SMZ prophylaxis. Choice of antibiotic prophylaxis vs. IVIG should also involve consideration of adherence, ease of intravenous access, and cost, if IVIG is used, respiratory syncytial virus (RSV) IVIG (750 mg/kg), not monoclonal RSV antibody, may be substituted for IVIG during the RSV season to provide broad anti-infective protection, if this product is available

All HIV-infected persons, but particularly those who lack IgG antibody to Toxoplasma, should be counseled about the various sources of toxoplasmic infection. They should be advised not to eat raw or undercooked meat, particularly undercooked lamb, beef, pork or venison (BIII). Specifically, lamb,

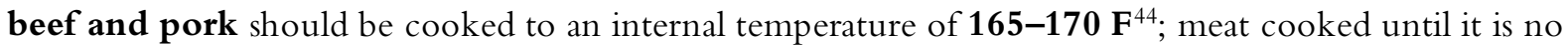
longer pink inside generally has an internal temperature of $\mathbf{1 6 5 - 1 7 0 ~} \mathbf{F}$ and therefore from a more practical perspective, satisfies this requirement. HIV-infected persons should wash their hands after contact with raw meat and after gardening or other contact with soil; in addition, they should wash fruits and vegetables well before eating them raw (BIII). If the patient owns a cat, the litter box should be changed daily, preferably by an HIV-negative, nonpregnant person; alternatively, the patient should wash the hands thoroughly after changing the litter box (BIII). Patients should be encouraged to keep their cats inside and not to adopt or handle stray cats (BIII). Cats should be fed only canned or dried commercial food or well-cooked table food, not raw or undercooked meats (BIII). Patients need not be advised to part with their cats or to have their cats tested for toxoplasmosis (EII). 


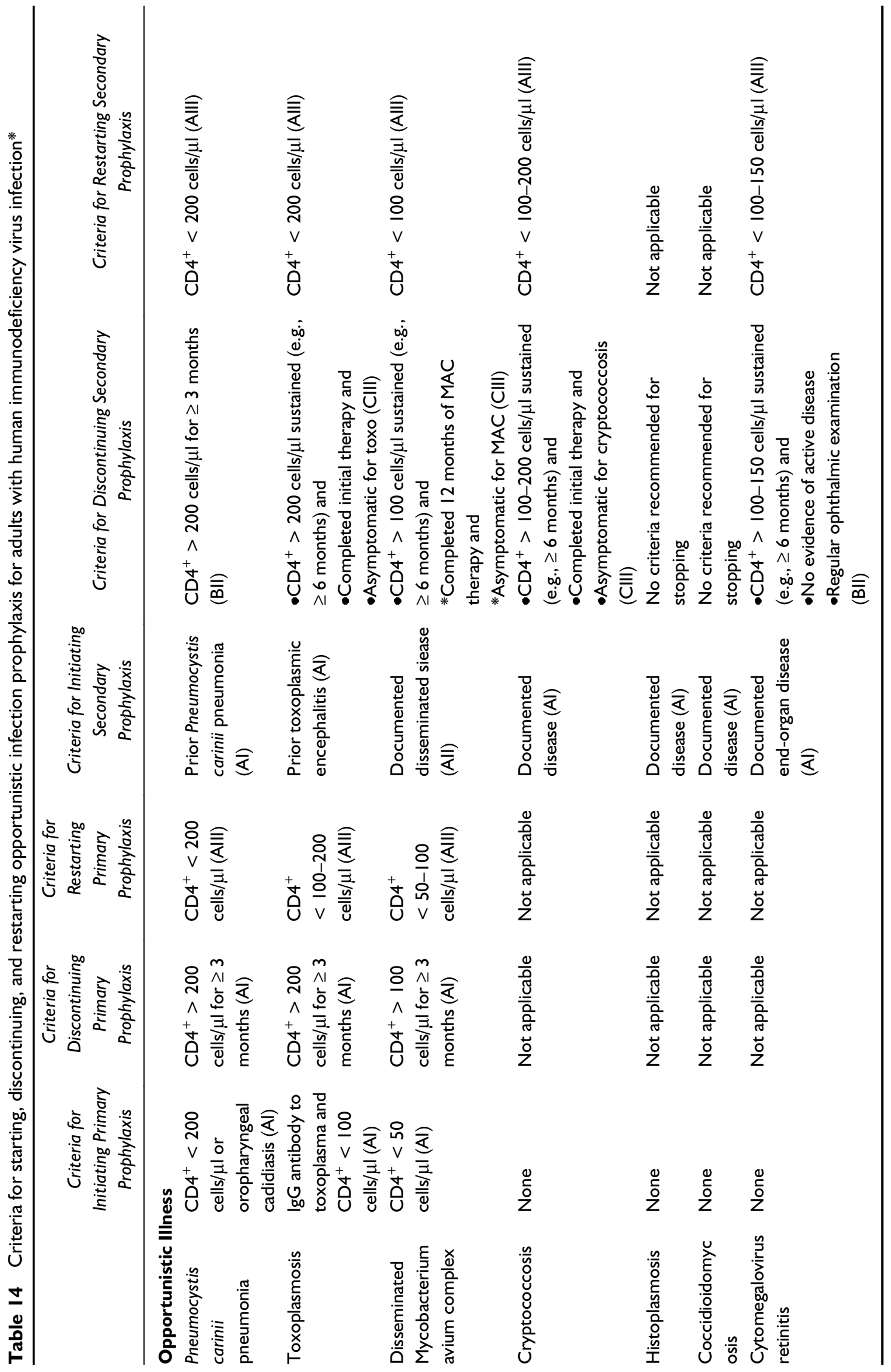




\section{Prevention of Disease}

\section{Initiation of primary prophylaxis}

Toxoplasma-seropositive patients who have a CD $4^{+} \mathrm{T}$ lymphocyte count of less than $100 / \mu 1$ should be administered prophylaxis against toxoplasmic encephalitis (TE) (AII) ${ }^{25}$. The double-strength tablet daily dose of TMP-SMZ recommended as the preferred regimen for PCP prophylaxis appears to be effective against TE as well and is therefore recommended (AII) ${ }^{25}$. If patients cannot tolerate TMP-SMZ, the recommended alternative is dapsone-pyrimethamine, which is also effective against PCP (BI) ${ }^{29,30}$. Atovaquone with or without pyrimethamine also may be considered (CIII). Prophylactic monotherapy with dapsone, pyrimethamine, azithromycin, or clarithromycin cannot be recommended on the basis of current data (DII). Aerosolized pentamidine does not protect against TE and is not recommended (EI $)^{21,25}$.

Toxoplasma-seronegative persons who are not taking a PCP prophylactic regimen known to be active against TE should be retested for IgG antibody to Toxoplasma when their CD $4^{+} \mathrm{T}$ lymphocyte count declines below $100 / \mu 1$ to determine whether they have seroconverted and are therefore at risk for TE (CIII). Patients who have seroconverted should be administered prophylaxis for TE as described above (AII).

\section{Discontinuation of primary prophylaxis}

Prophylaxis against TE should be discontinued in adult and adolescent patients who have responded to HAART with an increase in $\mathrm{CD4}^{+} \mathrm{T}$ lymphocyte counts to $>200 \mathrm{cells} / \mu \mathrm{l}$ for at least 3 months (AI).

Several observational studies ${ }^{37,41,47}$ and two randomized trials ${ }^{38,46}$ have shown that primary prophylaxis can be discontinued with minimal risk of developing $T E$ in patients who have responded to HAART with an increase in $\mathrm{CD}^{+} \mathrm{T}$ lymphocyte count from $<200$ cells $/ \mu 1$ to $>200$ cells $/ \mu 1$ for at least 3 months. In these studies, most patients were taking protease inhibitor-containing regimens and the median $\mathrm{CD}^{+} \mathrm{T}$ lymphocyte count at the time prophylaxis was discontinued was $>300$ cells $/ \mu 1$. At the time prophylaxis was discontinued, many patients had sustained suppression of plasma HIV RNA levels below the detection limits of available assays; the median follow up ranged from 7-22 months.

While patients with $\mathrm{CD}^{+} \mathrm{T}$ lymphocyte counts of $<100$ cells $/ \mu 1$ are at greatest risk for developing TE, the risk of TE occurring when the $\mathrm{CD}^{+}{ }^{+} \mathrm{T}$ lymphocyte count has increased to $100-200$ cells $/ \mu 1$ has not been studied as rigorously as a rise to $>200$ cells $/ \mu$ l. Thus, the recommendation specifies discontinuation of prophylaxis after an increase to $>200$ cells $/ \mu 1$.

Discontinuation of primary TE prophylaxis is recommended not only because prophylaxis appears to add very little to disease prevention for toxoplasmosis, but also because discontinuation of drug reduces pill burden, the potential for drug toxicity, drug interaction and selection of drug resistant pathogens.

\section{Restarting primary prophylaxis}

Prophylaxis should be reintroduced if the $\mathrm{CD}^{+} \mathrm{T}$ lymphocyte count decreases to $<$ 100-200 cells $/ \mu 1$ (AIII).

\section{Prevention of recurrence}

Patients who have completed initial therapy for TE should be administered lifelong suppressive therapy (secondary prophylaxis or CMT) $(\mathrm{AI})^{48,49}$ unless immune reconstitution occurs as a consequence of HAART (see below). The combination of pyrimethamine plus sulfadiazine 
plus leucovorin is highly effective for this purpose (AI). A commonly used regimen for patients who cannot tolerate sulfa drugs is pyrimethamine plus clindamycin (BI); however, only the combination of pyrimethamine plus sulfadiazine appears to provide protection against $\mathrm{PCP}$ as well (AII).

\section{Discontinuation of secondary prophylaxis (CMT)}

Adult and adolescent patients receiving secondary prophylaxis (CMT) for TE appear to be at low risk for recurrence of TE when they have successfully completed initial therapy for $T E$, remain asymptomatic with respect to signs and symptoms of $T E$, and have a sustained increase in their $\mathrm{CD}^{+} \mathrm{T}$ lymphocyte counts to $>200$ cells/ $\mu$ l following HAART (e.g., 6 months $)^{41,42,46}$. While the numbers of patients who have been evaluated remain small and occasional recurrences have been seen, based on these observations and on inference from more extensive cumulative data suggesting the safety of discontinuation of secondary prophylaxis for other OIs during advanced HIV disease, it is reasonable to consider discontinuation of CMT in such patients (CIII). Some experts would obtain a magnetic resonance image of the brain as part of their evaluation to determine whether or not discontinuation of therapy is appropriate.

\section{Restarting secondary prophylaxis}

Secondary prophylaxis (CMT) should be reintroduced if the $\mathrm{CD}^{+} \mathrm{T}$ lymphocyte count decreases to $<200$ cells $/ \mu 1$ (AIII).

\section{Special considerations}

\section{Children}

TMP-SMZ, when administered for PCP prophylaxis, also provides prophylaxis against toxoplasmosis. Atovaquone might also provide protection (CIII). Children aged greater than 12 months who qualify for PCP prophylaxis and who are receiving an agent other than TMP-SMZ or atovaquone should have serologic testing for Toxoplasma antibody (BIII), because alternative drugs for PCP prophylaxis might not be effective against Toxoplasma. Severely immunosuppressed children who are not receiving TMP-SMZ or atovaquone who are found to be seropositive for Toxoplasma should be administered prophylaxis for both PCP and toxoplasmosis (i.e., dapsone plus pyrimethamine) (BIII).

Children with a history of toxoplasmosis should be administered lifelong prophylaxis to prevent recurrence (AI). The safety of discontinuing primary or secondary prophylaxis in HIV-infected children receiving HAART has not been studied extensively.

\section{Pregnant Women}

TMP-SMZ can be administered for prophylaxis against TE as described for PCP (AIII). However, because of the low incidence of TE during pregnancy and the possible risk associated with pyrimethamine treatment, chemoprophylaxis with pyrimethamine-containing regimens can reasonably be deferred until after pregnancy (CIII). For prophylaxis against recurrent TE, the health-care provider and clinician should be well informed about the benefit of lifelong therapy and the concerns about teratogenicity of pyrimethamine. The above guidelines should be used when making decisions regarding secondary prophylaxis for TE in pregnancy.

In rare cases, HIV-infected pregnant women who have serologic evidence of remote toxoplasmic infection have transmitted Toxoplasma to the fetus in utero. Pregnant HIV-infected women who have evidence of primary toxoplasmic infection or active toxoplasmosis (including TE) should be evaluated and managed 
during pregnancy in consultation with appropriate specialists (BIII). Infants born to women who have serologic evidence of infections with HIV and Toxoplasma should be evaluated for congenital toxoplasmosis (BIII).

\section{CRYPTOSPORIDIOSIS}

\section{Prevention of exposure}

1. HIV-infected persons should be educated and counseled about the many ways that Cryptosporidium can be transmitted (BIII). Modes of transmission include having direct contact with infected adults, diaper-aged children and infected animals; drinking contaminated water; coming into contact with contaminated water during recreational activities and eating contaminated food.

2. HIV-infected persons should avoid contact with human and animal feces. They should be advised to wash their hands after contact with human feces (e.g., diaper changing), after handling pets and after gardening or other contact with soil. HIV-infected persons should avoid sexual practices that might result in oral exposure to feces (e.g., oral-anal contact) (BIII).

3. HIV-infected persons should be advised that newborn and very young pets might pose a small risk for transmitting cryptosporidial infection, but they should not be advised to destroy or give away healthy pets. Persons contemplating the acquisition of a new pet should avoid bringing any animal that has diarrhea into their households, should avoid purchasing a dog or cat aged less than six months, and should not adopt stray pets. HIV-infected persons who wish to assume the small risk for acquiring a puppy or kitten aged less than six months should request that their veterinarian examine the animal's stool for Cryptosporidium before they have contact with the animal (BIII).

4. HIV-infected persons should avoid exposure to calves and lambs and to premises where these animals are raised (BII).

5. HIV-infected persons should not drink water directly from lakes or rivers (AIII).

6. Waterborne infection also might result from swallowing water during recreational activities. HIV-infected persons should be aware that many lakes, rivers, salt-water beaches, and some swimming pools, recreational water parks, and ornamental water fountains might be contaminated with human or animal waste that contains Cryptosporidium. They should avoid swimming in water that is likely to be contaminated and should avoid swallowing water while swimming or playing in recreational waters (BIII). 7. Several outbreaks of cryptosporidiosis have been linked to municipal water supplies. During outbreaks or in other situations in which a community 'boil-water' advisory is issued, boiling water for 1 minute will eliminate the risk for cryptosporidiosis (AI). Use of submicron personal-use water filters* (home/office types) and/or bottled water** also might reduce the risk (CIII). The magnitude of the risk for acquiring cryptosporidiosis from drinking water in a non-outbreak setting is uncertain, and current data are inadequate to recommend that all HIV-infected persons boil water or avoid drinking tap water in nonoutbreak settings. However, HIV-infected persons who wish to take independent action to reduce the risk for waterborne cryptosporidiosis may choose to take precautions similar to those recommended during outbreaks. Such decisions should be made in conjunction with health-care providers. Persons who opt for a personal-use filter or bottled water should be aware of the complexities involved in selecting appropriate products, the lack of enforceable standards for the destruction or removal of oocysts, the cost of the products, and the logistic difficulty of using these products consistently.

8. Patients who take precautions to avoid acquiring cryptosporidiosis from drinking water should be advised that ice made from contaminated tap water also can be a source of infection (BII). Such persons also should be aware that fountain beverages served in restaurants, bars, theaters and other places also might pose a risk because these beverages, as well as the ice they contain, are made from tap water. Nationally distributed brands of bottled or canned carbonated soft drinks are safe to drink. Commercially packaged non-carbonated soft drinks and fruit juices that do not require refrigeration until after they are opened (i.e., 
those that can be stored unrefrigerated on grocery shelves) also are safe. Nationally distributed brands of frozen fruit juice concentrate are safe if they are reconstituted by the user with water from a safe source. Fruit juices that must be kept refrigerated from the time they are processed to the time of consumption might be either fresh (unpasteurized) or heat-treated (pasteurized); only those juices labeled as pasteurized should be considered free of risk from Cryptosporidium. Other pasterurized beverages and beers also are considered safe to drink (BII). No data are available concerning survival of Cryptosporidium oocysts in wine. 9. HIV-infected persons should avoid eating raw oysters because cryptosporidial oocysts can survive in oysters for more than 2 months and have been found in oysters taken from some commercial oyster beds (BIII). Cryptosporidium-infected patients should not work as food handlers, especially if the food to be handled is intended to be eaten without cooking (BII). Because most food-borne outbreaks of cryptosporidiosis are believed to have been caused by infected food handlers, more specific recommendations to avoid exposure to contaminated food cannot be made.

10. In a hospital, standard precautions (i.e., use of gloves and hand washing after removal of gloves) should be sufficient to prevent transmission of cryptosporidiosis from an infected patient to a susceptible HIV-infected person (BII). However, because of the potential for fomite transmission, some experts recommend that HIV-infected persons, especially those who are severely immunocompromised, should not share a room with a patient with cryptosporidiosis (CIII).

\section{Prevention of disease}

11. Rifabutin or clarithromycin, when taken for Mycobacterium avium complex prophylaxis, have been found to protect against cryptosporidiosis ${ }^{50,51}$. However, data are insufficient at this time to warrant a recommendation for using these drugs as chemoprophylaxis for cryptosporidiosis.

\section{Prevention of recurrence}

12. No drug regimens are known to be effective in preventing the recurrence of cryptosporidiosis.

\section{Special considerations}

\section{Children}

13. At present, no data indicate that formula-preparation practices for infants should be altered in an effort to prevent cryptosporidiosis (CIII). However, in the event of a 'boil water' advisory, similar precautions for the preparation of infant formula should be taken as for drinking water for adults (AII).

\section{MICROSPORIDIOSIS}

\section{Prevention of exposure}

1. Other than general attention to hand washing and other personal hygiene measures, no precautions to reduce exposure can be recommended at this time.

\section{Prevention of disease}

2. No chemoprophylactic regimens are known to be effective in preventing microsporidiosis. 


\section{Prevention of recurrence}

3. No chemotherapeutic regimens are known to be effective in preventing the recurrence of microsporidiosis.

\section{TUBERCULOSIS}

\section{Prevention of exposure}

1. HIV-infected persons should be advised that certain activities and occupations might increase the likelihood of exposure to tuberculosis (TB) (BIII). These include volunteer work or employment in health-care facilities, correctional institutions and shelters for the homeless, as well as in other settings identified as high risk by local health authorities.

Decisions about whether to continue with activities in these settings should be made in conjunction with the health-care provider and should be based on factors such as the patient's specific duties in the workplace, the prevalence of TB in the community and the degree to which precautions are taken to prevent the transmission of TB in the workplace (BIII). Whether the patient continues with such activities might affect the frequency with which screening for TB needs to be conducted.

\section{Prevention of disease}

2. When HIV infection is first recognized, the patient should receive a tuberculin skin test (TST) by administration of intermediate-strength (5-TU) purified protein derivative (PPD) by the Mantoux method (AI). Routine evaluation for anergy is not recommended. However, there are selected situations in which anergy evaluation might assist in guiding individual decisions about preventive therapy ${ }^{52,53}$.

3. All HIV-infected persons who have a positive TST result (greater than or equal to $5 \mathrm{~mm}$ of induration) should undergo chest radiography and clinical evaluation to rule out active TB. HIV-infected persons who have symptoms suggestive of TB should promptly undergo chest radiography and clinical evaluation regardless of their TST status (AII).

4. All HIV-infected persons, regardless of age, who have a positive TST result yet have no evidence of active TB and no history of treatment for active or latent TB should be treated for latent TB infection. Options include isoniazid daily (AII) or twice weekly (BII) for nine months; four months of therapy daily with either rifampin (BIII) or rifabutin (CIII); or two months of therapy with either rifampin and pyrazinamide $(\mathrm{BI})$ or rifabutin and pyrazinamide $(\mathrm{CIII})^{52-54}$. There have been reports of fatal and severe liver injury associated with the treatment of latent TB infection in HIV-uninfected persons treated with the two-month regimen of daily rifampin and pyrazinamide; therefore it may be prudent to use regimens that do not contain pyrazinamide in HIV-infected persons whose completion of treatment can be assured ${ }^{55}$. Because HIV-infected persons are at risk for peripheral neuropathy, those receiving isoniazid should also receive pyridoxine (BIII). A decision to use a regimen containing either rifampin or rifabutin should be

\footnotetext{
*Only filters capable of removing particles $1 \mu \mathrm{m}$ in diameter should be considered. Filters that provide the greatest assurance of oocyst removal include those that operate by reverse osmosis, those labeled as absolute $1 \mu \mathrm{m}$ filters, and those labeled as meeting NSF (National Sanitation Foundation) standard no. 53 for cyst removal. The nominal $1 \mu \mathrm{m}$ filter rating is not standardized, and many filters in this category might not be capable of removing $99 \%$ of oocysts. For a list of filters certified as meeting NSF standards, consult the International Consumer Line at 800-673-8010 or http://www.nsf.org/notice/crypto.html

**Sources of bottled water (e.g., wells, springs, municipal tap-water supplies, rivers and lakes) and methods for its disinfection differ; therefore, all brands should not be presumed to be free of cryptosporidial oocysts. Water from wells and springs is much less likely to be contaminated by oocysts than water from rivers or lakes. Treatment of bottled water by distillation or reverse osmosis ensures oocyst removal. Water passed through an absolute $1 \mu \mathrm{m}$ filter or a filter labeled as meeting NSF standard no. 53 for cyst removal before bottling will provide nearly the same level of protection. Use of nominal $1 \mu \mathrm{m}$ filters by bottlers as the only barrier to Cryptosporidia might not result in the removal of $99 \%$ of oocysts. For more information, the International Bottled Water Association can be contacted at 703-683-5213 or at http://bottled water.org
} 
made after careful consideration of potential drug interactions, especially those related to protease inhibitors and nonnucleoside reverse transcriptase inhibitors (see Special Considerations/Drug Interactions). Directly observed therapy should be used with intermittent dosing regimens (AI) and when otherwise operationally feasible (BIII) $)^{53}$.

5. HIV-infected persons who are close contacts of persons who have infectious TB should be treated for latent TB infection - regardless of their TST results, age or prior courses of treatment - after the diagnosis of active TB has been excluded (AII) ${ }^{52-54}$. In addition to household contacts, such persons might also include contacts in the same drug-treatment or health-care facility, co-workers and other contacts if transmission of TB is demonstrated.

6. For persons exposed to isoniazid-and/or rifampin-resistant $\mathrm{TB}$, the decision to use chemoprophylactic antimycobacterial agents other than isoniazid alone, rifampin or rifabutin alone, rifampin plus pyrazinamide or rifabutin plus pyrazinamide should be based on the relative risk for exposure to resistant organisms and should be made in consultation with public health authorities (AII).

7. TST-negative, HIV-infected persons from risk groups or geographic areas with a high prevalence of Mycobacterium tuberculosis infection might be at increased risk for primary or reactivation tuberculosis. However, the efficacy of treatment in this group has not been demonstrated. Decisions concerning the use of chemoprophylaxis in these situations must be considered individually.

8. Although the reliability of the TST might diminish as the $\mathrm{CD} 4^{+} \mathrm{T}$ lymphocyte count declines, annual repeat testing should be considered for HIV-infected persons who are TST-negative on initial evaluation and who belong to populations in which there is a substantial risk for exposure to M. tuberculosis (BIII). Clinicians should consider repeating the TST for persons whose initial skin test was negative and whose immune function has improved in response to HAART (i.e., those whose CD4 ${ }^{+}$ $T$ lymphocyte count has increased to greater than 200 cells $/ \mu 1)(B I I I)^{52}$. In addition to confirming TB infection, TST conversion in an HIV-infected person should alert health-care providers to the possibility of recent $M$. tuberculosis transmission and should prompt notification of public health officials for investigation to identify a possible source case.

9. The administration of bacille Calmette-Guerin (BCG) vaccine to HIV-infected persons is contraindicated because of its potential to cause disseminated disease (EII).

\section{Prevention of recurrence}

10. Chronic suppressive therapy for a patient who has successfully completed a recommended regimen of treatment for tuberculosis is not necessary (DII).

\section{Special Considerations}

\section{Drug interactions}

11. Rifampin can induce metabolism of all the protease inhibitors and nonnucleoside reverse transcriptase inhibitors. This can result in more rapid drug clearance and possibly subtherapeutic drug concentrations of most of these antiretroviral agents. Rifampin should not be co-administered with the following protease inhibitors and nonnucleoside reverse transcriptase inhibitors: amprenavir, indinavir, lopinavir/ritonavir, nelfinavir, saquinavir and delavirdine ${ }^{53}$. However, it may be used with ritonavir, ritonavir plus saquinavir, efavirenz and possibly with nevirapine. Rifabutin is an acceptable alternative to rifampin but should not be used with the protease inhibitor hard-gel saquinavir or delavirdine; caution is advised if the drug is coadministered with soft-gel saquinavir, because data are sparse. Rifabutin can be administered at one-half the usual daily dose, i.e., reduce from $300 \mathrm{mg}$ to $150 \mathrm{mg}$ per day, with indinavir, nelfinavir or amprenavir or with one-fourth the usual dose, i.e., $150 \mathrm{mg}$ every other day or three times a week, with ritonavir, ritonavir plus saquinavir, or lopinavir/ritonavir. 
When rifabutin is administered with indinavir as the sole protease inhibitor, the dose of indinavir should be increased from $800 \mathrm{mg}$ every $8 \mathrm{~h}$ to $1000 \mathrm{mg}$ every $8 \mathrm{~h}$. Pharmacokinetic data suggest that rifabutin at an increased dose can be administered with efavirenz; doses of 450-600 $\mathrm{mg}$ per day have been suggested ${ }^{54}$. However, little information is available about appropriate dosing if a protease inhibitor is used concurrently with efavirenz and rifabutin; with such a combination the rifabutin dose might need to be reduced. Rifabutin can be used without dose adjustment with nevirapine.

\section{Children}

12. Infants born to HIV-infected mothers should have a TST (5-TU PPD) at or before the age of 9-12 months and should be retested at least once a year (AIII). HIV-infected children living in households with TST-positive persons should be evaluated for TB (AIII); children exposed to a person who has active TB should be administered preventive therapy after active TB has been excluded, regardless of their TST results (AII).

\section{Pregnant women}

13. Chemoprophylaxis for TB is recommended during pregnancy for HIV-infected patients who have either a positive TST or a history of exposure to active TB, after active TB has been excluded (AIII). A chest radiograph should be obtained before treatment and appropriate abdominal/pelvic lead apron shields should be used to minimize radiation exposure to the embryo/fetus. When an HIV-infected person has not been exposed to drug-resistant $\mathrm{TB}$, isoniazid daily or twice weekly is the prophylactic regimen of choice. Because of concerns regarding possible teratogenicity associated with drug exposures during the first trimester, providers may choose to initiate prophylaxis after the first trimester. Preventive therapy with isoniazid should be accompanied by pyridoxine to reduce the risk for neurotoxicity. Experience with rifampin or rifabutin during pregnancy is more limited, but anecdotal experience with rifampin has not been associated with adverse pregnancy outcomes. Pyrazinamide should generally be avoided, particularly in the first trimester because of lack of information concerning fetal effects.

\section{DISSEMINATED INFECTION WITH MYCOBACTERIUM AVIUM COMPLEX}

\section{Prevention of exposure}

1. Organisms of the M. avium complex (MAC) are common in environmental sources such as food and water. Current information does not support specific recommendations regarding avoidance of exposure.

\section{Prevention of disease}

\section{Initiation of primary prophylaxis}

2. Adults and adolescents who have HIV infection should receive chemoprophylaxis against disseminated MAC disease if they have a CD4 ${ }^{+} \mathrm{T}$ lymphocyte count of less than 50 cells/ $\mu 1(\mathrm{AI})^{56}$. Clarithromycin ${ }^{57,58}$ or azithromycin ${ }^{59}$ are the preferred prophylactic agents (AI). The combination of clarithromycin and rifabutin is no more effective than clarithromycin alone for chemoprophylaxis and is associated with a higher rate of adverse effects than either drug alone; this combination should not be used (EI) ${ }^{59}$. The combination of azithromycin with rifabutin is more effective than azithromycin alone; however, the additional cost, increased occurrence of adverse effects, potential for drug interactions and absence of a difference in survival when compared with azithromycin alone do not warrant a routine recommendation for this regimen $(\mathrm{CI})^{59}$. In addition to their preventive activity for MAC disease, clarithromycin and azithromycin each 
confer protection against respiratory bacterial infections (BII). If clarithromycin or azithromycin cannot be tolerated, rifabutin is an alternative prophylactic agent for MAC disease although rifabutin-associated drug interactions make this agent difficult to use $(\mathrm{BI})^{54}$. Tolerance, cost and drug interactions are among the issues that should be considered in decisions regarding the choice of prophylactic agents for MAC disease. Particular attention to interactions with antiretroviral protease inhibitors and nonnucleoside reverse transcriptase inhibitors is warranted (see Special Considerations/Drug Interactions). Before prophylaxis is initiated, disseminated MAC disease should be ruled out by clinical assessment, which might include obtaining a blood culture for MAC if warranted. Because treatment with rifabutin could result in the development of resistance to rifampin in persons who have active TB, active TB should also be excluded before rifabutin is used for prophylaxis.

3. Although the detection of MAC organisms in the respiratory or gastrointestinal tract might predict the development of disseminated MAC infection, no data are available on the efficacy of prophylaxis with clarithromycin, azithromycin, rifabutin or other drugs in patients with MAC organisms at these sites and a negative blood culture. Therefore, routine screening of respiratory or gastrointestinal specimens for MAC cannot be recommended (DIII).

\section{Discontinuation of primary prophylaxis}

4. Primary MAC prophylaxis should be discontinued in adult and adolescent patients who have responded to HAART with an increase in $\mathrm{CD}^{+} \mathrm{T}$ lymphocyte count to $>100 \mathrm{cells} / \mu 1$ for at least three months (AI). Two large randomized, placebo controlled trials and observational data have shown that such patients can discontinue primary prophylaxis with minimal risk of developing $\mathrm{MAC}^{37,60-62}$. Discontinuation of primary prophylaxis in patients meeting the criteria above is recommended not only because prophylaxis appears to add very little to disease prevention for MAC or for bacterial infections, but also because discontinuation of drug reduces pill burden, the potential for drug toxicity, drug interactions, selection of drug resistant pathogens and cost.

\section{Restarting primary prophylaxis}

5. Primary prophylaxis should be reintroduced if the $\mathrm{CD4}^{+} \mathrm{T}$ lymphocyte count decreases to $<$ 50-100 cells/ $\mu$ l (AIII).

\section{Prevention of recurrence}

6. Adult and adolescent patients with disseminated MAC should receive lifelong therapy (i.e., secondary prophylaxis or CMT) (AII), unless immune reconstitution occurs as a consequence of HAART (see guideline 7 below). Unless good clinical or laboratory evidence of macrolide resistance exists, the use of a macrolide (clarithromycin or, alternatively, azithromycin) is recommended in combination with ethambutol (AII) with or without rifabutin $(\mathrm{CI})^{63,64}$. Treatment of MAC disease with clarithromycin in a dose of $1000 \mathrm{mg}$ twice a day is associated with a higher mortality rate than has been observed with clarithromycin administered at $500 \mathrm{mg}$ twice a day; thus, the higher dose should not be used (EI) ${ }^{65,66}$. Clofazimine has been associated with adverse clinical outcomes in the treatment of MAC disease and should not be used (DII) ${ }^{66}$.

\section{Discontinuation of secondary prophylaxis (CMT)}

7. Patients appear to be at low risk for recurrence of MAC when they have completed a course of at least 12 months of treatment for MAC, remain asymptomatic with respect to MAC 
signs and symptoms, and have a sustained increase, e.g., six months, in their CD4 ${ }^{+} \mathrm{T}_{\text {lympho- }}$ cyte counts to $>100$ cells $/ \mu 1$ following HAART. While the numbers of patients who have been evaluated remain small, and recurrences could occur ${ }^{41,42,68-70}$, based on these observations and on inference from more extensive data suggesting the safety of discontinuation of secondary prophylaxis for other OIs during advanced HIV disease, it may be reasonable to consider discontinuation of CMT in such patients (CIII). Some experts would obtain a blood culture for MAC, even in asymptomatic patients, prior to discontinuation of therapy, to substantiate that disease is no longer active.

\section{Restarting secondary prophylaxis}

8. Secondary prophylaxis should be reintroduced if the $\mathrm{CD}^{+} \mathrm{T}$ lymphocyte count decreases to $<100$ cells $/ \mu$ l (AIII).

\section{Special considerations}

\section{Drug interactions}

9. Rifabutin should not be administered to patients receiving certain protease inhibitors and nonnucleoside reverse transcriptase inhibitors because the complex interactions have been incompletely studied and the clinical implications of those interactions are unclear ${ }^{16,54}$ (see Special Considerations: Drug interactions in the Tuberculosis section, above). Protease inhibitors may increase clarithromycin levels, but no recommendation to adjust the dose of either clarithromycin or protease inhibitors can be made on the basis of existing data. Efavirenz can induce metabolism of clarithromycin. This may result in reduced serum concentration of clarithromycin but increased concentration of 14-OH clarithromycin, an active metabolite of clarithromycin. Although the clinical significance of this interaction is not known, the efficacy of clarithromycin in MAC prophylaxis could be reduced because of this interaction. Azithromycin pharmacokinetics are not affected by the cytochrome P450 system; azithromycin can be used safely in the presence of protease inhibitors and/or nonnucleoside reverse transcriptase inhibitors without concerns of drug interactions.

\section{Children}

10. HIV-infected children aged less than 13 years who have advanced immunosuppression also can develop disseminated MAC infections and prophylaxis should be offered to high-risk children according to the following $\mathrm{CD}^{+} \mathrm{T}$ lymphocyte thresholds: children aged greater than or equal to six years, less than 50 cells/ $\mu \mathrm{l}$; children aged $2-6$ years, less than 75 cells/ $\mu$; children aged $1-2$ years, less than 500 cells $/ \mu 1$; and children aged less than 12 months, less than 750 cells/ $\mu 1$ (AII). For the same reasons that clarithromycin and azithromycin are the preferred prophylactic agents for adults, they should also be considered for children (AII); oral suspensions of both agents are commercially available in the United States. No liquid formulation of rifabutin suitable for pediatric use is commercially available in the United States. Children with a history of disseminated MAC should be administered lifelong prophylaxis to prevent recurrence (AII). The safety of discontinuing MAC prophylaxis in children whose CD $4^{+} \mathrm{T}$ lymphocyte counts have increased in response to HAART has not been studied.

\section{Pregnant women}

11. Chemoprophylaxis for MAC disease should be administered to pregnant women as is done for other adults and adolescents (AIII). However, because of general concerns about administering drugs during the 
first trimester of pregnancy, some providers may choose to withhold prophylaxis during the first trimester. Animal studies and anecdotal evidence of safety in humans suggest that of the available agents, azithromycin is the drug of choice (BIII) ${ }^{71}$. Experience with rifabutin is limited. Clarithromycin has been demonstrated to be a teratogen in animals and should be used with caution during pregnancy ${ }^{72}$. For secondary prophylaxis $(\mathrm{CMT})$, azithromycin plus ethambutol are the preferred drugs $(\mathrm{BIII})^{70}$.

\section{BACTERIAL RESPIRATORY INFECTIONS}

\section{Prevention of exposure}

1. Because Streptococcus pneumoniae and Haemophilus influenzae are common in the community, no effective way exists to reduce exposure to these bacteria.

\section{Prevention of disease}

2. Adults and adolescents who have a $\mathrm{CD}^{+} \mathrm{T}$ lymphocyte count of greater than or equal to 200 cells $/ \mathrm{ml}$ should be administered a single dose of 23 -valent polysaccharide pneumococcal vaccine if they have not received this vaccine during the previous five years $(\mathrm{BII})^{73-77}$. One randomized placebo-controlled trial of pneumococcal vaccine in Africa paradoxically found an increase in pneumonia among vaccinated subjects ${ }^{78}$. However, several observational studies in the United States have not identified increased risk associated with vaccination and have identified benefit in this group ${ }^{73-77}$. Most experts believe that the potential benefit of pneumococcal vaccination in the United States outweighs the risk. Immunization should also be considered for patients with $\mathrm{CD}^{+} \mathrm{T}$ lymphocyte counts $<200$ cells/ $\mu 1$, although there is no clinical evidence for efficacy (CIII). Revaccination may be considered for patients who were initially immunized when their $\mathrm{CD} 4^{+} \mathrm{T}$ lymphocyte count was $<200$ cells $/ \mu 1$ and whose $\mathrm{CD} 4^{+}$ count has increased to $>200$ cells $/ \mu 1$ in response to HAART (CIII). The recommendation to vaccinate is increasingly pertinent because of the increasing incidence of invasive infections with drug-resistant (including TMP-SMZ-, macrolide- and beta-lactam-resistant) strains of S. pneumoniae.

3. The duration of the protective effect of primary pneumococcal vaccination is unknown. Periodic revaccination may be considered; an interval of five years has been recommended for persons not infected with HIV and also might be appropriate for persons infected with HIV (CIII $)^{76}$. There is, however, no evidence for clinical benefit from revaccination.

4. The incidence of $H$. influenzae type B infection in adults is low. Therefore, $H$. influenzae type B vaccine is not generally recommended for adult use (DIII).

5. TMP-SMZ, when administered daily for PCP prophylaxis, reduces the frequency of bacterial respiratory infections. This should be considered in the selection of an agent for PCP prophylaxis (AII). However, indiscriminate use of this drug (when not indicated for PCP prophylaxis or other specific reasons) might promote the development of TMP-SMZ-resistant organisms. Thus, TMP-SMZ should not be prescribed solely to prevent bacterial respiratory infection (DIII). Similarly, clarithromycin administered daily and azithromycin administered weekly for MAC prophylaxis might be effective in preventing bacterial respiratory infections; this should be considered in the selection of an agent for prophylaxis against MAC disease (BII). However, these drugs should not be prescribed solely for preventing bacterial respiratory infection (DIII).

6. An absolute neutrophil count that is depressed because of HIV disease or drug therapy is associated with an increased risk for bacterial infections, including pneumonia. To reduce the risk for such bacterial infections, providers may consider taking steps to reverse neutropenia, either by stopping myelosuppressive drugs (CII) or by administering granulocyte-colony-stimulating factor (G-CSF) (CII). 


\section{Prevention of recurrence}

7. Some clinicians may administer antibiotic chemoprophylaxis to HIV-infected patients who have very frequent recurrences of serious bacterial respiratory infections (CIII). TMP-SMZ, administered for PCP prophylaxis and clarithromycin or azithromycin, administered for MAC prophylaxis, are appropriate for drug-sensitive organisms. However, providers should be cautious about using antibiotics solely for preventing the recurrence of serious bacterial respiratory infections because of the potential development of drug-resistant microorganisms and drug toxicity.

\section{Special considerations}

\section{Children}

8. HIV infected children, less than five years old should be administered $H$. influenzae type B vaccine (AII) and pneumococcal conjugate vaccine ${ }^{77-81}$ (BII) in accordance with the guidelines of the Advisory Committee on Immunization Practices ${ }^{74,76,79}$ and the American Academy of Pediatrics $^{80}$. Children aged greater than two years should also receive the 23-valent polysaccharide pneumococcal vaccine (BII). Revaccination with a second dose of the 23 valent polysaccharide pneumococcal vaccine should generally be offered after 3-5 years to children aged less than or equal to ten years and after five years to children aged greater than ten years (BIII).

9. To prevent serious bacterial infections in HIV-infected children who have hypogammaglobulinemia (IgG less than $400 \mathrm{mg} / \mathrm{dl}$ ), clinicians should use intravenous (i.v.) immunoglobulin (IVIG) (AI). Respiratory syncytial virus (RSV) IVIG $(750 \mathrm{mg} / \mathrm{kg}$ ), not monoclonal RSV antibody, may be substituted for IVIG during the RSV season to provide broad anti-infective protection, if RSV IVIG is available.

10. To prevent recurrence of serious bacterial respiratory infections, antibiotic chemoprophylaxis may be considered (BI). However, providers should be cautious about using antibiotics solely for this purpose because of the potential development of drug-resistant microorganisms and drug toxicity. The administration of IVIG should also be considered for HIV-infected children who have recurrent serious bacterial infections, although such treatment might not provide additional benefit to children who are being administered daily TMP-SMZ. However, IVIG may be considered for children who have recurrent serious bacterial infections despite receiving TMP-SMZ or other antimicrobials (CIII) ${ }^{82}$.

\section{Pregnant women}

11. Pneumococcal vaccination is recommended during pregnancy for HIV-infected patients who have not been vaccinated during the previous five years (BIII). Among nonpregnant adults, vaccination has been associated with a transient burst of HIV replication. Whether the transient viremia can increase the risk for perinatal HIV transmission is unknown. Because of this concern, when feasible, vaccination may be deferred until after HAART has been initiated to prevent perinatal HIV transmission (CIII).

\section{BACTERIAL ENTERIC INFECTIONS}

\section{Prevention of exposure}

\section{Food}

1. Health-care providers should advise HIV-infected persons not to eat raw or undercooked eggs (including foods that might contain raw eggs [e.g., some preparations of hollandaise sauce, Caesar and certain other salad dressings, some mayonnaises, uncooked cookie and cake batter, egg nog]); raw or undercooked poultry, meat, seafood (especially raw shellfish); unpasteurized dairy products; unpasteurized fruit juices; and raw seed sprouts (e.g., alfalfa sprouts, mung bean sprouts). Poultry 
and meat are safest when adequate cooking is confirmed with a thermometer (internal temperature of $180^{\circ} \mathrm{F}$ for poultry and $165^{\circ} \mathrm{F}$ for red meats). If a thermometer is not used, the risk of illness is decreased by consuming poultry and meat that have no trace of pink color. Color change of the meat (e.g., absence of pink) does not always correlate with internal temperature. (BIII). Produce should be washed thoroughly before being eaten (BIII).

2. Health-care providers should advise HIV-infected persons to avoid cross-contamination of foods. Uncooked meats, (including hot dogs) and their juices should not come into contact with other foods. Hands, cutting boards, counters, knives, and other utensils should be washed thoroughly after contact with uncooked foods (BIII).

3. Health-care providers should advise HIV-infected persons that, although the incidence of listeriosis is low, it is a serious disease that occurs with unusually high frequency among severely immunosuppressed HIV-infected persons. An immunosuppressed, HIV-infected person who wishes to reduce the risk of acquiring listeriosis as much as possible may choose to do the following (CIII): a) avoid soft cheeses (e.g., feta, Brie, Camembert, blue-veined and Mexican-style cheese such as queso fresco). Hard, processed and cream cheese (including slices and spreads), cottage cheese or yogurt need not be avoided; b) cook leftover foods or ready-to-eat foods (e.g., hot dogs) until steaming hot before eating; c) avoid foods from delicatessen counters (e.g., prepared salads, meats, cheeses) or heat/reheat these foods until steaming before eating; d) avoid refrigerated pates and other meat spreads, or heat/reheat these foods until steaming. Canned or shelf-stable pate and meat spreads need not be avoided and e) avoid raw or unpasteurized milk (including goat's milk) or milk-products, or foods which contain unpasteurized milk or milk-products. (CIII).

\section{Pets}

4. When obtaining a new pet, HIV-infected persons should avoid animals aged less than six months, especially those that have diarrhea (BIII).

5. HIV-infected persons should avoid contact with animals that have diarrhea (BIII). HIV-infected pet owners should seek veterinary care for animals with diarrheal illness, and a fecal sample from such animals should be examined for Cryptosporidium, Salmonella, and Campylobacter.

6. HIV-infected persons should wash their hands after handling pets (especially before eating) and should avoid contact with pets' feces (BIII).

7. HIV-infected persons should avoid contact with reptiles (e.g., snakes, lizards, iguanas and turtles) as well as chicks and ducklings because of the risk for salmonellosis (BIII).

\section{Travel}

8. The risk for food-borne and waterborne infections among immunosuppressed, HIV-infected persons is magnified during travel to developing countries. Persons who travel to such countries should avoid foods and beverages that might be contaminated, particularly raw fruits and vegetables, raw or undercooked seafood or meat, tap water, ice made with tap water, unpasteurized milk and dairy products, and items sold by street vendors (AII). Foods and beverages that are generally safe include steaming-hot foods, fruits that are peeled by the traveler, bottled (especially carbonated) beverages, hot coffee and tea, beer, wine, and water brought to a rolling boil for 1 minute (AII). Treatment of water with iodine or chlorine might not be as effective as boiling but can be used when boiling is not practical (BIII). 


\section{Prevention of disease}

9. Prophylactic antimicrobial agents are not generally recommended for travelers (DIII). The effectiveness of these agents depends on local antimicrobial-resistance patterns of gastrointestinal pathogens, which are seldom known. Moreover, these agents can elicit adverse reactions and can promote the emergence of resistant organisms. However, for HIV-infected travelers, antimicrobial prophylaxis may be considered, depending on the level of immunosuppression and the region and duration of travel (CIII). The use of fluoroquinolones such as ciprofloxacin (500 $\mathrm{mg}$ per day) can be considered when prophylaxis is deemed necessary (CIII). As an alternative (e.g., for children, pregnant women, and persons already taking TMP-SMZ for PCP prophylaxis), TMP-SMZ might offer some protection against traveler's diarrhea (BIII). The risk of toxicity should be considered before treatment with TMP-SMZ is initiated solely because of travel.

10. Antimicrobial agents such as fluoroquinolones should be given to patients before their departure, to be taken empirically (e.g., $500 \mathrm{mg}$ of ciprofloxacin twice a day for 3-7 days) should significant traveler's diarrhea develop (BIII). Fluoroquinolones should be avoided for children aged less than 18 years and pregnant women, and alternative antibiotics should be considered (BIII). Travelers should consult a physician if their diarrhea is severe and does not respond to empirical therapy, if their stools contain blood, if fever is accompanied by shaking chills, or if dehydration develops. Antiperistaltic agents (e.g., loperamide) can be used to treat mild diarrhea. However, the use of these drugs should be discontinued if symptoms persist beyond $48 \mathrm{~h}$. Moreover, these agents should not be administered to patients who have a high fever or who have blood in the stool (AII).

11. Some experts recommend that HIV-infected persons who have Salmonella gastroenteritis be administered antimicrobial therapy to prevent extraintestinal spread of the pathogen. However, no controlled study has demonstrated a beneficial effect of such treatment, and some studies of immunocompetent persons have suggested that antimicrobial therapy can lengthen the shedding period. The fluoroquinolones - primarily ciprofloxacin (750 $\mathrm{mg}$ twice a day for 14 days) - can be used when antimicrobial therapy is chosen (CIII).

\section{Prevention of recurrence}

12. HIV-infected persons who have Salmonella septicemia require long-term therapy (i.e., secondary prophylaxis or CMT) to prevent recurrence. Fluoroquinolones, primarily ciprofloxacin, are usually the drugs of choice for susceptible organisms (BII).

13. Household contacts of HIV-infected persons who have salmonellosis or shigellosis should be evaluated for persistent asymptomatic carriage of Salmonella or Shigella so that strict hygienic measures and/or antimicrobial therapy can be instituted and recurrent transmission to the HIV-infected person can be prevented (CIII).

\section{Special considerations}

\section{Children}

14. Like HIV-infected adults, HIV-infected children should wash their hands after handling pets (especially before eating) and should avoid contact with pets' feces. Hand washing should be supervised (BIII).

15. HIV-exposed infants aged less than three months and all HIV-infected children who have severe immunosuppression should be administered treatment for Salmonella gastroenteritis to prevent extraintestinal spread of the pathogen (CIII). Choices of antibiotics include TMP-SMZ, ampicillin, cefotaxime, ceftriaxone or chloramphenicol; fluoroquinolones should be used with caution and only if no alternatives exist. 
16. HIV-infected children who have Salmonella septicemia should be offered long-term therapy to prevent recurrence (CIII). TMP-SMZ is the drug of choice; ampicillin or chloramphenicol can be used if the organism is susceptible. Fluoroquinolones should be used with caution and only if no alternative exists. 17. Antiperistaltic drugs are not recommended for children (DIII).

\section{Pregnant women}

18. Because both pregnancy and HIV infection confer a risk for listeriosis, pregnant HIV-infected women should heed recommendations regarding listeriosis (BII).

19. Because extraintestinal spread of Salmonella during pregnancy might lead to infection of the placenta and amniotic fluid and result in pregnancy loss similar to that seen with Listeria monocytogenes, pregnant women with Salmonella gastroenteritis should receive treatment (BIII). Choices for treatment include ampicillin, cefotaxime, ceftriaxone, or TMP-SMZ. Fluoroquinolones should be avoided.

20. Fluoroquinolones should not be used during pregnancy. TMP-SMZ might offer some protection against traveler's diarrhea.

\section{BARTONELLOSIS}

\section{Prevention of exposure}

1. HIV-infected persons, particularly those who are severely immunosuppressed, are at unusually high risk for developing relatively severe disease due to infection with Bartonella, which can be transmitted from cats. These persons should consider the potential risks of cat ownership (CIII). Persons who acquire a cat should adopt or purchase an animal aged greater than one year that is in good health (BII).

2. Although declawing is not generally advised, HIV-infected persons should avoid rough play with cats and situations in which scratches are likely (BII). Any cat-associated wound should be washed promptly (CIII). Cats should not be allowed to lick open wounds or cuts of HIV-infected persons (BIII).

3. Care of cats should include flea control (CIII).

4. No evidence indicates any benefits to cats or their owners from routine culture or serologic testing of the pet for Bartonella infection (DII).

\section{Prevention of disease}

5. No data support chemoprophylaxis for Bartonella-associated disease (CIII).

\section{Prevention of recurrence}

6. Relapse or reinfection with Bartonella has sometimes followed a course of primary treatment. Although no firm recommendation can be made regarding prophylaxis in this situation, long-term suppression of infection with erythromycin or doxycycline should be considered (CIII).

\section{Special considerations}

\section{Children}

7. The risks of cat ownership for HIV-infected children who are severely immunocompromised should be discussed with parents and caretakers (CIII). 


\section{Pregnant women}

8. If long-term suppression of Bartonella infection is required, erythromycin should be used. Tetracycline should not be used during pregnancy.

\section{CANDIDIASIS}

\section{Prevention of exposure}

1. Candida organisms are common on mucosal surfaces and skin. No measures are available to reduce exposure to these fungi.

\section{Prevention of disease}

2. Data from prospective controlled trials indicate that fluconazole can reduce the risk for mucosal (oropharyngeal, esophageal and vaginal) candidiasis and cryptococcosis as well in patients with advanced HIV disease $\mathrm{e}^{76-78}$. However, routine primary prophylaxis is not recommended because of the effectiveness of therapy for acute disease, the low mortality associated with mucosal candidiasis, the potential for resistant Candida organisms to develop, the possibility of drug interactions, and the cost of prophylaxis (DIII).

\section{Prevention of recurrence}

3. Many experts do not recommend chronic prophylaxis of recurrent oropharyngeal or vulvovaginal candidiasis for the same reasons that they do not recommend primary prophylaxis. However, if recurrences are frequent or severe, providers may consider administering an oral azole (fluconazole $[\mathrm{CI}]^{83-85}$ or itraconazole solution [CI]). Other factors that influence choices about such therapy include the impact of the recurrences on the patient's well-being and quality of life, the need for prophylaxis for other fungal infections, cost, toxicities, drug interactions, and the potential to induce drug resistance among Candida and other fungi. Prolonged use of systemically absorbed azoles, particularly in patients with low CD $4^{+}$ $\mathrm{T}$ lymphocyte counts (i.e., less than 100 cells/ $\mu \mathrm{l}$ ), increases the risk for the development of azole resistance. 4. Adults or adolescents who have a history of documented esophageal candidiasis, particularly multiple episodes, should be considered candidates for chronic suppressive therapy. Fluconazole at a dose of 100-200 $\mathrm{mg}$ daily is appropriate (BI). However, the potential development of azole resistance should be taken into account when long-term azoles are considered.

\section{Special considerations}

\section{Children}

5. Primary prophylaxis of candidiasis in HIV-infected infants is not indicated (DIII).

6. Suppressive therapy with systemic azoles should be considered for infants who have severe recurrent mucocutaneous candidiasis (CIII) and particularly for those who have esophageal candidiasis (BIII).

\section{Pregnant women}

7. Experience is limited with the use of systemic antifungal drugs during human pregnancy. Four cases of infants born with craniofacial and skeletal abnormalities following prolonged in utero exposure to fluconazole have been reported ${ }^{86,87}$. In addition, itraconazole is embryotoxic and teratogenic in animal systems ${ }^{88}$. These same potential risks of teratogenicity are presumed to apply to other systemically absorbed azole antifungals, such as ketoconazole. Therefore, chemoprophylaxis against oropharyngeal, esophageal, 
or vaginal candidiasis using systemically absorbed azoles should not be initiated during pregnancy (DIII), and azoles should be discontinued for HIV-infected women who become pregnant (DIII). Effective birth control measures should be recommended to all HIV-infected women on azole therapy for candidiasis (AIII).

\section{CRYPTOCOCCOSIS}

\section{Prevention of exposure}

1. HIV-infected persons cannot completely avoid exposure to Cryptococcus neoformans. No evidence exists that exposure to pigeon droppings is associated with an increased risk for acquiring cryptococcosis.

\section{Prevention of disease}

2. Routine testing of asymptomatic persons for serum cryptococcal antigen is not recommended because of the low probability that the results will affect clinical decisions (DIII).

3. Prospective controlled trials indicate that fluconazole and itraconazole can reduce the frequency of cryptococcal disease among patients who have advanced HIV disease. However, most experts recommend that antifungal prophylaxis not be used routinely to prevent cryptococcosis because of the relative infrequency of cryptococcal disease, the lack of survival benefits associated with prophylaxis, the possibility of drug interactions, the potential development of antifungal drug resistance, and cost. The need for prophylaxis or suppressive therapy for other fungal infections (e.g., candidiasis, histoplasmosis, or coccidioidomycosis) should be considered in making decisions about prophylaxis for cryptococcosis. If used, fluconazole at doses of 100-200 mg daily is reasonable for patients whose CD4 ${ }^{+} \mathrm{T}_{\text {lymphocyte }}$ counts are less than 50 cells/ $\mu 1(\mathrm{CI})^{83}$.

\section{Prevention of recurrence}

4. Patients who have completed initial therapy for cryptococcosis should be administered lifelong suppressive treatment, (i.e., secondary prophylaxis or CMT) (AI) unless immune reconstitution occurs as a consequence of HAART (see recommendation 5 below). Fluconazole is superior to itraconazole in preventing relapse of cryptococcal disease and is the preferred drug (AI) ${ }^{89-91}$.

\section{Discontinuation of secondary prophylaxis (CMT)}

5. Adult and adolescent patients appear to be at low risk for recurrence of cryptococcosis when they have successfully completed a course of initial therapy for cryptococcosis, remain asymptomatic with respect to signs and symptoms of cryptococcosis, and have a sustained increase (e.g., six months) in their CD4 ${ }^{+} \mathrm{T}$ lymphocyte counts to $>100-200$ cells $/ \mu 1$ following HAART. The numbers of patients who have been evaluated remain small ${ }^{22,93}$. Based on these observations and on inference from more extensive data suggesting the safety of discontinuation of secondary prophylaxis for other OIs during advanced HIV disease and while recurrences could occur it may be reasonable to consider discontinuation of CMT in such patients (CIII). Some experts would perform a lumbar puncture to determine if the CSF is culture negative before stopping therapy even if patients have been asymptomatic; other experts do not believe this is necessary. 


\section{Restarting secondary prophylaxis}

\section{Maintenance therapy should be reinitiated if the $\mathrm{CD}^{+} \mathrm{T}$ lymphocyte count decreases to 100-200 cells/ $\mu$ l (AIII).}

\section{Special considerations}

\section{Children}

7. No data exist on which to base specific recommendations for children, but lifelong suppressive therapy with fluconazole after an episode of cryptococcosis is appropriate (AIII).

\section{Pregnant women}

8. Prophylaxis with fluconazole or itraconazole should not be initiated during pregnancy because of the low incidence of cryptococcal disease, the lack of a recommendation for primary prophylaxis against cryptococcosis in nonpregnant adults, and potential teratogenic effects of these drugs during pregnancy $(\mathrm{DIII})^{86,87}$. For patients who conceive while being administered primary prophylaxis and who elect to continue their pregnancy, prophylaxis should be discontinued. The occurrence of craniofacial and skeletal abnormalities in infants following prolonged in utero exposure to fluconazole should be considered when assessing the therapeutic options for HIV-infected women who become pregnant and are receiving secondary prophylaxis (CMT) for cryptococcosis ${ }^{86,87}$. If a woman meets the criteria for discontinuation of secondary prophylaxis as discussed above, strong consideration should be given to discontinuing therapy during pregnancy as long as the $\mathrm{CD} 4^{+} \mathrm{T}$ lymphocyte could remains above 100-200 cells $/ \mu 1$. For patients requiring therapy, amphotericin B may be preferred, especially during the first trimester. Effective birth control measures should be recommended to all HIV-infected women on azole therapy for cryptococcosis (AIII).

\section{HISTOPLASMOSIS}

\section{Prevention of exposure}

1. Although HIV-infected persons living in or visiting histoplasmosis-endemic areas cannot completely avoid exposure to Histoplasma capsulatum, those whose $\mathrm{CD}^{+} \mathrm{T}$ lymphocyte counts are less than 200 cells/ $\mu$ l should avoid activities known to be associated with increased risk (e.g., creating dust when working with surface soil; cleaning chicken coops that are heavily contaminated with droppings; disturbing soil beneath bird-roosting sites; cleaning, remodeling or demolishing old buildings; and exploring caves) (CIII).

\section{Prevention of disease}

2. Routine skin testing with histoplasmin and serologic testing for antibody or antigen in histoplasmosis-endemic areas are not predictive of disease and should not be performed (DII).

3. Data from a prospective randomized controlled trial indicate that itraconazole can reduce the frequency of histoplasmosis among patients who have advanced HIV infection and who live in H. capsulatumendemic areas ${ }^{94}$. However, no survival benefit was observed among persons receiving itraconazole. Prophylaxis with itraconazole may be considered in patients with $\mathrm{CD}^{+} \mathrm{T}$ lymphocyte counts less than 100 cells $/ \mu \mathrm{l}$ who are at especially high risk because of occupational exposure or who live in a community with a hyperendemic rate of histoplasmosis (greater than or equal to ten cases per 100 patient-years) (CI). 


\section{Prevention of recurrence}

4. Patients who complete initial therapy for histoplasmosis should be administered lifelong suppressive treatment (i.e., secondary prophylaxis or CMT) with itraconazole (200 mg twice a day) (AI $)^{94}$.

\section{Discontinuation of secondary prophylaxis (CMT)}

5. Although patients receiving secondary prophylaxis (CMT) might be at low risk for recurrence of systemic mycosis when their $\mathrm{CD}^{+} \mathrm{T}$ lymphocyte counts increase to greater than $100 \mathrm{cells} / \mu 1$, in response to HAART, the numbers of patients who have been evaluated are insufficient to warrant a recommendation to discontinue prophylaxis.

\section{Special considerations}

\section{Children}

6. Because primary histoplasmosis can lead to disseminated infection in children, a reasonable option is to administer lifelong suppressive therapy after an acute episode of the disease (AIII).

\section{Pregnant women}

7. Because of the embryotoxicity and teratogenicity of itraconazole in animal systems, primary prophylaxis against histoplasmosis should not be offered during pregnancy (DIII) ${ }^{81}$. These data as well as the observation of craniofacial and skeletal abnormalities in infants following prolonged in utero exposure to fluconazole ${ }^{86,87}$ should be considered when assessing the need for CMT in HIV-infected pregnant women with histoplasmosis. For such patients, therapy with amphotericin B may be preferred, especially during the first trimester. For women receiving HAART with a sustained rise in $\mathrm{CD}^{+}{ }^{+} \mathrm{T}$ lymphocyte counts above 100 cells $/ \mu 1$, discontinuation of azole prophylaxis, especially during the first trimester, should be considered. Effective birth control measures should be recommended to all HIV-infected women on azole therapy for histoplasmosis (AIII).

\section{COCCIDIOIDOMYCOSIS}

\section{Prevention of exposure}

1. Although HIV-infected persons living in or visiting areas in which coccidioidomycosis is endemic cannot completely avoid exposure to Coccidioides immitis, they should, when possible, avoid activities associated with increased risk (e.g., those involving extensive exposure to disturbed native soil, for example, at building excavation sites or during dust storms) (CIII).

\section{Prevention of disease}

2. Routine skin testing with coccidioidin (spherulin) in coccidioidomycosis-endemic areas is not predictive of disease and should not be performed (DII). Within the endemic area, a positive serologic test might indicate an increased risk for active infection; however, routine testing does not appear to be useful and should not be performed (DIII).

3. Primary prophylaxis for HIV-infected persons who live in coccidioidomycosis-endemic areas is not routinely recommended. 


\section{Prevention of recurrence}

4. Patients who complete initial therapy for coccidioidomycosis should be administered lifelong suppressive therapy (i.e., secondary prophylaxis or CMT) (AII) using either $400 \mathrm{mg}$ of fluconazole by mouth each day or $200 \mathrm{mg}$ of itraconazole twice a day ${ }^{96}$. Patients with meningeal disease require consultation with an expert.

\section{Discontinuation of secondary prophylaxis (CMT)}

5. Although patients receiving secondary prophylaxis $(\mathrm{CMT})$ might be at low risk for recurrence of systemic mycosis when their $\mathrm{CD}^{+} \mathrm{T}$ lymphocyte counts increase to greater than $100 \mathrm{cells} / \mu \mathrm{l}$, in response to HAART, the numbers of patients who have been evaluated are insufficient to warrant a recommendation to discontinue prophylaxis.

\section{Special considerations}

\section{Children}

6. Although no specific data are available regarding coccidioidomycosis in HIV-infected children, a reasonable option is to administer lifelong suppressive therapy after an acute episode of the disease (AIII).

\section{Pregnant women}

7. The potential teratogenicity of fluconazole ${ }^{86,87}$ and itraconazole ${ }^{81}$ should be considered when assessing the therapeutic options for HIV-infected women who become pregnant while receiving CMT for coccidioidomycosis. For such patients, therapy with amphotericin B may be preferred, especially during the first trimester. For women receiving HAART with a sustained rise in $\mathrm{CD}^{+} \mathrm{T}$ lymphocyte counts above 100 cells/ $\mu 1$, discontinuation of azole prophylaxis, especially during the first trimester, should be considered. Effective birth control measures should be recommended for all HIV-infected women on azole therapy for coccidioidomycosis (AIII).

\section{CYTOMEGALOVIRUS DISEASE}

\section{Prevention of exposure}

1. HIV-infected persons who belong to risk groups with relatively low rates of seropositivity for cytomegalovirus (CMV) and who therefore cannot be presumed to be seropositive should be tested for antibody to CMV (BIII). These groups include patients who have not had male homosexual contact or used injection drugs.

2. HIV-infected adolescents and adults should be advised that CMV is shed in semen, cervical secretions and saliva and that latex condoms must always be used during sexual contact to reduce the risk for exposure to CMV and to other sexually transmitted pathogens (AII).

3. HIV-infected adults and adolescents who are child-care providers or parents of children in child-care facilities should be informed that they are at increased risk for acquiring CMV infection (BI). Similarly, parents and other caretakers of HIV-infected children should be advised of the increased risk to children at these centers (BIII). The risk for acquiring CMV infection can be diminished by good hygienic practices such as hand washing (AII).

4. HIV-exposed infants and HIV-infected children, adolescents, and adults who are seronegative for CMV and require blood transfusion should be administered only CMV antibody-negative or leukocyte-reduced cellular blood products in nonemergency situations (BIII). 


\section{Prevention of disease}

5. Prophylaxis with oral ganciclovir may be considered for HIV-infected adults and adolescents who are CMV seropositive and who have a CD4 ${ }^{+} \mathrm{T}$ lymphocyte count of less than 50 cells/ $\mu \mathrm{l}(\mathrm{CI})^{97,98}$. Ganciclovir-induced neutropenia, anemia, conflicting reports of efficacy, lack of proven survival benefit, the risk for developing ganciclovir-resistant CMV and cost are among the issues that should be considered when deciding whether to institute prophylaxis in individual patients. Acyclovir is not effective in preventing CMV disease, and valacyclovir is not recommended because of an unexplained trend toward increased deaths among persons with AIDS who were administered valacyclovir for CMV prophylaxis ${ }^{99}$. Therefore, neither acyclovir nor valacyclovir should be used for this purpose (EI). The most important method for preventing severe CMV disease is recognition of the early manifestations of the disease. Early recognition of CMV retinitis is most likely when the patient has been educated on this topic. Patients should be made aware of the significance of increased floaters in the eye and should be advised to assess their visual acuity regularly by using simple techniques such as reading newsprint (BIII). Regular funduscopic examinations performed by an ophthalmologist are recommended by some experts for patients with low (e.g., less than 50 cells $/ \mu \mathrm{l}) \mathrm{CD}^{+} \mathrm{T}$ lymphocyte counts (CIII).

\section{Prevention of recurrence}

6. CMV disease is not cured with courses of the currently available antiviral agents (e.g., ganciclovir, foscarnet, cidofovir or fomivirsen). Following induction therapy, secondary prophylaxis (CMT) is recommended for life (AI), unless there is immune reconstitution as a consequence of HAART (see recommendation 7 below). Regimens demonstrated to be effective for chronic suppression in randomized, controlled clinical trials include parenteral or oral ganciclovir, parenteral foscarnet, combined parenteral ganciclovir and foscarnet, parenteral cidofovir, and (for retinitis only) ganciclovir administration via intraocular implant or repetitive intravitreous injections of fomivirsen $(\mathrm{AI})^{100-108}$. Oral valganciclovir has been approved by the FDA for both acute induction therapy and for maintenance therapy although much of the data have not been published. Repetitive intravitreous injections of ganciclovir, foscarnet and cidofovir have been reported to be effective for secondary prophylaxis of CMV retinitis in uncontrolled case series ${ }^{109,110}$. Intraocular therapy alone does not provide protection to the contralateral eye or to other organ systems and typically is combined with oral ganciclovir ${ }^{100}$. The choice of a CMT for patients treated for CMV disease should be made in consultation with an expert. For patients with retinitis, this decision should be made in consultation with an ophthalmologist and should take into consideration the anatomic location of the retinal lesion, vision in the contralateral eye, the immunologic and virologic status of the patient, and the patient's response to HAART (BIII).

\section{Discontinuation of secondary prophylaxis (CMT)}

7. Several case series have reported that maintenance therapy can be discontinued safely in adult and adolescent patients with $\mathrm{CMV}$ retinitis whose $\mathrm{CD4}^{+} \mathrm{T}$ lymphocyte counts have shown a sustained (e.g., six months) increase to $>100-150$ cells $/ \mu 1$ in response to HAART ${ }^{112-116}$. These patients have remained disease-free for greater than 30-95 weeks, whereas in the pre-HAART era, retinitis typically reactivated within 6-8 weeks after stopping CMV therapy. Plasma HIV RNA levels were variable in these patients, suggesting that the $\mathrm{CD} 4^{+} \mathrm{T}$ lymphocyte count is the primary determinant of immune recovery to CMV. Discontinuation of prophylaxis should be considered in patients with a sustained, (e.g., 6 months) increase in CD4 ${ }^{+}$ T lymphocyte count to $>100-150$ cells $/ \mu 1$ in response to HAART (BII). Such decisions should be made in consultation with an ophthalmologist and should take into account such factors as magnitude and duration of $\mathrm{CD}^{+} \mathrm{T}$ lymphocyte increase, anatomic location of the retinal 
lesion, vision in the contralateral eye and the feasibility of regular ophthalmologic monitoring (BII). All patients who have had anti-CMV maintenance therapy discontinued should continue to undergo regular ophthalmologic monitoring for early detection of CMV relapse (as well as for immune reconstitution uveitis) (AIII). CMV viral load or other markers of CMV infection, e.g., antigenemia or viral DNA tests are not well standardized; their role in predicting relapse remains to be defined ${ }^{117-118}$. Relapses have been reported rarely in patients with $\mathrm{CD}^{+}$ T lymphocyte count $>100-150$ cells $/ \mu 1^{119}$.

\section{Restarting secondary prophylaxis}

8. Relapse of CMV retinitis occurs in patients whose anti-CMV maintenance therapy has been discontinued and whose $\mathrm{CD}^{+} \mathrm{T}$ lymphocyte count has decreased to $50 \mathrm{cells} / \mathrm{ml}^{109}$. Therefore, reinstitution of secondary prophylaxis should be reinstituted when the $\mathrm{CD}^{+}$ T-lymphocyte count has decreased to 100-150 cells/ $\mu 1$ (AIII). Relapse has been reported in patients whose $\mathrm{CD}^{+} \mathrm{T}$ lymphocyte counts are higher then 100 cells/ $\mu 1$, but such reports are rare to date ${ }^{119}$.

\section{Children}

\section{Special considerations}

9. Some experts recommend obtaining a CMV urine culture on all HIV-infected (or exposed) infants at birth or at an early postnatal visit to identify those infants with congenital CMV infection (CIII). In addition, beginning at one year of age, CMV antibody testing on an annual basis may be considered for CMV-seronegative (and culture-negative) HIV-infected infants and children who are severely immunosuppressed (Table 10) (CIII). Annual testing will allow identification of children who have acquired CMV infection and might benefit from screening for retinitis.

10. HIV-infected children who are CMV-infected and severely immunosuppressed might benefit from a dilated retinal examination performed by an ophthalmologist every 4-6 months (CIII). In addition, older children should be counseled to be aware of floaters in the eye, similar to the recommendation for adults (BIII).

11. Oral ganciclovir results in reduced CMV shedding in CMV-infected children and may be considered for primary prophylaxis against CMV disease in CMV-infected children who are severely immunosuppressed (e.g., CD4 ${ }^{+} \mathrm{T}$ lymphocyte count less than 50 cells/ $\left.\mu \mathrm{l}\right)(\mathrm{CII})$.

12. Patients with a history of CMV disease should be administered lifelong prophlyaxis to prevent recurrence (AII). For children with CMV disease, no data are available to guide decisions concerning discontinuation of secondary prophylaxis (CMT) when the CD4+ T lymphocyte count has increased in response to HAART.

\section{Pregnant women}

13. Indications for prophylaxis are the same for pregnant women as for non-pregnant women. The choice of agents to be used in pregnancy should be individualized after consultation with experts.

\section{HERPES SIMPLEX VIRUS DISEASE}

\section{Prevention of exposure}

1. HIV-infected persons should use latex condoms during every act of sexual intercourse to reduce the risk for exposure to herpes simplex virus (HSV) and to other sexually transmitted pathogens (AII). They should specifically avoid sexual contact when herpetic lesions (genital or orolabial) are evident (AII). 


\section{Prevention of disease}

2. Antiviral prophylaxis after exposure to HSV, or to prevent initial episodes of HSV disease in individuals with latent infection is not recommended (DIII).

\section{Prevention of recurrence}

3. Because episodes of HSV disease can be treated successfully, chronic therapy with acyclovir is not required after lesions resolve. However, persons who have frequent or severe recurrences can be administered daily suppressive therapy with oral acyclovir or oral famciclovir (AI) ${ }^{120-121}$. Valacyclovir also is an option (CIII). Foscarnet or cidofovir i.v. can be used to treat infection due to acyclovir-resistant isolates of HSV, which are routinely resistant to ganciclovir as well (AII).

\section{Special considerations}

\section{Children}

4. The recommendations for preventing initial disease and recurrence among adults and adolescents apply to children as well.

\section{Pregnant women}

5. Oral acyclovir prophylaxis during late pregnancy is a controversial strategy recommended by some experts to prevent neonatal herpes transmission. However, such prophylaxis is not routinely recommended. For patients who have frequent, severe recurrences of genital HSV disease, acyclovir prophylaxis might be indicated (BIII). No pattern of adverse pregnancy outcomes has been reported after acyclovir exposures $^{122}$.

\section{VARICELLA-ZOSTER VIRUS DISEASE}

\section{Prevention of exposure}

1. HIV-infected children and adults who are susceptible to varicella-zoster virus (VZV) (i.e., those who have no history of chickenpox or shingles or are seronegative for VZV) should avoid exposure to persons with chickenpox or shingles (AII). Household contacts (especially children) of susceptible HIV-infected persons should be vaccinated against VZV if they have no history of chickenpox and are seronegative for HIV, so that they will not transmit VZV to their susceptible HIV-infected contacts (BIII).

Prevention of disease

2. Very little data regarding the safety and efficacy of varicella vaccine in HIV-infected adults are available, and no recommendation for its use can be made for this population. (See Special Considerations/Children, below).

3. For the prophylaxis of chickenpox, HIV-infected children and adults who are susceptible to VZV (i.e., those who have no history of chickenpox or shingles or who have no detectable antibody against VZV) should be administered varicella zoster immune globulin (VZIG) as soon as possible but within $96 \mathrm{~h}$ after close contact with a patient who has chickenpox or shingles (AIII). Data are lacking on the effectiveness of acyclovir for preventing chickenpox in susceptible HIV-infected children or adults.

4. No preventive measures are currently available for shingles.

\section{Prevention of recurrence}

5. No drug has been proven to prevent the recurrence of shingles in HIV-infected persons. 


\section{Special considerations}

\section{Children}

6. HIV-infected children who are asymptomatic and not immunosuppressed (i.e., in immunologic category 1, Table 10) should receive live attenuated varicella vaccine at 12-15 months of age or later (BII). Varicella vaccine should not be administered to other HIV-infected children because of the potential for disseminated viral infection (EIII).

\section{Pregnant women}

7. VZIG is recommended for VZV-susceptible, HIV-infected pregnant women within $96 \mathrm{~h}$ after exposure to VZV (AIII). If oral acyclovir is used, VZV serology should be performed so that the drug can be discontinued if the patient is seropositive for VZV (BIII).

\section{HUMAN HERPESVIRUS 8 INFECTION (KAPOSI'S SARCOMA-ASSOCIATED HERPES VIRUS)}

\section{Prevention of exposure}

1. Persons co-infected with HIV and HHV-8 are at risk for developing Kaposi's sarcoma (KS) and, there is evidence that progression to KS may be accelerated in individuals who seroconvert to HHV-8 after being infected with HIV. Thus it is important to prevent acquisition of $\mathrm{HHV}-8$ infections in those already infected with $\mathrm{HIV}^{123-125}$. The three major routes of $\mathrm{HHV-8}$ transmission appear to be oral (the virus infects oral epithelial cells, and infection has been associated with deep kissing), via semen (HHV-8 is less frequently detected in semen than in saliva), and through blood via needle sharing ${ }^{12-128}$. Patients should be counseled that deep kissing and sexual intercourse with individuals who have high risk of being infected with $\mathrm{HHV}-8$, e.g., persons who have KS or who are infected with HIV, may lead to acquisition of the agent that causes KS (CIII). Although the efficacy of condom use for preventing HHV-8 exposure has not been established, HIV-infected persons should use latex condoms during every act of sexual intercourse to reduce exposure to sexually transmitted pathogens (AII). HIV-infected injection drug users should be counseled to not share drug injection equipment, even if both users are already HIV-infected, because of the chance of becoming infected with $\mathrm{HHV}-8$ or other bloodborne pathogens (BIII).

\section{Prevention of disease}

2. Because clinical use of routine serologic testing to identify HHV-8 infection has not been established, no recommendation for serologic testing can be made at this time.

3. Lower rates of KS have been observed among AIDS patients treated with ganciclovir or foscarnet for CMV retinitis ${ }^{99}$. HHV-8 replication in vitro is inhibited by ganciclovir, foscarnet, and cidofovir. However, because the efficacy and clinical use of these drugs in preventing KS have not been established, no recommendation can be made concerning the use of these or other drugs to prevent $\mathrm{KS}$ in individuals coinfected with HIV and HHV-8.

4. Potent antiretroviral drug combinations that suppress HIV replication reduce the frequency of KS in HIV-infected persons ${ }^{129}$ and should be considered for all persons who qualify for such therapy (BII). 


\section{Prevention of recurrence}

5. Effective suppression of HIV replication with antiretroviral drugs in HIV-infected patients with KS might prevent KS progression or the development of new lesions and should be considered for all persons with KS (BII).

\section{Special considerations}

\section{Children}

6. In parts of the world where HHV-8 is endemic, mother-to-child transmission of HHV-8 has been reported and ${ }^{130-133}$ horizontal transmission among young children, possibly via saliva occurs. However, no recommendations are currently available for preventing HHV-8 transmission from child to child.

\section{HUMAN PAPILLOMAVIRUS INFECTION}

\section{Prevention of exposure}

1. HIV-infected persons should use latex condoms during every act of sexual intercourse to reduce the risk for exposure to sexually transmitted pathogens (AII), although little evidence exists to suggest that condoms reduce the risk for infection with human papillomavirus (HPV).

\section{Prevention of disease}

\section{HPV-associated genital epithelial cancers in HIV-infected women}

2. After a complete history of previous cervical disease has been obtained, HIV-infected women should have a pelvic examination and a Pap smear. In accordance with the recommendation of the Agency for Health Care Policy and Research, the Pap smear should be obtained twice in the first year after diagnosis of HIV infection and, if the results are normal, annually thereafter (AII).

3. If the results of the Pap smear are abnormal, care should be provided according to the Interim Guidelines for Management of Abnormal Cervical Cytology published by a National Cancer Institute Consensus Panel and briefly summarized in Recommendations 4-8, which follow ${ }^{134}$.

4. For patients whose Pap smears are interpreted as atypical squamous cells of undetermined significance (ASCUS), several management options are available; the choice depends in part on whether the interpretation of ASCUS is qualified by a statement indicating that a neoplastic process is suspected. Follow-up by Pap tests without colposcopy is acceptable, particularly when the diagnosis of ASCUS is not qualified further or the cytopathologist suspects a reactive process. In such situations, Pap tests should be repeated every 4-6 months for 2 years until three consecutive smears have been negative. If a second report of ASCUS occurs in the 2-year follow-up period, the patient should be considered for colposcopic evaluation (BIII).

5. Women who have a diagnosis of unqualified ASCUS associated with severe inflammation should be evaluated for an infectious process. If specific infections are identified, reevaluation should be performed after appropriate treatment, preferably after 2-3 months (BIII).

6. If the diagnosis of ASCUS is qualified by a statement indicating that a neoplastic process is suspected, the patient should be managed as if a low-grade squamous intraepithelial lesion (LSIL) were present (see recommendation 7) (BIII). If a patient who has a diagnosis of ASCUS is at high risk (i.e., previous positive Pap tests or poor adherence to follow-up), the option of colposcopy should be considered (BIII).

7. Several management options are available for patients who have LSIL. Follow up with Pap tests every 4-6 months is used by many clinicians and is currently used in countries outside the United States as an established method of management. Patients managed in this way must be carefully selected and considered 
reliable for follow-up. If repeat smears show persistent abnormalities, colposcopy and directed biopsy are indicated (BIII). Colposcopy and directed biopsy of any abnormal area on the ectocervix constitute another appropriate option (BIII).

8. Women who have cytologic diagnosis of high-grade squamous intraepithelial lesions (HSILs) or squamous cell carcinoma should undergo colposcopy and directed biopsy (AII).

9. No data are available to suggest that these guidelines to prevent cervical disease should be modified for women on HAART.

HPV-associated anal intraepithelial neoplasia and anal cancer in HIV-infected homosexuals and in women

10. Evidence from several studies shows that HPV-positive homosexuals and HPV infected women are at increased risk for anal HSILs and might be at increased risk for anal cancer. In view of this evidence, coupled with a recent cost-effectiveness analysis projecting that screening and treatment for anal HSILs provide clinical benefits comparable to other measures to prevent OIs in HIV-infected persons ${ }^{131}$, anal cytology screening of HIV-infected homosexuals and women might become a useful preventive measure in the near future. However, further studies of screening and treatment programs for anal HSILs need to be carried out before recommendations for routine anal cytology screening can be made.

\section{Prevention of recurrence}

11. The risks for recurrence of squamous intraepithelial lesions and cervical cancer after conventional therapy are increased among HIV-infected women. The prevention of illness associated with recurrence depends on careful follow-up of patients after treatment. Patients should be monitored with frequent cytologic screening and, when indicated, with colposcopic examination for recurrent lesions (AI) ${ }^{134,144}$.

12. In one recent study of HIV-infected women treated for HSILs using standard therapy, low-dose intravaginal 5-fluorouracil ( $2 \mathrm{~g}$ twice a week for six months) reduced the short-term risk for recurrence and possibly the grade of recurrence ${ }^{136}$. However, clinical experience with this therapy is too limited to provide a recommendation for routine use.

\section{Special considerations}

\section{Pregnant women}

13. Use of intravaginal 5-fluorouracil to prevent recurrent dysplasia is not recommended during pregnancy.

\section{HEPATITIS C VIRUS INFECTION}

\section{Prevention of exposure}

1. The chief route of hepatitis $\mathrm{C}$ virus $(\mathrm{HCV})$ transmission in the United States is injection drug use. Because injection drug use is a complex behavior, clinicians should assess the individual's readiness to change this practice and encourage efforts to provide patient education and support directed at recovery.

\section{Patients who inject drugs should be advised 137-139}

(a) to stop using injection drugs (AIII);

(b) to enter and complete a substance-abuse treatment program, including a relapse prevention program (AIII). 


\section{If they are continuing to inject drugs (BIII)}

- to never reuse or share syringes, needles, rinse water or drug preparation equipment; if, nonetheless, injection equipment that has been used by other persons is shared, to first clean the equipment with bleach and water as is recommended for prevention of HIV;

- to use only sterile syringes obtained from a reliable source (e.g., pharmacies or syringe exchange programs);

- to use sterile (e.g., boiled) water to prepare drugs; if not possible, to use clean water from a reliable source (e.g., fresh tap water);

- to use a new or disinfected container (cooker) and a new filter (cotton) to prepare drugs;

- to clean the injection site with a new alcohol swab before injection; and

- to safely dispose of syringes after one use.

2. Persons considering tattooing or body piercing should be informed of potential risks of acquiring bloodborne infections, which could be transmitted if equipment is not sterile or if proper infection control procedures are not followed (e.g., washing hands, using latex gloves and cleaning and disinfecting surfaces $)^{139}$ (BIII).

3. To reduce risks for acquiring bloodborne infections, patients should be advised not to share dental appliances, razors or other personal care articles (BIII).

4. Although the efficiency of sexual transmission of HCV is low, safe-sexual practices should be encouraged for all HIV infected persons and barrier precautions (e.g., latex condoms) are recommended to reduce the risk for exposure to sexually transmitted pathogens (AII).

\section{Prevention of disease}

5. All patients with HIV infection should be screened for HCV infection (BIII). Screening is recommended because some HIV-infected patients (e.g., injection drug users, and patients with hemophilia) are at increased risk for HCV infection and HCV related disease, and because knowledge of HCV status is important for management of all HIV-infected patients (e.g., to interpret and manage elevated liver related tests). Screening should be performed by using enzyme immunoassays (EIAs) licensed for detection of antibody to HCV (anti-HCV) in blood (BIII). Positive anti-HCV results should be verified with additional testing (i.e., recombinant immunoblot assay $\left[\mathrm{RIBA}^{\mathrm{TM}}\right]$ or reverse transcriptase polymerase chain reaction (RT-PCR) for HCV RNA). The presence of HCV RNA in blood might also be assessed in HIV-infected persons with undetectable antibody but other evidence of chronic liver disease (e.g., unexplained elevated liver-specific enzymes) or when acute HCV infection is suspected (CIII).

6. Persons coinfected with HIV and HCV should be advised not to drink excessive amounts of alcohol (AII). Avoiding alcohol altogether might be prudent because it is unclear whether even occasional alcohol use (e.g., less than 12 ounces of beer or less than 10 grams of alcohol per day) increases the incidence of cirrhosis among HCV-infected persons (CIII).

7. Patients with chronic hepatitis $C$ should be vaccinated against hepatitis A because a) the risk for fulminant hepatitis associated with hepatitis A appears increased in such patients; b) hepatitis A vaccine is safe for HIV-infected persons; and c) although immunogenicity is reduced in patients with advanced HIV infection, more than two thirds of patients develop protective antibody responses (BIII). Prevaccination screening for total (IgG and $\operatorname{IgM}$ ) antibody to hepatitis A virus is cost-effective and therefore recommended when greater than 30\% prevalence of hepatitis A virus antibody is expected in the population being screened (e.g., persons greater than 40 years of age $)^{140}$. Patients should also be immunized for HBV if they are susceptible (BIII).

8. HIV-HCV-coinfected patients may develop HCV associated liver disease over a shorter time course than patients infected with $\mathrm{HCV}$ alone ${ }^{141-144}$ and should be evaluated for chronic liver disease and for the possible need for treatment. Limited data suggest that HCV treatment can be safely 
provided to patients coinfected with HIV and HCV. Because the optimal means of treating coinfected patients has not been established and many HIV-infected patients have conditions that complicate therapy (e.g., depression), this care should occur in a clinical trial or be coordinated by providers with experience treating both HIV and HCV infections (BIII).

9. In some studies, the incidence of antiretroviral-associated liver enzyme elevations has been increased in patients coinfected with $\mathrm{HIV}$ and $\mathrm{HCV}^{142}$; such increases might not require treatment modifications. Thus, although liver enzymes should be carefully monitored, HAART should not be routinely withheld from patients coinfected with HIV and HCV (DIII). However, coinfected patients initiating HAART might have an inflammatory reaction that mimics an exacerbation of underlying liver disease. In this situation, careful monitoring of liver function is required.

\section{Prevention of recurrence}

10. If the serum HCV RNA level becomes undetectable during HCV therapy and remains undetectable for 6 months after HCV therapy is stopped (sustained virologic response), greater than $90 \%$ of HIVuninfected patients with hepatitis $\mathrm{C}$ will remain HCV RNA negative for greater than five years and have improved liver histology ${ }^{145}$. For HIV-HCV-coinfected patients, the durability of treatment response and requirement for maintenance therapy are unknown.

\section{Special considerations}

\section{Children}

11. Transmission of HCV from mother to child appears to be more frequent for mothers co-infected with HIV and HCV than for those infected with HCV alone. Therefore, children born to women coinfected with HIV and HCV should be tested for HCV infection ${ }^{137}$ (BI). Because maternal HCV antibody can persist for up to 18 months, testing should be performed at or after two years of age. If earlier diagnosis is desired, RT-PCR for HCV RNA may be performed after one month of age and should be repeated at a subsequent time. The average rate of HCV infection among infants born to coinfected women is approximately $15 \%$ (range, $5-36 \%)^{146}$. Data are limited on the natural history of HCV infection and treatment of chronic hepatitis $\mathrm{C}$ in children. In addition, anmtiviral treatment for chronic hepatitis $\mathrm{C}$ is not approved for patients $<18$ years of age.

\section{REFERENCES}

1. CDC. USPHS/IDSA guidelines for the prevention of opportunistic infections in persons infected with human immunodeficiency virus: a summary. MMWR 1995;44(No. RR-8)

2. USPHS/IDSA Prevention of Opportunistic Infections Working Group. USPHS/IDSA guidelines for the prevention of opportunistic infections in persons infected with human immunodeficiency virus: diseasespecific recommendations. Clin Infect Dis 1995;21(Suppl:1):S32-S43

3. USPHS/IDSA Prevention of Opportunistic Infections Working Group. USPHS/IDSA guidelines for the prevention of opportunistic infections in persons infected with human immunodeficiency virus: a summary. Ann Intern Med 1996;124:348-68

4. CDC. USPHS/IDSA guidelines for the prevention of opportunistic infections in persons infected with human immunodeficiency virus. MMWR 1997;46(No. RR-12)

5. CDC. USPHS/IDSA guidelines for the prevention of opportunistic infections in persons infected with human immunodeficiency virus. MMWR 1999;48(No. RR-10)

6. USPHS/IDSA prevention of opportunistic infections working group. 1997 USPHS/IDSA guidelines for the prevention of opportunistic infections in persons infected with human immunodeficiency virus: disease-specific recommendations. Clin Infect Dis 1997;25(Suppl:3):S313-S315 
7. USPHS/IDSA prevention of opportunistic infections working group. 1999 USPHS/IDSA guidelines for the prevention of opportunistic infections in persons infected with human immunodeficiency virus. Clin Infect Dis 1999;30(Suppl:1):S1-S93

8. USPHS/IDSA Prevention of Opportunistic Infections Working Group. USPHS/IDSA guidelines for the prevention of opportunistic infections in persons infected with human immunodeficiency virus. Ann Intern Med 1997;127:922-46

9. USPHS/IDSA Prevention of Opportunistic Infections Working Group. USPHS/IDSA guidelines for the prevention of opportunistic infections in persons infected with human immunodeficiency virus. Am Fam Physician 1997;56:823-30, 1131-46, 1387-92

10. USPHS/IDSA Prevention of Opportunistic Infections Working Group. USPHS/IDSA guidelines for the prevention of opportunistic infections in persons infected with human immunodeficiency virus. Am Fam Physician 2000;61:163-171

11. USPHS/IDSA Prevention of Opportunistic Infections Working Group. 1997 USPHS/IDSA report on the prevention of opportunistic infections in persons infected with human immunodeficiency virus. Pediatrics 1998;102:1064-85

12. Kaplan JE, Masur H, Jaffe HW, Holmes KK. Reducing the impact of opportunistic infections in patients with HIV infection: new guidelines. [Editorial]. JAMA 1995;274:347-8

13. Kaplan JE, Masur H, Jaffe HW, Holmes KK. Preventing opportunistic infections in persons infected with HIV: 1997 guidelines [Editorial]. JAMA 1997;278:337-8

14. CDC. Report of the NIH Panel to define principles of therapy of HIV infection and guidelines for use of antiretroviral agents in HIV-infected adults and adolescents. MMWR 1998;47(No.RR-5)

15. McNaghten AD, Hanson DL, Jones JL, et al., and the Adult/Adolescent Spectrum of Disease Group. Effects of antiretroviral therapy and opportunistic illness primary chemoprophylaxis on survival after AIDS diagnosis. AIDS 1999;13:1687-95

16. USPHS/IDSA Guidelines for the use of antiretroviral agents in HIV-infected adults and adolescents. http//:www.hivatis.org.

17. Gross PA, Barrett TL, Dellinger EP, et al. Purpose of quality standards for infectious diseases. Clin Infect Dis 1994;18:421

18. Phair J, Munoz A, Saah A, Detels R, et al. and the Multicenter AIDS Cohort Study Group. The risk of Pneumocystis carinii pneumonia among men infected with HIV-1. N Engl J Med 1990;322:61-5

19. Kaplan JE, Hanson DL, Navin TR, Jones JL. Risk factors for primary Pneumocystis carinii pneumonia in human immunodeficiency virus-infected adolescents and adults in the United States: reassessment of indications for chemoprophylaxis. J Infect Dis 1998;178:1126-32

20. CDC. Guidelines for prophylaxis against Pneumocystis carinii pneumonia for persons infected with human immunodeficiency virus. MMWR 1989;38:1-9

21. Bozzette SA, Finkelstein DM, Spector SA, et al. A randomized trial of three antipneumocystis agents in patients with advanced human immunodeficiency virus infection. N Engl J Med 1995;332:693-9

22. Schneider MME, Hoepelman AIM, Schattenkerk JKME, et al. and the Dutch AIDS Treatment Group. A controlled trial of aerosolized pentamidine or trimethoprim-sulfamethoxazole as primary prophylaxis against Pneumocystis carinii pneumonia in patients with human immunodeficiency virus infection. $N$ Engl J Med 1992;327:1836-41

23. Schneider MME, Nielsen TL, Nelsing S, et al. Efficacy and toxicity of two doses of trimethoprimsulfamethoxazole as primary prophylaxis against Pneumocystis carinii pneumonia in patients with human immunodeficiency virus. J Infect Dis 1995;171:1632-6

24. El-Sadr W, Luskin-Hawk R, Yurik TM, et al. A randomized trial of daily and thrice weekly trimethoprimsulfamethoxazole for the prevention of Pneumocystis carinii pneumonia in HIV infected individuals. Clin Infect Dis 1999;29:775-83

25. Carr A, Tindall B, Brew BJ, et al. Low-dose trimethoprim-sulfamethoxazole prophylaxis for toxoplasmic encephalitis in patients with AIDS. Ann Intern Med 1992;117:106-11

26. Hardy WD, Feinberg J, Finkelstein DM, et al., for the AIDS Clinical Trials Group. A controlled trial of trimethoprim-sulfamethoxazole or aerosolized pentamidine for secondary prophylaxis of Pneumocystis carinii pneumonia in patients with the acquired immunodeficiency syndrome: AIDS Clinical Trials Group protocol 021. N Engl J Med 1992;327:1842-8 
27. Leoung G, Standford J, Giordano M, et al. A randomized, double-blind trial of TMP/SMX dose escalation vs. direct challenge in $\mathrm{HIV}+$ persons at risk for PCP and with prior treatment-limiting rash or fever. Presented at the 37th Interscience Conference on Antimicrobial Agents and Chemotherapy. Washington, DC: Am Soc Microbiol, 1997;(abstr. LB10)

28. Para MF, Dohn M, Frame P, et al., for the ACTG 268 Study Team. Reduced toxicity with gradual initiation of trimethoprim-sulfamethoxazole as primary prophylaxis for Pneumocystis carinii pneumonia: AIDS Clinical Trials Group 268. J AIDS 2000;24:337-43

29. Podzamczer D, Salazar A, Jiminez J, et al. Intermittent trimethoprim sulfamethoxazole compared with dapsone-pyrimethamine for the simultaneous primary prophylaxis of Pneumocystis pneumonia and toxoplasmosis in patients infected with HIV. Ann Intern Med 1995;122:755-61

30. Opravil M, Hirschel B, Lazzarin A, et al. Once-weekly administration of dapsone/pyrimethamine vs. aerosolized pentamidine as combined prophylaxis for Pneumocystis carinii pneumonia and toxoplasmic encephalitis in human immunodeficiency virus-infected patients. Clin Infect Dis 1995;20:531-41

31. Chan C, Montaner J, LeFebvre EA, et al. Atovaquone suspension compared with aerosolized pentamidicine for prevention of Pneumocystis carinii pneumonia in human immunodeficiency virus infected subsets intolerant of trimethoprim or sulfamethoxazole. J Infect Dis 1999;180:369-76

32. El-Sadr W, Murphy RL, Yurik RM, et al. Atovaquone compared with dapsone for the prevention of Pneumocystis carinii pneumonia in patients with HIV infection who cannot tolerate trimethoprim, sulfonamides, or both. N Engl J Med 1998;339:1889-95

33. Furrer H, Egger M, Opravil M, et al. Discontinuation of primary prophylaxis against Pneumocystis carinii pneumonia in HIV-1-infected adults treated with combination antiretroviral therapy. N Engl J Med 1999; 340:1301-6

34. Weverling GJ, Mocroft A, Ledergerber B, et al. Discontinuation of Pneumocystis carinii pneumonia prophylaxis after start of highly active antiretroviral therapy in HIV-1 infection. Lancet 1999;353:1293-8

35. Yangco BF, VonBargen JC, Moorman AC, Holmberg SD. Discontinuation of chemoprophylaxis for Pneumocystis Carinii penumonia in patients with HIV infection. Ann Intern Med 2000;132:201-5

36. Schneider MME, Borleffs JCC, Stolk RP, et al. Discontinuation of Pneumocystis carinii pneumonia prophylaxis in HIV-1 infected patients treated with highly active antiretroviral therapy. Lancet 1999;353:201-3

37. Dworkin M, Hanson D, Jones J, Kaplan J and the Adult/Adolescent Spectrum of HIV Disease Project (ASD). Risk for preventable opportunistic infections in persons with AIDS after antiretroviral therapy increases CD4+ T-lymphocyte counts above prophylaxis thresholds. J Infect Dis 2000;182:611-5

38. Mussini C, Pezzotti P, Govoni A, et al. Discontinuation of primary prophylaxis for Pneumocystis carinii pneumonia and toxoplasmic encephalitis in human immunodeficiency virus type I-infected patients: the changes in opportunistic prophylaxis study. J Infect Dis 2000;181:1635-42

39. Lopez JC, Miro JM, Pena JM, Podzamczer D, and the GESIDA 04/98 Study Group. A randomized trial of the discontinuation of primary and secondary prophylaxis against Pneumocystis carinii pneumonia after HAART in patients with hiv infection. N Engl J Med 2001;344:159-67

40. Furrer H, Opravil M, Rossi M, et al. Discontinuation of primary prophylaxis in HIV infected patients at high risk of penumocystis pneumonia: a prospective multicentre study. AIDS 2001;15:501-7

41. Kirk O, Lundgren JD, Pederson $\mathrm{C}$, et al. Can chemoprophylaxis against opportunistic infections be discontinued after an increase in CD4 cells induced by highly active antiretroviral therapy? AIDS 1999; 13:1647-51

42. Soriano V, Dona C, Rodriguez-Rosado, et al. Discontinuation of secondary prophylaxis for opportunistic infections in HIV-infected patients receiving highly active antiretroviral therapy. AIDS 2000,14:383-6

43. Ledergerber B, Mocroft A, Reiss P, et al. Discontinuation of secondary prophylaxis against Pneumocystis carinii pneumonia in patients with HIV infection who have a response to antiretroviral therapy. $N$ Engl J Med 2001;344:168-74

44. CDC. 1995 revised guidelines for prophylaxis against Pneumocystis carinii pneumonia for children infected with or perinatally exposed to human immunodeficiency virus. MMWR 1995;44(No. RR-4)

45. Department of Agriculture: http://www.foodsafety.gov.

46. Miro JM, Podzamczer D, Pena JM, et al. Discontinuation of Primary and Secondary Toxoplasma gondii Prophylaxis is Safe in HIV-1 Infected Patients after Immunological Recovery with HAART. Final Results of 
the GESIDA 04/98 Study. Presented at the 39 th Interscience Conference on Antimicrobial Agents and Chemotherapy. Am Soc Microbiol San Francisco, CA: 2000;(abstr.L16)

47. Furrer H, Oparavil M, Bernasconi E, et al. Stopping primary prophylaxis in HIV-1 infected patients at high risk of toxoplasma encephalitis. Lancet 2000;355:2217-8

48. Katlama C, DeWit S, O'Doherty E, et al. Pyrimethamine-clindamycin vs. pyrimethamine-sulfadiazine as acute and long-term therapy for toxoplasmic encephalitis in patients with AIDS. Clin Infect Dis 1996;22:268-75

49. Dannemann B, McCutchan JA, Israelski D, et al. Treatment of toxoplasmic encephalitis in patients with AIDS: a randomized trial comparing pyrimethamine plus clindamycin to pyrimethamine plus sulfadiazine. Ann Intern Med 1992;116:33-43

50. Holmberg SD, Moorman AC, Von Bargen JC, et al. Possible effectiveness of clarithromycin and rifabutin for cryptosporidiosis chemoprophylaxis in HIV disease. JAMA 1998;279:384-6

51. Fichtenbaum CJ, Zackin R, Feinberg J, et al. Rifabutin but not clarithromycin prevents cryptosporidiosis in persons with advanced HIV infection. AIDS 2000;14:2889-93

52. CDC. Targeted tuberculin testing and treatment of latent tuberculosis infection. MMWR 2000;49(No RR-6)

53. CDC. Prevention and treatment of tuberculosis among patients infected with human immunodeficiency virus: principles of therapy and revised recommendations. MMWR 1998;47;(RR-20)

54. CDC and Prevention. Notice to Readers: Updated guidelines for the use of rifabutin or rifampin for the treatment and prevention of tuberculosis among HIV-infected patients taking protease inhibitors or nonnucleoside reverse transcriptase inhibitors. MMWR 2000; 49:183-9

55. CDC Update: Fatal and severe liver injuries associated with Rifampin and Pyrazinanude for latent tuberculosis infection and revisions in Am Thoracic Soc/CDC Recommendations, United States. MMWR 2001; 50 (NG.34)

56. Masur H and the Public Health Service Task Force on Prophylaxis and Therapy for Mycobacterium avium complex. Recommendations on prophylaxis and therapy for disseminated Mycobacterium avium complex disease in patients infected with the human immunodeficiency virus. N Engl J Med 1993;329:898-904

57. Benson CA, Williams PL, Cohn DL and the ACTG 196/CPCRA 009 Study Team. Clarithromycin or Rifabutin alone or in combination for primary prophylaxis of Mycobacterium avium complex disease in patients with AIDS: a randomized, double-blinded, placebo-controlled trial. The AIDS Clinical Trials Group 196/Terry Beirn Community Programs for Clinical Research on AIDS 009 Protocol Team. J Infect Dis 2000;18:1289-97

58. Pierce M, Crampton S, Henry D, et al. A randomized trial of clarithromycin as prophylaxis against disseminated Mycobacterium avium complex infection in patients with advanced acquired immunodeficiency syndrome. N Engl J Med 1996;335:384-91

59. Havlir DV, Dube MP, Sattler FR, et al. Prophylaxis against disseminated Mycobacterium avium complex with weekly azithromycin, daily rifabutin, or both. N Engl J Med 1996;335:392-8

60. El-Sadr WM, Burman WJ, Grant LB, et al. Discontinuation of prophylaxis for mycobacterium avium complex disease in HIV-infected patients who have a response to antiretroviral therapy. NEnglJMed 2000;342:1085-92

61. Currier JS, Williams PL, Koletar SL, et al. Discontinuation of mycobacterium avium complex prophylaxis in patients with antiretroviral therapy-induced increases in CD4+ cell count. A randomized, double-blind, placebo-controlled trial. AIDS Clinical Trial Group 362 Study Team. Ann Intern Med 2000;133:493-503

62. Furrer H, Rossi M, Telenti A, Lederberger B. Discointinuing or withholding primary prophylaxis against Mycobacterium avium in patients on succesful antiretroviral combination therapy. AIDS 2000;14:1409-12

63. Gordin F, Sullam P, Shafran S, et al. A randomized, placebo-controlled study of rifabutin added to a regimen of clarithromycin and ethambutol for treatment of disseminated infection with Mycobacterium avium complex (MAC). Clin Infect Dis 1999;28:1080-5

64. Benson C, Williams P, Currier J, et al. ACTG223: An open, prospective, randomized study comparing efficacy and safety of clarithromycin (C) plus ethambutol (E), rifabutin (R), or both for treatment (Rx) of MAC disease in patients with AIDS. Presented at the 6th Conference on Retroviruses and Opportunistic Infections. Alexandria, Virginia: Foundation for Retrovirology and Human Health, 1999;(abstr.249)

65. Chaisson RE, Benson CA, Dube MP, et al. Clarithromycin therapy for bacteremic Mycobacterium avium complex disease: a randomized, double-blind, dose-ranging study in patients with AIDS. Ann Intern Med 1994;121:905-11 
66. Cohn DL, Fisher E, Peng GT, et al. A prospective randomized trial of four three-drug regimens in the treatment of disseminated Mycobacterium avium complex disease in AIDS patients: excess mortality associated with high dose clarithromycin. Clin Infect Dis 1999;29:125-33

67. Chaisson RE, Keiser P, Pierce M, et al. Clarithromycin and ethambutol with or without clofazimine for the treatment of bacteremic Mycobacterium avium complex disease in patients with HIV infection. AIDS 1997;11:311-7.

68. Rabaud C, Jouan M, Mary-Krausse M, et al. Mycobacterium avium (MAC) infections during HAART era (1996-98) in HIV-infected French patients. Presented at the 7th Conference on Retroviruses and Opportunistic Infections, January 30-February 2, San Francisco, CA. 2000;(abstr.2054)

69. Aberg JA, Yijko DM, Jacobson MA. Eradication of AIDS-related disseminated Mycobacterium avium complex infection after 12 months of antimycobacterial therapy combined with highly active antiretroviral therapy. J Infect Dis 1998;178:1446-9

70. Shafran SD, Gill MJ, Lajonde RG, et al. Successful Discontinuation of MAC Therapy Following Effective HAAR T.Presented at the 8th Conference on Retroviruses and Opportunistic Infections, February 4-8, 2001; Chicago, IL. 2001;(abstr.547)

71. Adair CD, Gunter M, Stovall TG, et al. Chlamydia in pregnancy: a randomized trial of azithromycin and erythromycin. Obstet Gynecol 1998;91:165-8

72. Physicians' desk reference. 55th edition. Medical Economics Company, Inc. New Jersey 2001

73. Dworkin MS, Ward JW, Hanson DL, et al. Pneumococcal disease among HIV-Infected persons: incidence, risk factors, and impact of vaccination. Clin Infect Dis 2001;32:794-800

74. Guerrero M, et al. Pneumonia in HIV-Infected Patients: A case-control survey of factors involved in risk and prevention. AIDS 1999;13:1975-81

75. Gebo KA, Moore RD, Keruly JC, Chaisson RE. Risk factors for pneumococcal disease in human immunodeficiency virus-infected patients. J Infect Dis 1996;173:857-62

76. CDC. Prevention of pneumococcal disease: recommendations of the Advisory Committee on Immunization Practices (ACIP). MMWR 1997;46(No. RR-8)

77. Breiman RF, Keller DW, Phelan MA. Evaluation of effectiveness of 23-valent pneumococcal capsular polysaccharide vaccine for HIV-infected patients. Arch Intern Med 2000;160:2633-8

78. French N, Nakiyingi J, Carpenter LM, et al. 23-valent pneumococcal polysaccharide vaccine in HIV-1infected Ugandan adults: double-blind, randomised, and placebo-controlled trial. Lancet 2000;355:2106-11

79. CDC and Prevention. Recommended childhood immunization schedule - United States. MMWR 2001; 50:7-11

80. American Academy of Pediatrics. Committee on Infectious Diseases. Policy Statement: Recommendations for the prevention of pneumococcal infections, including the use of pneumococcal conjugate vaccine (prevnar), pneumococcal polysaccharide vaccine, and antibiotic prophylaxis. Pediatrics 2000;106:362-6

81. CDC. Preventing pneumococal disease among infants and young children: recommendations of the Advisory Committee on Immunization Practices (ACIP). MMWR 2000;49(RR9):1-35

82. Spector SA, Gerber RD, McGrath N, et al. A controlled trial of intrevenous immune globulin for the prevention of serious bacterial infections in children receiving zidovudine for advanced human immunodeficiency virus infection. N Engl J Med 1994;331:1181-7

83. Powderly WG, Finkelstein DM, Feinberg J, et al. A randomized trial comparing fluconazole with clotrimazole troches for the prevention of fungal infections in patients with advanced human immunodeficiency virus infection. N Engl J Med 1995;332:700-5

84. Schuman P, Capps L, Peng G, et al. Weekly fluconazole for the prevention of mucosal candidiasis in women with HIV infection: a randomized, double-blind, placebo-controlled trial. Ann Intern Med 1997;126:689-96

85. Havlir DV, Dube MP, McCutchan JA, et al. Prophylaxis with weekly versus daily fluconazole for fungal infections in patients with AIDS. Clin Infect Dis 1998;27:1369-75

86. Pursley TJ, Blomquist IK, Abraham J, et al. Fluconazole-induced congenital anomalies in three infants. Clin Infect Dis 1996;22:336-40

87. Aleck KA, Bartley DL. Multiple malformation syndrome following fluconazole use in pregnancy: report of an additional patient. Am J Med Genet 1997;72:253-6

88. Janssen Pharmaceutical Company. Product information: Sporanox (itraconazole) oral solution. In Physicians' desk reference. 53rd edition. Montvale, New Jersey: Medical Economics Company, Inc., 1999;1441 
89. Bozzette SA, Larsen R, Chiu J, et al. A controlled trial of maintenance therapy with fluconazole after treatment of cryptococcal meningitis in the acquired immunodeficiency syndrome. N Engl J Med 1991;324:580

90. Powderly WG, Saag MS, Cloud GA, et al. A controlled trial of fluconazole or amphotericin B to prevent relapse of cryptococcal meningitis in patients with the acquired immunodeficiency syndrome. $N$ Engl $J$ Med 1992;326:793

91. Saag MS, and the NIAID Mycoses Study Group. Comparison of fluconazole versus itraconazole as maintenance therapy of AIDS-associated cryptococcal meningitis. Clin Infect Dis 1999;28:291-6

92. Aberg JA, Price RW, Heeren DM, et al. Discontinuation of antifungal therapy for cryptococcosis after immunologic response to antiretroviral therapy. Presented at the 7th Conference on Retroviruses and Opportunistic Infections, January 30-February 2. San Francisco, CA. 2000;(abstr.250)

93. Mussini C, Cossarizza A, Pezzotti P, et al. Discontinuation or continuation of maintenance therapy for cryptococcal meningitis in patients with AIDS treated with HAART. Presented at the 8th Conference on Retroviruses and Opportunistic Infections, February 4-8, Chicago, IL. 2001;(abstr 546)

94. McKinsey DS, Wheat LJ, Cloud GA, et al. Itraconazole prophylaxis for fungal infections in patients with advanced human immunodeficiency virus infection: randomized, placebo-controlled. double-blind study. Clin Infect Dis 1999;28:1049-56

95. Wheat J, Hafner R, Wulfsohn M, et al., and the NIASID Clinical Trials and Mycoses Study Group Collaborators. Prevention of relapse of histoplasmosis with itraconazole in patients with the acquired immunodeficiency syndrome. Ann Intern Med 1993;118:610-16

96. Galgiani JN, Catanzaro A, Cloud GA, et. al. Comparison of oral fluconazole and itraconazole for progressive, nonmeningeal coccidioidomycosis. A randomized, double-blind trial. Ann Intern Med 2000;133:676-86

97. Spector SA, McKinley GF, Lalezari JFP, et al. Oral ganciclovir for the prevention of cytomegalovirus disease in persons with AIDS. N Engl J Med 1996;334:1491-7

98. Brosgart CL, Louis TA, Hillman DW, et al. A randomized, placebo-controlled trial of the safety and efficacy of oral ganciclovir for prophylaxis of cytomegalovirus disease in HIV-infected individuals. AIDS 1998;12:269-77

99. Feinberg JE, Hurwitz S, Cooper D, et al. A randomized, double-blind trial of valacyclovir prophylaxis for cytomegalovirus disease in patients with advanced human immunodeficiency virus infection. AIDS Clinical Trials Group Protocol 204/Glaxo Wellcome 123-014 International CMV Prophylaxis Study Group. J Infect Dis 1998;177:48-56

100. Martin DF, Kupperman BD, Wolitz RA, et al. Oral ganciclovir for patients with cytomegalovirus retinitis treated with a ganciclovir implant. N Engl J Med 1999;340:1063-70

101. Drew WL, Ives D, Lalezari JP, et al. Oral ganciclovir as maintenance treatment for cytomegalovirus retinitis in patients with AIDS. N Engl J Med 1995;333:615-20

102. Studies of Ocular Complications of AIDS Research Group. Parenteral cidofovir for cytomegalovirus retinitis in patients with AIDS: The HPMPC Peripheral Cytomegalovirus Retinitis Trial. A randomized, controlled trial. Ann Intern Med 1997;126:264-74

103. Palestine AG, Polis MA, DeSmet MD, et al. A randomized, controlled trial of foscarnet in the treatment of cytomegalovirus retinitis in patients with AIDS. Ann Intern Med 1991;115:665-73

104. Spector SA, Weingeist T, Pollard RE, et al. A randomized, controlled study of intravenous ganciclovir therapy for cytomegalovirus peripheral retinitis in patients with AIDS. J Infect Dis 1993;168:557-63

105. Studies of Ocular Complications of AIDS in collaboration with the AIDS Clinical Trials Group: Combination foscarnet and ganciclovir therapy vs. monotherapy for the treatment of relapsed cytomegalovirus retinitis in patients with AIDS. Arch Ophthalmol 1996;114:23-33

106. Diaz-Llopis M, Espa a E, Mu oz G, et al. High dose intravitreal foscarnet in the treatment of cytomegalovirus retinitis in AIDS. Br J Ophthalmol 1994;78:120-4

107. Lewis RA, Carr LM, Doyle K, et al. Parenteral cidofovir for cytomegalovirus retinitis in patients with AIDS: the HPMPC Peripheral Cytomegalovirus Retinitis Trial. Ann Intern Med 1997;126:264

108. DeSmet MD, Meenken C, van den Horn GJ. Fomivirsen - a phosphorothioate oligonucleotide for the treatment of CMV retinitis. Ocular Immunol Inflamm 1999;7:189-98

109. Kirsch LS, Arevelo JF, Chavez de la Paz E, et al. Intravitreal cidofovir (HPMPC) treatment of cytomegalovirus retinitis in patients with AIDS. Ophthalmol 1995;102:533-43

110. Young S, Morlet N, Besen G, et al. High-dose (2000-microgram) intravitreous ganciclovir in the treatment of cytomegalovirus retinitis. Ophthalmol 1998;105:1404-10 
111. Tural C, Romeu J, Sicrera G, et al. Long-lasting remission of cytomegalovirus retinitis without maintenance therapy in human immunodeficiency virus-infected patients. J Infect Dis 1998;177:1080-3

112. Vrabec TR, Baldassano VF, Whitcup SM. Discontinuation of maintenance therapy in patients with quiescent cytomegalovirus retinitis and elevated CD4 ${ }^{+}$counts. Ophthalmol 1998;105:1259-64

113. MacDonald JC, Torriani FJ, Morse, et al. Lack of reactivation of cytomegalovirus (CMV) retinitis after stopping CMV maintenance therapy in AIDS patients with sustained elevations in CD4 T cells in response to highly active antiretroviral therapy. J Infect Dis 1998;177:1182-7

114. Whitcup SM, Fortin E, Lindblad AS, et al. Discontinuation of anti-cytomegalovirus therapy in persons with HIV infection and cytomegalovirus retinitis. JAMA 1999;282:1633-7

115. Jabs DA, Bolton SG, Dunn JP, et al. Discontinuing anticytomegalovirus therapy in patients with immune reconstitution after combination antiretroviral therapy. Am J Ophthalmol 1998;126:817-22

116. Jouan M, Saves H, Tubiana R, et al. Discontinuation of maintenancetherapy for cytomegalovirus retinitis in HIV infected patients receving highly active antiretroviral therapy. Restimop Study Team. AIDS 2001;15:23-31

117. Spector SA, Wong R, Hsia K, et al. Plasma cytomegalovirus (CMV) DNA load predicts CMV disease and survival in AIDS patients. J Clin Invest 101:497-502

118. Salmon-Cerm D, Mazeron M-C, Caput S, et al. Plasma cytomegalovirus DNA, PP65 antigenaemia and a low CD 4 cell count remain risk factors for cytomegalovirus disease in patients receving highly active antiretroviral therapy. AIDS 2000;14:1042-9

119. Torriani FJ, Freeman WR, MacDonald JC, et al. CMV retinitis recurs after stopping treatment in virological and immunological failures of potent antiretroviral therapy. AIDS 2000;14:173-80

120. Schacker T, Zeh J, Hu HL, et al. Frequency of symptomatic and asymptomatic herpes simplex virus type 2 reactivations among human immunodeficiency virus-infectedmen. J Infect Dis 1998;178:1616-22

121. Schacker T, Hu HL, Koelle DM, et al. Famciclovir for the suppression of symptomatic and asymptomatic herpes simplex virus reactivation in HIV-infected persons: a double-blind, placebo-controlled trial. Ann Intern Med 1998;128:21-8

122. CDC. Pregnancy outcomes following systemic prenatal acyclovir exposure: June 1984-June 1993. MMWR 1993;42:806-9

123. Jacobson LP, Jenkins FJ, Springer G, et al. Interaction of human immunodeficiency virus type 1 and human herpesvirus type 8 infections on the incidence of Kaposi's sarcoma. J Infect Dis 2000;181:1940-9

124. Renwick N, Halaby T, Weverling GJ, et al. Seroconversion ofr human heresvirus 8 during HIV infecitonis highly predictive of Kaposi's sarcoma. AIDS 1998;12:2481-8

125. Martin JN, Ganem DE, Osmond DH, et al. Sexual transmission and the natural history of human herpsvirus 8 infection. N Engl J Med 1998;338:948-54

126. PaukJ, Huang ML, Brodie SJ, et al. Mucosal shedding of human herpesvirus 8. N Engl J Med 2000;343:1369-77

127. Cannon MJ, Dollard SC, Smith DK, et al. HIV Epidemiology Research Study Group. Blood-borne and sexual transmission of human herpesvirus 8 in women with or at risk for human immunodeficiency virus infection. N Engl J Med 2001;344:637-43

128. Whitley D, Smith NA, Mathew S et al. Human herpesvirus 8 seroepidemiology among women and detection in the genital tract of seropositive women. J Infect Dis 1999;179:254-6

129. Ledergerber B, Egger M, Erard V, et al. AIDS-related opportunistic illnesses occurring after initiation of potent antiretroviral therapy: the Swiss HIV Cohort Study. JAMA 1999;23:2220-6

130. Bourboulia D, Whitby D, Boshoff C, et al. Serologic evidence of mother to child transmission of Kaposisarcoma-associated herpesvirus infection. JAMA 1998;280:31-2

131. He J, Bhat G, Kankasa C, et al. Seroprevalence of human herpesvirus 8 among Zambian women of childbearing age without Kaposi's sarcoma (KS) and mother-child pairs with KS. J Infect Dis 1998;178:787-90

132. Sitas F, Newton R, Boshoff C. Increasing probability of mother to child transmission of HHV-8 with increasing maternal antibody titer for HHV-8. N Engl J Med 1999;340:1923

133. Plancoulaine $\mathrm{S}$, Abel L, van Beveren M, et al. Human herpesvirus 8 trnasmission from mother to child and between siblings in an endemic population. Lancet 2000;356:1062-5

134. Kurman RJ, Henson DE, Herbst AL, et al. Interim guidelines for management of abnormal cervical cytology. JAMA 1994;271:1866-9 
135. Goldie SJ, Kuntz KM, Weinstein MC, et al. The clinical effectiveness and cost-effectiveness of screening for anal squamous intraepithelial lesions in homosexual and bisexual HIV-positive men. JAMA 1999;281:1822-9

136. Maiman M, Watts DH, Andersen J, et al. Vaginal 5-fluorouracil for high grade cervical dysplasia in HIVinfection: A randomized trial. Obstet Gynecol 1999;94:954-61

137. CDC. Recommendations for prevention and control of hepatitis C virus (HCV) infection and HCV-related chronic disease. MMWR 1998;47(No.RR-19)

138. Sulkowski MS, Thomas DL, Chaisson RE, Moore RD. Hepatotoxicity associated with antiretroviral therapy in adults infected with human immunodeficiency virus and the role of hepatitis $\mathrm{B}$ and $\mathrm{C}$ virus infection. JAMA 2000;283:74-80

139. Darby SC, Ewart DW, Giangrande PL, et al. Mortality from liver cancer and liver disease in haemophilic men and boys in UK given blood products contaminated with hepatitis C. Lancet 1997;350:1425-31

140. Eyster ME, Dimondstone LS, Lien JM, et al. Natural history of hepatitis C virus infection in multitransfused hemophiliacs: effect of co-infection with human immunodeficiency virus. The Multicenter Hemophilia Cohort Study. J AIDS 1993;6:602-10

141. Darby SC, Ewart DW, Giangrande PLF, et al. Mortality from liver cancer and liver disease in haemophilic men and boys in UK given blood products contaminated with hepatitis C. Lancet 1997;350:1425-31

142. Thomas DL, Shih JW, Alter HG, et al. Effect of HIV infection on hepatitis C virus infection among injection drug users. J Infect Dis 1996;174:690-5

143. Rodriguez-Rosado R, Garcia-Samaniego J, Soriano V. Hepatotoxicity after introduction of highly active antiretroviral therapy [Letter]. AIDS 1998;12:1256

144. Saves M, Raffi F, Clevenbergh $\mathrm{P}$, et al. Hepatitis B or Hepatitis C virus infection is a risk factor for severe hepatic cytolysis after initiation of a protease containing antiretroviral regimen in human immunodeficiency virus infected patients. The APROCO Study Group. Antimicrob Agents Chemother 2000;44:3451-5

145. Chemello L, Cavalletto L, Casarin C, et al. Persistent hepatitis C viremia predicts late relapse after sustained response to interferon in chronic hepatitis C. Ann Intern Med 1996;124:1058-60

146. Mast EE, Alter MJ. Hepatitis C. Semin Pediatr Infect Dis 1997;8:17-22

\section{APPENDIX}

\section{Recommendations to Help Patients Avoid Exposure to or Infection with Opportunistic Pathogens*}

\section{SEXUAL EXPOSURES}

1. Patients should use a latex condom during every act of sexual intercourse to reduce the risk for acquiring CMV, HSV and HPV (AII). Condom use also will, theoretically, reduce the risk for acquiring human herpesvirus 8, as well as super-infection with an HIV strain that has become resistant to antiretroviral drugs (BIII) and will prevent transmission of HIV and other sexually transmitted pathogens to others (AII). Data regarding the use and efficacy of female condoms are incomplete, but these devices should be considered as a risk-reduction strategy (BIII).

2. Patients should avoid sexual practices that might result in oral exposure to feces (e.g., oral-anal contact) to reduce the risk for intestinal infections (e.g., cryptosporidiosis, shigellosis, campylobacteriosis, amebiasis, giardiasis and hepatitis A (BIII). Latex condom use alone may not reduce the risk of acquiring these fecal-orally transmitted pathogens, especially those which have low infectious doses. Persons wishing to reduce their risk of exposure might consider using dental dams or similar barrier methods for oral-anal and oral-genital contact, changing condoms after anal intercourse and wearing latex gloves during digital-anal contact. Frequently washing hands and genitals with warm soapy water during and after activities which may bring these body parts in contact with feces may further reduce risk of illness. (CIII).

3. Hepatitis $B$ immunizations is recommended for all susceptible (anti-HBc-negative) HIV-infected patients (BII). 


\section{Hepatitis A immunization is recommended for all susceptible men who have sex with men, as well as others with indications for HAV vaccine (BIII).}

\section{INJECTION DRUG USE EXPOSURES}

1. Injection drug use is a complex behavior that puts HIV-infected persons at risk for $\mathbf{H B V}$ and $\mathrm{HCV}$ infection, additional, possibly drug-resistant strains of HIV and other blood-borne pathogens. Providers should assess the individual's readiness to change this practice and encourage efforts to provide education and support directed at recovery. Patients should be counseled to stop using injection drugs (AIII) and to enter and complete substance-abuse treatment, including relapse prevention programs (AIII).

2. If they are continuing to inject drugs, patients should be advised (BIII)

- to never reuse or share syringes, needles, water or drug preparation equipment; if, nonetheless, injection equipment that has been used by other persons is shared, to first clean the equipment with bleach and water (USPHS. HIV prevention bulletin: medical advice for persons who inject illicit drugs. Rockville, Maryland: CDC, 1997);

- to use only sterile syringes obtained from a reliable source (e.g., pharmacies or syringe exchange programs);

- to use sterile (e.g., boiled) water to prepare drugs; if not possible, to use clean water from a reliable source (e.g., fresh tap water); to use a new or disinfected container (cooker) and a new filter (cotton) to prepare drugs;

- to clean the injection site with a new alcohol swab before injection;

- to safely dispose of syringes after one use.

3. All susceptible injection drug users should be immunized against hepatitis B (BII) and hepatitis A (BIII).

*Letters and roman numerals in parentheses indicate the strength of the recommendation and the quality of evidence supporting it (see table 2).

\section{ENVIRONMENTAL AND OCCUPATIONAL EXPOSURES}

1. Certain activities or types of employment might increase the risk for exposure to tuberculosis (BIII). These include volunteer work or employment in health-care facilities, correctional institutions, and shelters for the homeless, as well as other settings identified as high risk by local health authorities. Decisions about whether to continue with such activities should be made in conjunction with the health-care provider and should be based on such factors as the patient's specific duties in the workplace, the prevalence of tuberculosis in the community, and the degree to which precautions designed to prevent the transmission of tuberculosis are taken in the workplace (BIII). These decisions will affect the frequency with which the patient should be screened for tuberculosis.

2. Child-care providers and parents of children in child care are at increased risk for acquiring CMV infection, cryptosporidiosis, and other infections (e.g., hepatitis A and giardiasis) from children. The risk for acquiring infection can be diminished by good hygienic practices, such as hand washing after fecal contact (e.g., during diaper changing) and after contact with urine or saliva (AII). All children in child-care facilities also are at increased risk for acquiring these same infections; parents and other caretakers of HIV-infected children should be advised of this risk (BIII).

3. Occupations involving contact with animals (e.g., veterinary work and employment in pet stores, farms, or slaughterhouses) might pose a risk for cryptosporidiosis, toxoplasmosis, salmonellosis, campylobacteriosis or Bartonella infection. However, the available data are insufficient to justify a recommendation against work in such settings.

4. Contact with young farm animals, especially animals with diarrhea, should be avoided to reduce the risk for cryptosporidiosis (BII). 
5. Hand washing after gardening or other contact with soil might reduce the risk for cryptosporidiosis and toxoplasmosis (BIII).

6. In areas endemic for histoplasmosis, patients should avoid activities known to be associated with increased risk (e.g., creating dust when working with surface soil; cleaning chicken coops that are heavily contaminated with compost droppings; disturbing soil beneath bird-roosting sites; cleaning, remodeling or demolishing old buildings; and cave exploring) (CIII).

7. In areas endemic for coccidioidomycosis, when possible, patients should avoid activities associated with increased risk, including those involving extensive exposure to disturbed native soil (e.g., at building excavation sites or during dust storms) (CIII).

\section{PET-RELATED EXPOSURES}

Health-care providers should advise HIV-infected persons of the potential risk posed by pet ownership. However, they should be sensitive to the possible psychological benefits of pet ownership and should not routinely advise HIV-infected persons to part with their pets (DIII). Specifically, providers should advise HIV-infected patients of the following precautions (MMWR August 20, 1999).

\section{General}

1. Veterinary care should be sought when a pet develops diarrheal illness. If possible, HIV-infected persons should avoid contact with animals that have diarrhea (BIII). A fecal sample should be obtained from animals with diarrhea and examined for Cryptosporidium, Salmonella and Campylobacter.

2. When obtaining a new pet, HIV-infected patients should avoid animals aged $<6$ months (or $<1$ year for cats; see Cats section), especially those with diarrhea (BIII). Because the hygienic and sanitary conditions in pet-breeding facilities, pet stores and animal shelters are highly variable, the patient should be cautious when obtaining a pet from these sources. Stray animals should be avoided. Animals aged $<6$ months, especially those with diarrhea, should be examined by a veterinarian for Cryptosporidium, Salmonella, and Campylobacter (BIII).

3. Patients should wash their hands after handling pets (especially before eating) and avoid contact with pets' feces to reduce the risk for cryptosporidiosis, salmonellosis, and campylobacteriosis (BIII). Hand washing for HIV-infected children should be supervised.

\section{Cats}

4. Patients should be aware that cat ownership increases their risk for toxoplasmosis and Bartonella infection, as well as enteric infections (CIII). Those who elect to obtain a cat should adopt or purchase an animal that is aged $>1$ year and in good health to reduce the risk for cryptosporidiosis, Bartonella infection, salmonellosis and campylobacteriosis (BII).

5. Litter boxes should be cleaned daily, preferably by an HIV-negative, nonpregnant person; if the HIV-infected patient performs this task, he or she should wash hands thoroughly afterward to reduce the risk for toxoplasmosis (BIII).

6. To reduce the risk for toxoplasmosis, HIV-infected patients should keep cats indoors, not allow them to hunt, and not feed them raw or undercooked meat (BIII).

7. Although declawing is not generally advised, patients should avoid activities that might result in cat scratches or bites to reduce the risk for Bartonella infection (BII). Patients should also wash sites of cat scratches or bites promptly (CIII) and should not allow cats to lick the patients' open cuts or wounds (BIII).

8. Care of cats should include flea control to reduce the risk for Bartonella infection (CIII).

9. Testing cats for toxoplasmosis (EII) or Bartonella infection (DII) is not recommended. 


\section{Birds}

10. Screening healthy birds for Cryptococcus neoformans, Mycobacterium avium or Histoplasma capsulatum is not recommended (DIII).

\section{Other}

11. Contact with reptiles (e.g., snakes, lizards, iguanas, and turtles) as well as chicks and ducklings should be avoided to reduce the risk for salmonellosis (BIII).

12. Gloves should be used during the cleaning of aquariums to reduce the risk for infection with Mycobacterium marinum (BIII).

13. Contact with exotic pets (e.g., nonhuman primates) should be avoided (CIII).

\section{FOOD AND WATER-RELATED EXPOSURES}

1. Raw or undercooked eggs (including foods that might contain raw eggs [e.g., some preparations of hollandaise sauce, Caesar and certain other salad dressings, some mayonnaises, uncooked cookie and cake batter, egg nog]); raw or undercooked poultry, meat, seafood (especially raw shellfish); and unpasteurized dairy products; unpasteurized fruit juice; and raw seed sprouts (e.g., alfalfa sprouts, mung bean sprouts). Poultry and meat are safest when adequate cooking is confirmed with a thermometer (internal temperature of $180 \mathrm{~F}$ for poultry and $165 \mathrm{~F}$ for red meats). If a thermometer is not used, the risk of illness is decreased by consuming poultry and meat that have no trace of pink. Color change of the meat (e.g., absence of pink) does not always correlate with internal temperature. Produce should be washed thoroughly before being eaten (BIII).

2. Cross-contamination of foods should be avoided. Uncooked meats should not be allowed to come in contact with other foods; hands, cutting boards, counters, and knives and other utensils should be washed thoroughly after contact with uncooked foods (BIII).

3. Although the incidence of listeriosis is low, it is a serious disease that occurs unusually frequently among HIV-infected persons who are severely immunosuppressed. An immunosuppressed, HIV-infected person who wishes to reduce the risk of acquiring listeriosis as much as possible may choose to do the following:

(a) avoid soft cheeses (e.g., feta, Brie, Camembert, blue-veined and Mexican-style cheese such as queso fresco). Hard cheeses, processed cheeses, cream cheese (including slices and spreads), cottage cheese, or yogurt need not be avoided;

(b) cook leftover foods or ready-to-eat foods (e.g., hot dogs) until steaming hot before eating;

(c) avoid foods from delicatessen counters (e.g., prepared salads, meats, cheeses) or heat/reheat these foods until steaming before eating;

(d) avoid refrigerated pates and other meat spreads, or heat/reheat these foods until steaming if eaten. Canned or shelf-stable pate and meat spreads need not be avoided;

(e) avoid raw or unpasteurized milk (including goat's milk) or milk-products, or foods which contain unpasteurized milk or milk-products. (CIII).

4. Patients should not drink water directly from lakes or rivers because of the risk for cryptosporidiosis and giardiasis (AIII). Waterborne infection might also result from swallowing water during recreational activities. Patients should avoid swimming in water that is likely to be contaminated with human or animal waste and should avoid swallowing water during swimming (BII).

5. During outbreaks or in other situations in which a community 'boil water advisory' is issued, boiling water for 1 minute will eliminate the risk for acquiring cryptosporidiosis (AI). Using submicron, personal-use water filters (home/office types) and/or drinking bottled water might also reduce the risk (see Cryptosporidiosis section in Disease-Specific Recommendations for information on personal-use filters and bottled water) (CIII). Current data are inadequate to support a recommendation that all HIV-infected 
persons boil or otherwise avoid drinking tap water in nonoutbreak settings. However, persons who wish to take independent action to reduce their risk for waterborne cryptosporidiosis may choose to take precautions similar to those recommended during outbreaks. Such decisions are best made in conjunction with a health-care provider. Persons who opt for a personal-use filter or bottled water should be aware of the complexities involved in selecting the appropriate products, the lack of enforceable standards for destruction or removal of oocysts, the cost of the products, and the difficulty of using these products consistently. Patients taking precautions to avoid acquiring cryptosporidiosis from drinking water should be advised that ice made from contaminated tap water also can be a source of infection (BII). Such persons should be aware that fountain beverages served in restaurants, bars, theaters, and other public places might also pose a risk, because these bever-ages, as well as the ice they might contain, are made from tap water. Nationally distributed brands of bottled or canned carbonated soft drinks are safe to drink. Commercially packaged noncarbonated soft drinks and fruit juices that do not require refrigeration until after they are opened (i.e., those that can be stored unrefrigerated on grocery shelves) also are safe. Nationally distributed brands of frozen fruit juice concentrate are safe if they are reconstituted by the user with water from a safe source. Fruit juices that must be kept refrigerated from the time they are processed to the time of consumption might be either fresh (unpasteurized) or heat-treated (pasteurized); only juices labeled as pasteurized should be considered free of risk from Cryptosporidium. Other pasteurized beverages and beers are also considered safe to drink (BII). No data are available concerning survival of Cryptosporidium oocystsin wine.

\section{TRAVEL-RELATED EXPOSURES}

1. Travel, particularly to developing countries, might result in significant risks for the exposure of HIV-infected persons to opportunistic pathogens, especially for patients who are severely immunosuppressed. Consultation with health-care providers and/or with experts in travel medicine will help patients plan itineraries (BIII).

2. During travel to developing countries, HIV-infected persons are at even higher risk for foodborne and waterborne infections than they are in the United States. Foods and beverages - in particular, raw fruits and vegetables, raw or undercooked seafood or meat, tap water, ice made with tap water, unpasteurized milk and dairy products, and items purchased from street vendors - might be contaminated (AII). Items that are generally safe include steaming hot foods, fruits that are peeled by the traveler, bottled (especially carbonated) beverages, hot coffee or tea, beer, wine, and water brought to a rolling boil for 1 minute (AII). Treating water with iodine or chlorine might not be as effective as boiling but can be used, perhaps in conjunction with filtration, when boiling is not practical (BIII).

3. Waterborne infections might result from swallowing water during recreational activities. To reduce the risk for cryptosporidiosis and giardiasis, patients should avoid swallowing water during swimming and should not swim in water that might be contaminated (e.g., with sewage or animal waste) (BII).

4. Antimicrobial prophylaxis for traveler's diarrhea is not recommended routinely for HIV-infected persons travelling to developing countries (DIII). Such preventive therapy can have adverse effects and can promote the emergence of drug-resistant organisms. Nonetheless, several studies (none involving an HIV-infected population) have shown that prophylaxis can reduce the risk for diarrhea among travelers (CDC. Health information for international travel, 1999-2000. Atlanta, Georgia: U.S. Department of Health and Human Services, 1999:202). Under selected circumstances (e.g., those in which the risk for infection is very high and the period of travel brief), the provider and patient may weigh the potential risks and benefits and decide that anti-biotic prophylaxis is warranted (CIII). For those persons to whom prophylaxis is offered, fluoroquinolones (e.g., ciprofloxacin [500 mg daily]) can be considered (CIII), although fluoroquinolones should not be given to children or pregnant women. Trimethoprimsulfamethoxazole (TMP-SMZ) (one double-strength tablet daily) also has been shown to be effective, but resistance to this drug is now common in tropical areas. Persons already taking TMP-SMZ for prophylaxis against Pneumocystis carinii pneumonia (PCP) might gain some protection against traveler's diarrhea. For 
HIV-infected persons who are not already taking TMP-SMZ, health-care providers should be cautious in prescribing this agent for prophylaxis of diarrhea because of the high rates of adverse reactions and the possible need for the agent for other purposes (e.g., PCP prophylaxis) in the future.

5. All HIV-infected travelers to developing countries should carry a sufficient supply of an antimicrobial agent to be taken empirically should diarrhea develop (BIII). One appropriate regimen is $500 \mathrm{mg}$ of ciprofloxacin twice a day for 3-7 days. Alternative antibiotics (e.g., TMP-SMZ) should be considered as empirical therapy for use by children and pregnant women (CIII). Travelers should consult a physician if their diarrhea is severe and does not respond to empirical therapy, if their stools contain blood, if, fever is accompanied by shaking chills, or if dehydration develops. Antiperistaltic agents (e.g., diphenoxylate and loperamide) are used for the treatment of diarrhea; however, they should not be used by patients with high fever or with blood in the stool, and their use should be discontinued if symptoms persist beyond $48 \mathrm{~h}$ (AII). Antiperistaltic agents are not recommended for children (DIII).

6. Travelers should be advised about other preventive measures appropriate for anticipated exposures (e.g., chemoprophylaxis for malaria, protection against arthropod vectors, treatment with immune globulin, and vaccination) (AII). They should avoid direct contact of the skin with soil or sand (e.g., by wearing shoes and protective clothing and using towels on beaches) in areas where fecal contamination of soil is likely (BIII).

7. In general, live-virus vaccines should be avoided (EII). One exception is measles vaccine, which is recommended for nonimmune persons. However, measles vaccine is not recommended for persons who are severely immunosuppressed (DIII); immune globulin should be considered for measles-susceptible, severely immunosuppressed persons who are anticipating travel to measles-endemic countries (BIII). Another exception is varicella vaccine, which may be administered to asymptomatic nonimmunosuppressed children (BII). Inactivated (killed) poliovirus vaccine should be used instead of oral (live) poliovirus vaccine, which is contraindicated for HIV-infected persons. Persons at risk for exposure to typhoid fever should be administered an inactivated parenteral typhoid vaccine instead of the live attenuated oral preparation. Yellow fever vaccine is a live-virus vaccine with uncertain safety and efficacy in HIV-infected persons. Travelers with asymptomatic HIV infection who cannot avoid potential exposure to yellow fever should be offered the choice of vaccination. If travel to a zone with yellow fever is necessary and vaccination is not administered, patients should be advised of the risk, instructed in methods for avoiding the bites of vector mosquitoes, and provided with a vaccination waiver letter.

8. In general, killed and recombinant vaccines (e.g., diphtheria-tetanus, rabies, hepatitis A, hepatitis B, Japanese encephalitis vaccines) should be used for HIV-infected persons just as they would be used for non-HIV-infected persons anticipating travel (BIII). Preparation for travel should include a review and updating of routine vaccinations, including diphtheria-tetanus for adults and all routine immunizations for children. The currently available cholera vaccine is not recommended for persons following a usual tourist itinerary, even if travel includes countries reporting cases of cholera (DII).

9. Travelers should be informed about other area-specific risks and instructed in ways to reduce those risks (BIII). Geographically focal infections that pose a high risk to HIV-infected persons include visceral leishmaniasis (a protozoan infection transmitted by the sandfly) and several fungal infections (e.g., Penicillium marneffei infection, coccidioidomycosis, and histoplasmosis). Many tropical and developing areas have high rates of tuberculosis. 


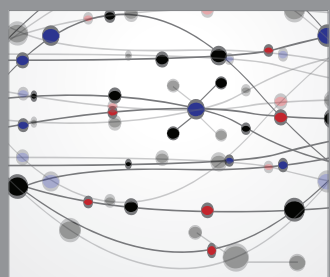

The Scientific World Journal
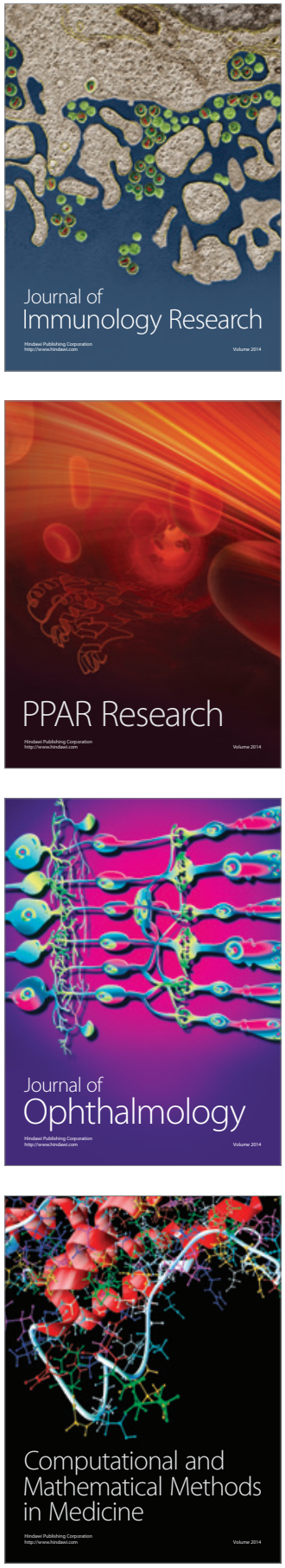

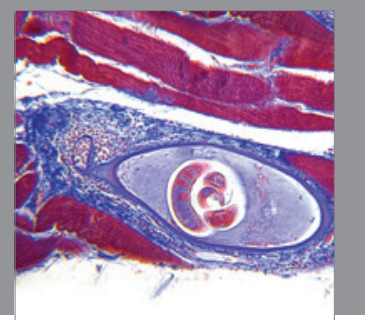

Gastroenterology

Research and Practice
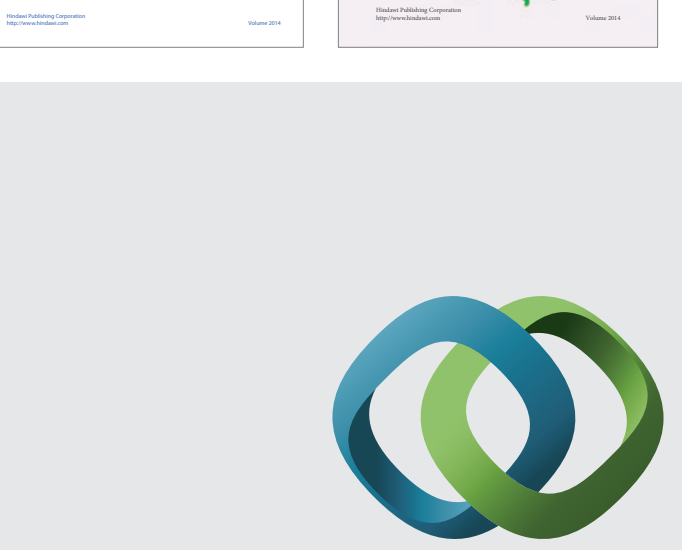

\section{Hindawi}

Submit your manuscripts at

http://www.hindawi.com
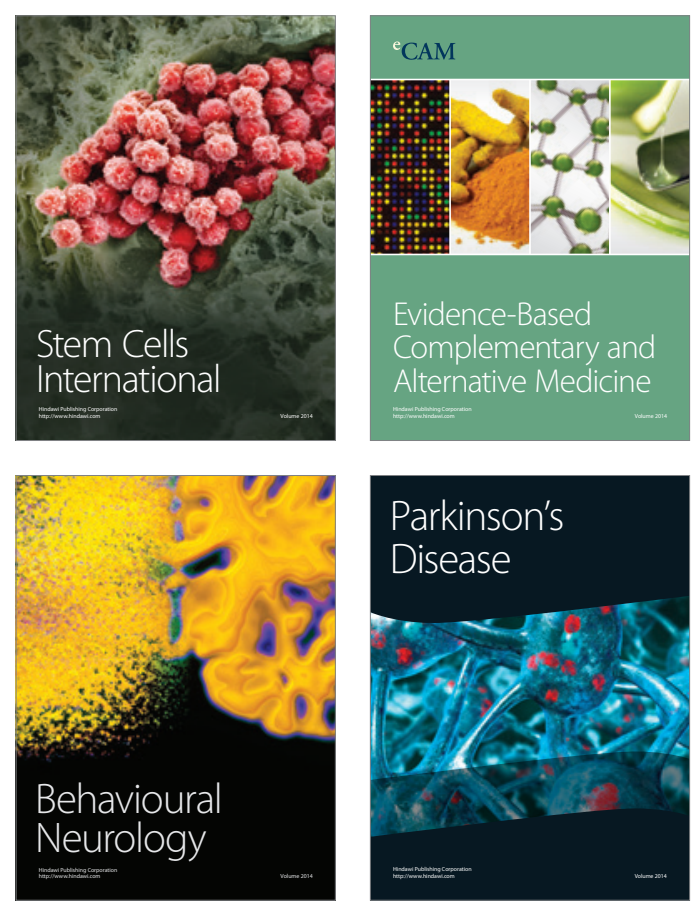

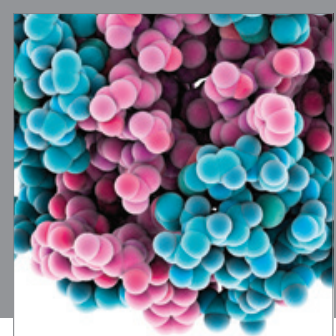

Journal of
Diabetes Research

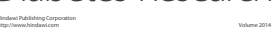

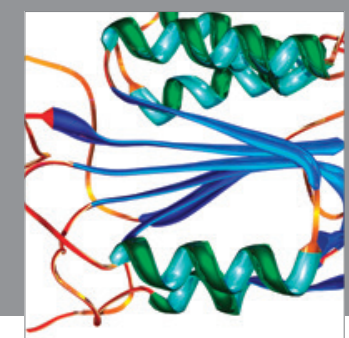

Disease Markers
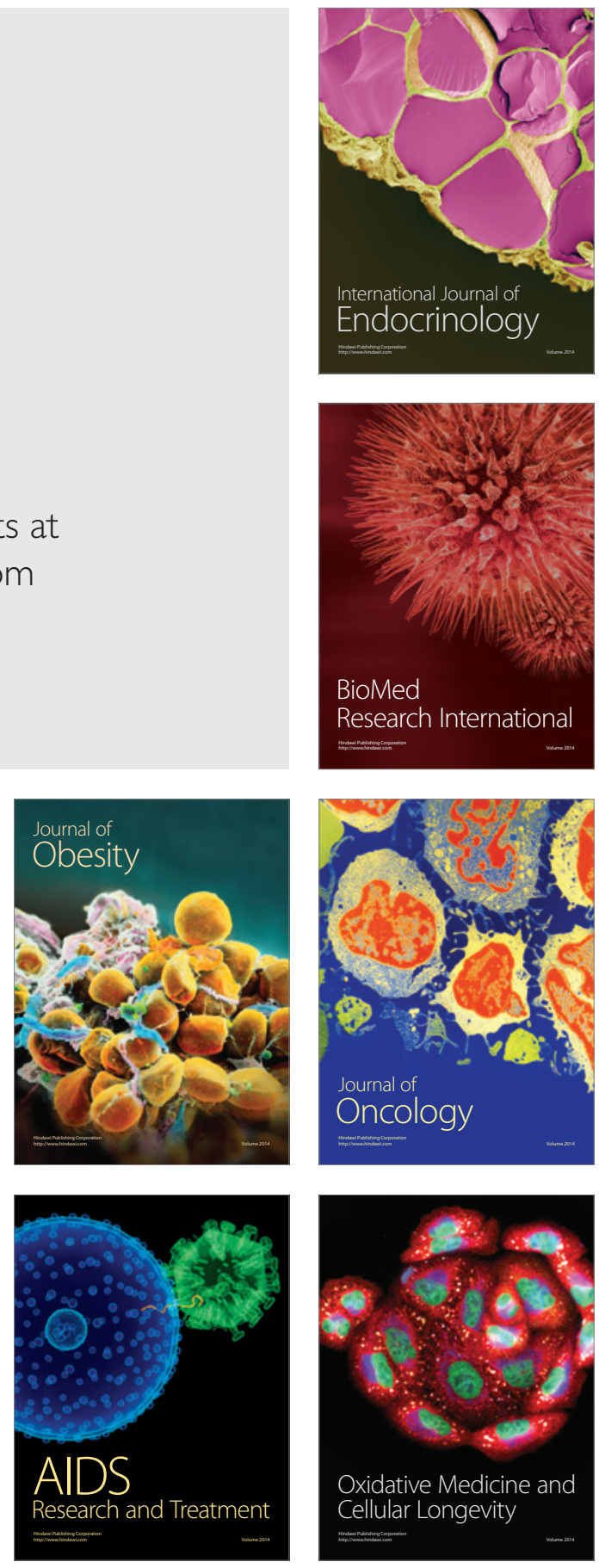